Prepared for the U.S. Department of Energy

under Contract DE-AC05-76RL01830

\title{
Materials Degradation and Detection (MD2): Deep Dive Final Report
}

JS McCloy

RO Montgomery

P Ramuhalli

RM Meyer

$\mathrm{SHu}$
Y Li

$\mathrm{CH}$ Henager, Jr.

BR Johnson

February 2013

Pacific Northwest

NATIONAL LABORATORY

Proudly Operated by Battelle Since 1965 



\section{DISCLAIMER}

This report was prepared as an account of work sponsored by an agency of the United States Government. Neither the United States Government nor any agency thereof, nor Battelle Memorial Institute, nor any of their employees, makes any warranty, express or implied, or assumes any legal liability or responsibility for the accuracy, completeness, or usefulness of any information, apparatus, product, or process disclosed, or represents that its use would not infringe privately owned rights. Reference herein to any specific commercial product, process, or service by trade name, trademark, manufacturer, or otherwise does not necessarily constitute or imply its endorsement, recommendation, or favoring by the United States Government or any agency thereof, or Battelle Memorial Institute. The views and opinions of authors expressed herein do not necessarily state or reflect those of the United States Government or any agency thereof.

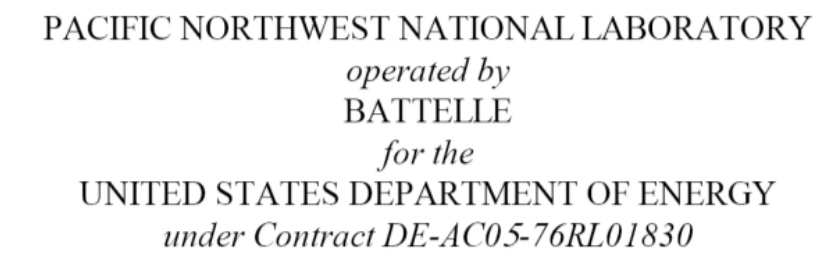

Printed in the United States of America

Available to DOE and DOE contractors from the Office of Scientific and Technical Information,

P.O. Box 62, Oak Ridge, TN 37831-0062;

ph: (865) 576-8401

fax: $(865) 576-5728$

email: reports@adonis.osti.gov

\footnotetext{
Available to the public from the National Technical Information Service, U.S. Department of Commerce, 5285 Port Royal Rd., Springfield, VA 22161 ph: (800) 553-6847 fax: $(703) 605-6900$ email: orders@ntis.fedworld.gov online ordering: http://www.ntis.gov/ordering.htm
} 


\title{
Materials Degradation and Detection (MD2): Deep Dive Final Report
}

\author{
JS McCloy \\ Y Li \\ RO Montgomery \\ $\mathrm{CH}$ Henager Jr. \\ P Ramuhalli \\ BR Johnson \\ RM Meyer \\ $\mathrm{S} \mathrm{Hu}$
}

February 2013

Prepared for the U.S. Department of Energy under Contract DE-AC05-76RL01830

Pacific Northwest National Laboratory

Richland, Washington 99352 


\section{TABLE OF CONTENTS}

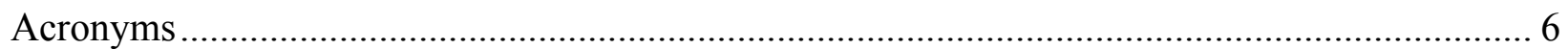

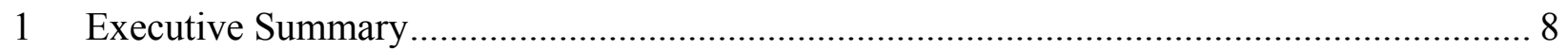

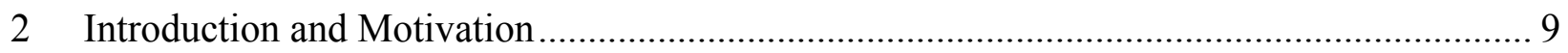

3 Overall approach to develop real-time monitoring of materials degradation.......................... 11

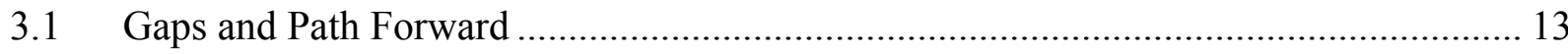

3.2 Material degradation modes in LWR primary coolant systems ................................... 14

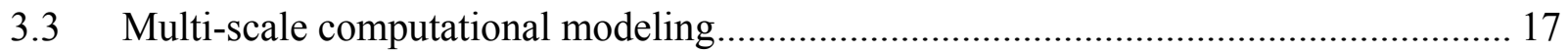

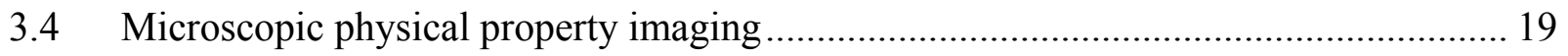

3.5 Engineering-scale degradation measurements - NDE............................................... 20

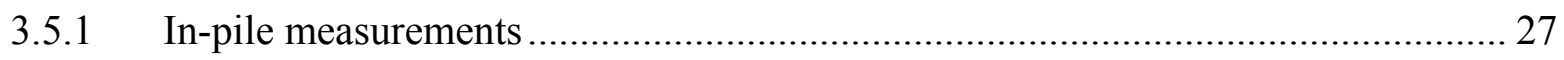

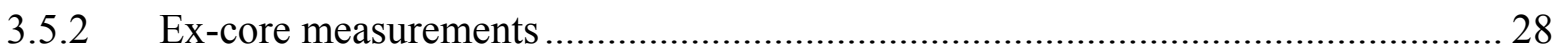

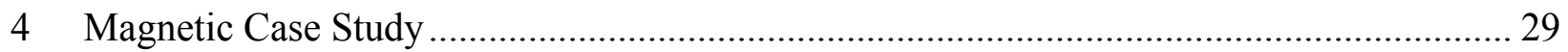

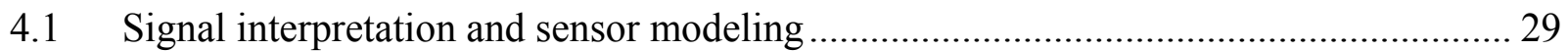

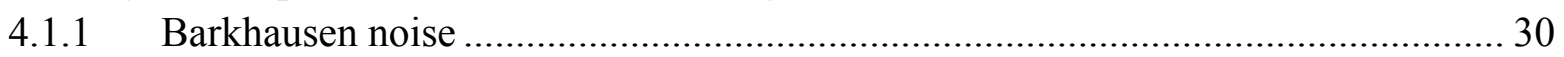

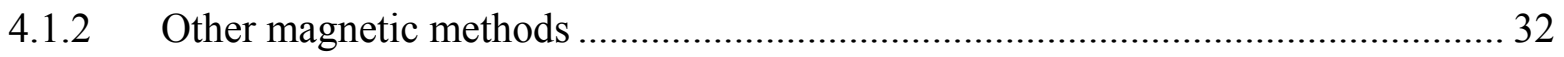

4.1.3 Irradiated steels - Barkhausen and other magnetic properties................................ 34

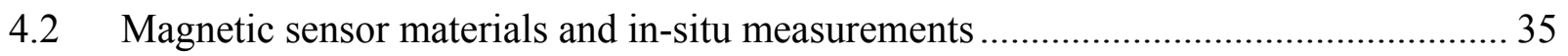

4.3 Characterization of magnetic microstructure and nanostructure .................................... 38

4.3.1 Magnetic imaging as input to microstructure simulations ........................................ 39

4.3.2 Existing literature on magnetic imaging of steels ................................................ 43

4.4 Phase field modeling of the effect of microstructures on magnetic response................ 43

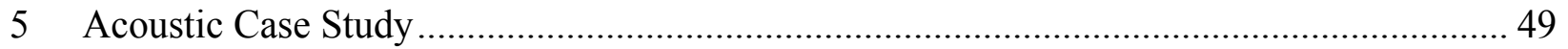

5.1 Acoustic Sensor Materials and Irradiation Studies ...................................................... 51

5.2 Acoustic Sensor Modeling and Signal Interpretation ................................................. 52

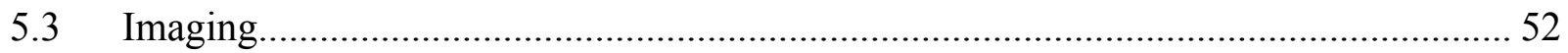

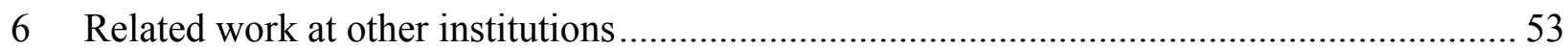

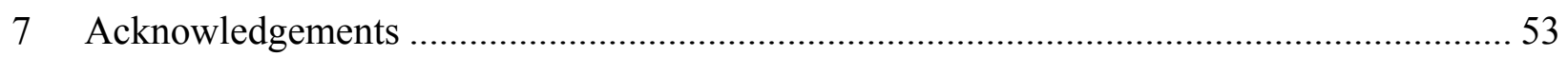

8 Appendix: literature review of effects of neutrons on magnetic materials............................5 54

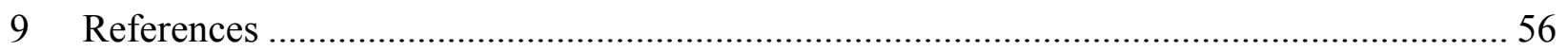




\section{TABLE OF FIGURES}

Figure 1. Plant capacity losses from materials degradation are $>\$ 1 \mathrm{~B} /$ year loss...................... 10 Figure 2. Conceptual illustration of the integrated parts of Material Degradation and Detection

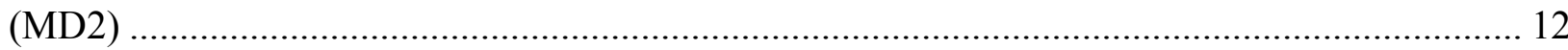

Figure 3. Schematic of approach for acoustic NDE sensor evaluation..................................... 13

Figure 4. Rigorous meso-scale modeling of materials, phase field modeling ( $\mathrm{Hu}$ et al. 2010)... 18 Figure 5. Illustration of the combined power of structural, chemical, and physical property

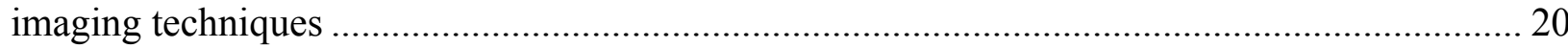

Figure 6. Potential NDE technologies and techniques (see acronym list) .............................. 22 Figure 7. Conceptual description of current state of art in field NDE and the gap towards which the present program is geared .................................................................................... 22 Figure 8. Microstructural defect length scales and applicable NDE techniques, after (Raj et al. 2003)

Figure 9. Sensor modeling through empirical correlations between fatigue stress and induced eddy currents 26

Figure 10. Conceptual relationships among components of mesoscale modeling and

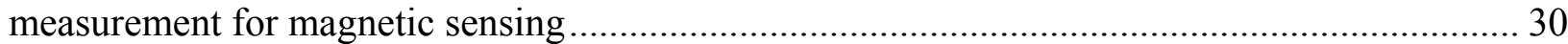

Figure 11. Schematic of First Order Revers Curve (FORC) measurements............................ 33

Figure 12. Schematic of NLU Measurement System .................................................... 51

\section{TABLE OF TABLES}

Table I. BWR component replacement cost in \$M (1999 cost basis, \$10K/man-rem, \$0.5M/day replacement power)

Table II. Degradation mechanisms and susceptible materials in LWR primary coolant systems 16 Table III. Candidate property changes for NDE monitoring of nuclear materials (see acronym

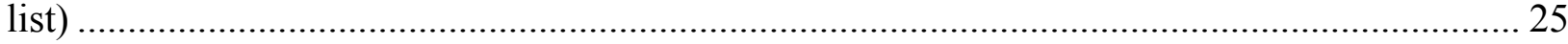

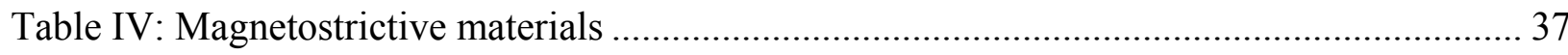

Table V. Summary of some magnetic imaging techniques ............................................. 40

Table VI. Down-select list of magnetic imaging methods relevant for NDE......................... 41

Table VII. Down-select trade study for magnetic imaging methods ...................................... 42

Table VIII. Material properties of iron (Fe) used in the simulations....................................... 45 


\section{Acronyms}

\begin{tabular}{|c|c|}
\hline $\mathrm{ABI}$ & automatic ball indenter \\
\hline $\mathrm{ACPD}$ & alternating current potential drop \\
\hline $\mathrm{AE}$ & acoustic emission \\
\hline AFAM & atomic force acoustic microscopy \\
\hline $\mathrm{AM}$ & acoustic microscopy \\
\hline AMR & anisotropic magneto-resistance \\
\hline APT & atom probe tomography \\
\hline ASME & American Society of Mechanical Engineers \\
\hline $\mathrm{B} \& \mathrm{PV}$ & boiler and pressure vessel code \\
\hline BEMM & ballistic electron magnetic microscopy \\
\hline $\mathrm{BMG}$ & bulk metallic glass \\
\hline BWR & boiling water reactor \\
\hline DBTT & ductile-brittle transition temperature \\
\hline DCPD & direct current potential drop \\
\hline EBSD & electron back-scatter diffraction \\
\hline $\mathrm{EC}$ & eddy current \\
\hline EDS & energy dispersive spectroscopy \\
\hline EMAT & electromagnetic acoustic transducer \\
\hline FORC & first order reversal curve \\
\hline GMR & giant magneto-resistance \\
\hline $\mathrm{HF}$ & high frequency \\
\hline IASCC & Irradiation-assisted stress corrosion cracking \\
\hline IGSCC & Intergranular stress corrosion cracking \\
\hline IR & infrared \\
\hline ISI & in-service inspection \\
\hline LVDT & linear variable differential transformer \\
\hline LWR & light water reactor \\
\hline MAE & magnetic acoustic emission \\
\hline $\mathrm{MBN}$ & magnetic Barkhausen noise \\
\hline MD2 & Materials Degradation and Detection \\
\hline MFM & magnetic force microscopy \\
\hline MOKE & magneto-optic Kerr effect \\
\hline MOS & magneto-optic sensor \\
\hline MTR & materials test reactor \\
\hline N/A & not applicable \\
\hline NDE & non-destructive evaluation \\
\hline NLU & nonlinear ultrasonics \\
\hline ODS & oxide dispersion strengthened \\
\hline
\end{tabular}




$\begin{array}{ll}\text { OSURR } & \text { Ohio State University Research Reactor } \\ \text { PEEM } & \text { photoelectron emission microscopy } \\ \text { PFM } & \text { piezoresponse force microscopy } \\ \text { PIE } & \text { post irradiation evaluation } \\ \text { PMMD } & \text { Proactive Management of Materials Degradation } \\ \text { PNNL } & \text { Pacific Northwest National Laboratory } \\ \text { PWR } & \text { pressurized water reactor } \\ \text { PZT } & \text { lead zirconate titanate } \\ \text { RPV } & \text { reactor pressure vessel } \\ \text { SAM } & \text { scanning acoustic microscopy } \\ \text { SANS } & \text { small angle neutron scattering } \\ \text { SAXS } & \text { small angle x-ray scattering } \\ \text { SCC } & \text { stress corrosion cracking } \\ \text { SEM } & \text { scanning electron microscopy } \\ \text { SEMPA } & \text { scanning electron microscopy polarization analysis } \\ \text { SHPM } & \text { scanning Hall probe microscopy } \\ \text { SNOM } & \text { scanning near-field optical microscopy } \\ \text { SOTA } & \text { state-of-the-art } \\ \text { SP-STM } & \text { spin-polarized scatting tunneling microscopy } \\ \text { SQUID } & \text { superconducting quantum interference device } \\ \text { SSM } & \text { scanning SQUID microscopy } \\ \text { TEM } & \text { transmission electron microscopy } \\ \text { TGSCC } & \text { transgranular stress corrosion cracking } \\ \text { TMR } & \text { tunnel magneto-resistance } \\ \text { UFM } & \text { ultrasonic force microscopy } \\ \text { UQ } & \text { uncertainty quantification } \\ \text { US } & \text { ultrasonic } \\ \text { V\&V } & \text { verification and validation } \\ \text { XMCD } & \text { x-ray magnetic circular dichroism } \\ & \end{array}$




\section{Executive Summary}

An effort is underway at Pacific Northwest National Laboratory (PNNL) to develop a fundamental and general framework to foster the science and technology needed to support realtime monitoring of early degradation in materials used in the production of nuclear power. The development of such a capability would represent a timely solution to the mounting issues operators face with materials degradation in nuclear power plants. The envisioned framework consists of three primary and interconnected "thrust" areas including 1) microstructural science, 2) behavior assessment, and 3) monitoring and predictive capabilities. A brief state-of-the-art assessment for each of these core technology areas is discussed in the paper.

The focus of this effort is to move beyond the current approach of in-service inspection through periodic nondestructive examination (NDE) of structural materials by developing the ability to use real-time monitoring of material degradation. The intent of real-time monitoring of materials degradation is to provide a better understanding of the surface and volumetric material changes occurring during the early stages of the incubation and micro-damage accumulation. By detecting the presence of the conditions conducive to the material degradation mechanisms at an early stage in the process, better insights are gained about the state of the material that can be used to introduce actions to mitigate further progression of the degradation mechanisms or understand the margin to failure. However, important scientific and technological breakthroughs are needed in characterizing, detecting, and understanding the early phases of environmental degradation in materials used in the production of nuclear energy. A critical step in achieving this objective is to develop an appropriate means to detect minor changes in material microstructures at the onset of degradation. In this case "appropriate detection" would need to satisfy several criteria: 1) be non-destructive; 2) be able to probe large volumes; 3) have submillimeter spatial resolution; 4) be capable of real-time/ on-line monitoring; 5) be able to operate remotely; 6) be able to withstand radiation environments at high temperatures.

Sections 2 and 3 of this report are adapted from a paper presented at the $20123^{\text {rd }}$ International Conference on Nuclear Power Plant Life Management (PLiM) discussing the outline of this proposed program, with additional information added. Following, we present two detailed case studies of candidate NDE technologies: magnetic methods and acoustic methods. In each category we discuss some of the theory related to sensing, some of the modeling work associated with understanding sensor materials and irradiation effects, and some of the methods for imaging microstructural properties related to the sensing modality. Finally, we discuss the research gaps and a proposed path forward, and acknowledge some complementary work being performed at other institutions. 


\section{Introduction and Motivation}

The loss in capacity factor due to material degradation issues for PWRs and BWRs has generally decreased over the last few decades (Figure 1), as plants have replaced problematic components and improved their inspection and maintenance programs (Ford 2007). Nonetheless, an increase in capacity factor of $1 \%$ in the U.S. nuclear fleet has the potential to offset $\sim 20$ billion pounds of $\mathrm{CO}_{2}$ (or other greenhouse gas) emissions each year (OECD 2011). However, it is anticipated that costs associated with management of materials performance will continue to increase as plants age. One method to improve capacity factors of nuclear power plants and to reduce the costs associated with managing materials performance is through the implementation of successful programs for the real-time monitoring of materials degradation.

The trend in component aging issues over time has shown that although fewer failures have occurred, the remaining mechanisms have increasing significance (Staehle 2012). Cracking in smaller components characterized early failures (such as sensitized stainless steel small-bore piping and bolts in reactor internals). These types of cracking, while still prevalent, represent a smaller fraction of component or material failures at present and have been mitigated through managing the operating conditions (water chemistry, etc.) as well as by replacement of components. At present, the major issues are with respect to large components (such as the pressure vessel head, pressurizer surge lines, welds in large bore piping, etc.), which appear to be impacted by late-onset forms of material degradation. Continued reliability of these components are challenging as they represent high-value components that are safety-critical, and as such, can result in expensive shut-down of operating plants. An estimate of the costs of component failures for BWR reactors is shown in Table I.

Current in-service inspection practices are based on requirements in the ASME B\&PV Code which were originally developed in the 1960's. The driving philosophy of the Code requirements is the management of fatigue degradation (Doctor 2008). The code specifies whether volumetric, surface, or visual examinations should be performed depending on the functional requirements of the component and the risks associated with its failure. In addition to the type of inspection, the code specifies the frequency of periodic exams and sampling criteria for performing exams of class 1, 2, and 3 components. The philosophy of current ISI requirements is challenged by the existence of diverse and challenging degradation mechanisms in nuclear power plants, such as stress corrosion cracking (SCC). In addition, as plants continue to age, it can be anticipated that new degradation mechanisms will continue to manifest in components (Wilkowski et al. 2002).

While current in-service inspection processes have been successful at detecting cracks in large-scale components, it is almost always after the fact (i.e., after the material degradation has reached a stage where replacement of the component is the only option). An example of this situation is the corrosion and subsequent cracking in the weld region of the control rod drive mechanism penetrations in the reactor vessel head at Davis-Besse. The environmental degradation incurred during operation resulted in the replacement of the entire reactor vessel 
head (IAEA 2007). The consequences of the material wastage due to boric acid corrosion may have been mostly adverted had real-time monitoring of crack formation and growth been available to provide indications of material degradation leading to leakage of primary coolant onto the component. Further reviews find that experience supports a need for the development of real-time materials degradation detection technologies that can monitor environmentally assisted material degradation of reactor structural components and provide sufficient lead time for maintenance, repair, or other mitigation activities. The program under development at PNNL addresses this need. An associated issue is the ability to determine critical locations to place monitoring capabilities to ensure that degradation that has immediate impacts on safety is detected in a timely fashion. In this, the PNNL effort will leverage previous (and ongoing) activities in Material Degradation Assessment (Proactive Materials Degradation Assessment (PMDA), Extended Materials Degradation Assessment (EMDA), and the industry-led Materials Degradation Matrix (MDM)) (Andresen et al. 2007; Lain 2008; Pathania 2008; Stark 2008). These assessments provide an indication of critical locations and materials, as well as the known (and possible future) degradation mechanisms associated with these locations and materials. Gaps in the technical knowledge required to achieve materials degradation detection are also identified in this assessment.
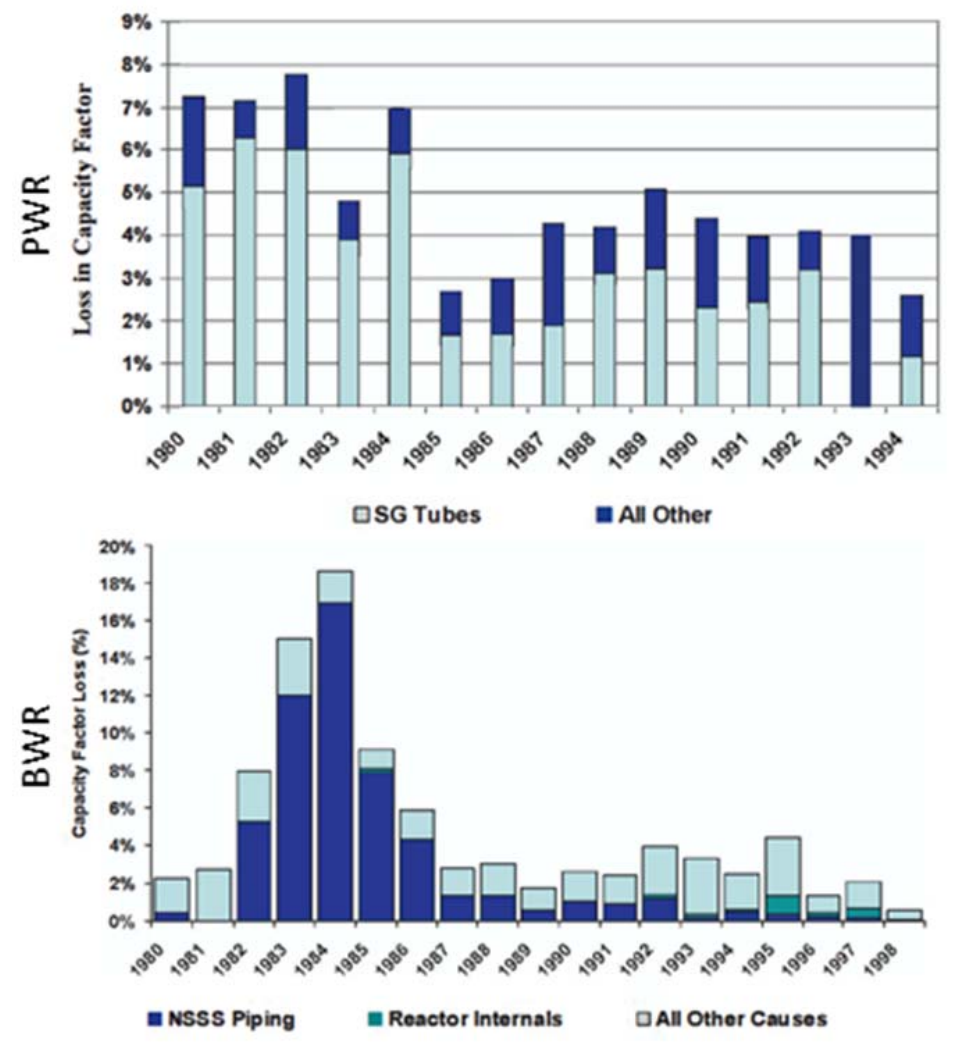

Figure 1. Plant capacity losses from materials degradation are $>\$ 1 \mathrm{~B} /$ year loss 
Table I. BWR component replacement cost in \$M (1999 cost basis, \$10K/man-rem, \$0.5M/day replacement power)

\begin{tabular}{|l|c|c|c|c|}
\hline Component Replacement & $\begin{array}{l}\text { Est. } \\
\text { Repair } \\
\text { Cost }\end{array}$ & $\begin{array}{l}\text { Rad. } \\
\text { Exposure } \\
\text { Costs }\end{array}$ & $\begin{array}{l}\text { Replacement } \\
\text { Power Costs }\end{array}$ & $\begin{array}{l}\text { Total } \\
\text { Cost }\end{array}$ \\
\hline Shroud Support to Vessel Weld & 250 & 55 & 182 & 487 \\
\hline CRD Stub Tube to Vessel Weld & 50 & 7 & 113 & 170 \\
\hline In-Core Housing & 50 & 2.25 & 50 & 102 \\
\hline Recirculation Piping & 20 & 12 & 63 & 95 \\
\hline Recirc. Inlet/Outlet Nozzles & 25 & 3 & 22 & 50 \\
\hline Jet Pump Riser Brace & 10 & 0.26 & 32 & 42 \\
\hline Core Support Plate & 4 & 0.3 & 25 & 29 \\
\hline Top Guide & 8 & 0.15 & 15 & 23 \\
\hline Instrumentation Penetrations & 6 & 2 & 13 & 21 \\
\hline
\end{tabular}

\section{Overall approach to develop real-time monitoring of materials degradation}

The framework that is being used to develop the science and technology needed for realtime monitoring of materials degradation in nuclear power reactors consists of three main interconnected thrust areas, described below and illustrated in Figure 2:

(1) Microstructural science: This thrust area will leverage developments in computational methods at the meso-scale and analytical and nano-scale microscopy to understand the onset and progression of prototypical degradation mechanisms in structural materials, under the influence of temperature, neutron irradiation, chemical attack, and other stressors. The focus will be on understanding degradation precursors (i.e., material microstructural changes that occur prior to crack coalescence and growth). A key area of concentration is the development of meso-scale quantitative property measurement techniques (physical property or micro-property imaging) to measure magnetic, acoustic, and electrical properties on sub-micron length scales.

(2) Behavior assessment: This thrust area will develop multi-scale, multi-physics computational models of material behavior changes caused by degradation mechanisms. Meso-scale models of degradation evolution and the resulting changes in physical properties of the material (such as acoustic, magnetic, and electrical) will be coupled to macro-scale models of the sensing physics to obtain insights into the sensitivity of measurement methods 
to early stages of damage. Advances in quantitative micro-property imaging technologies (e.g., magnetic force microscopy, acoustic force atomic microscopy, etc.) from thrust area (1) will be leveraged to verify and validate the models.

(3) Monitoring and predictive capabilities: The focus of this area is to leverage materials science, computational methods, and physical property imaging [including the developments in thrust areas (1) and (2)] to develop environmentally hardened sensors to monitor materials behavior under harsh conditions. In addition, the macroscopic measurements from these sensors will be utilized, along with the multi-scale, multi-physics models, to develop inverse analysis methods that attempt to quantify the level of damage at the microstructural level.

At the heart of each of these thrust areas are common research activities: computational modeling and model-based inverse analysis, micro-scale physical property measurements, and engineering-scale nondestructive measurements. A state-of-the-art assessment of these core technology areas is discussed next, along with a proposed plan for addressing the S\&T needs for developing continuous monitoring technologies.

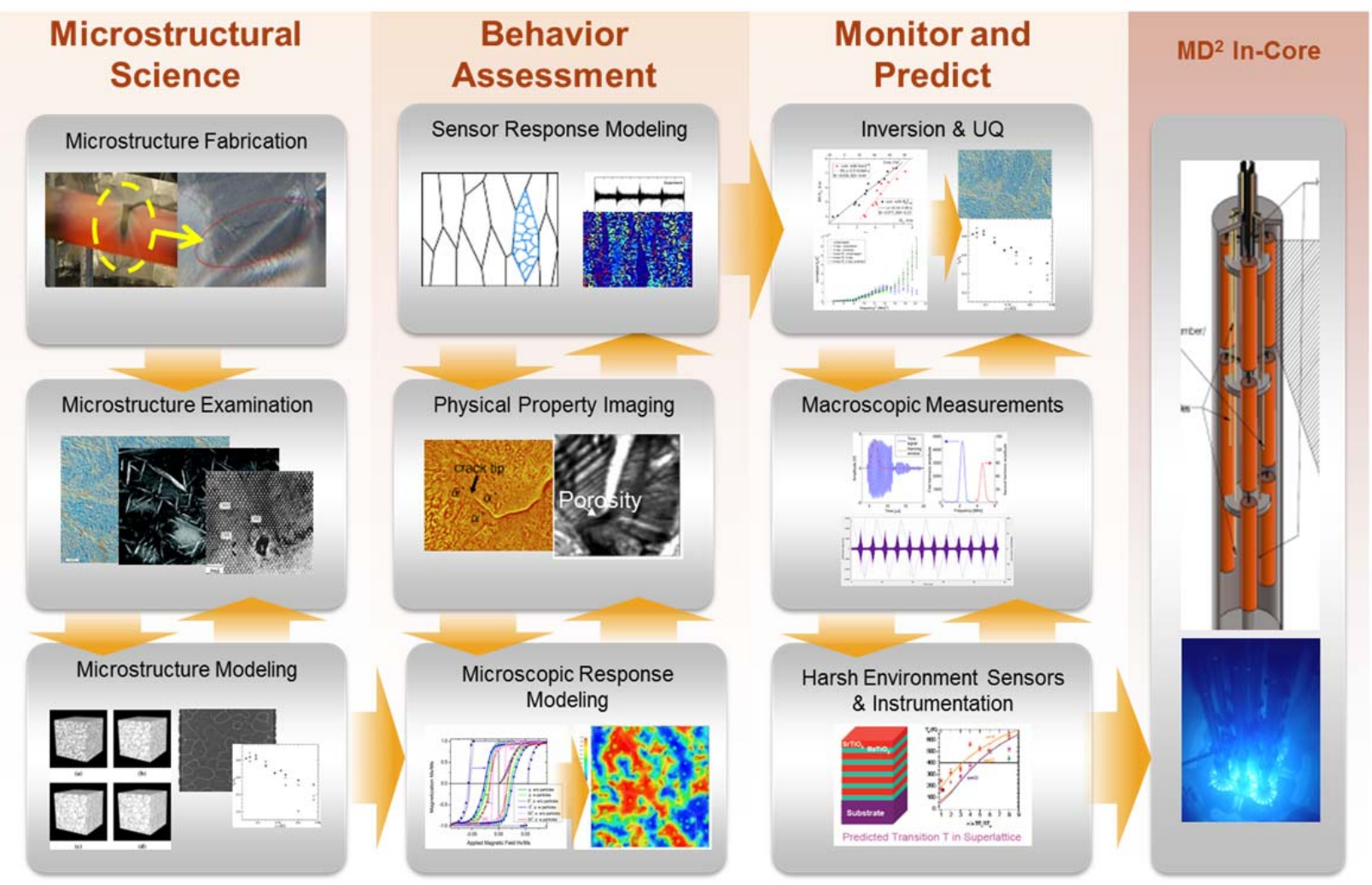

Figure 2. Conceptual illustration of the integrated parts of Material Degradation and Detection (MD2) 


\subsection{Gaps and Path Forward}

Given the available technical literature in this area, and the gaps identified in the different thrust areas, the following interconnected approach is proposed and shown schematically in Figure 3, with an example for acoustic NDE, showing specific gaps where verification and validation $(\mathrm{V} \& \mathrm{~V})$ are needed. Note: reference acronym section as appropriate.

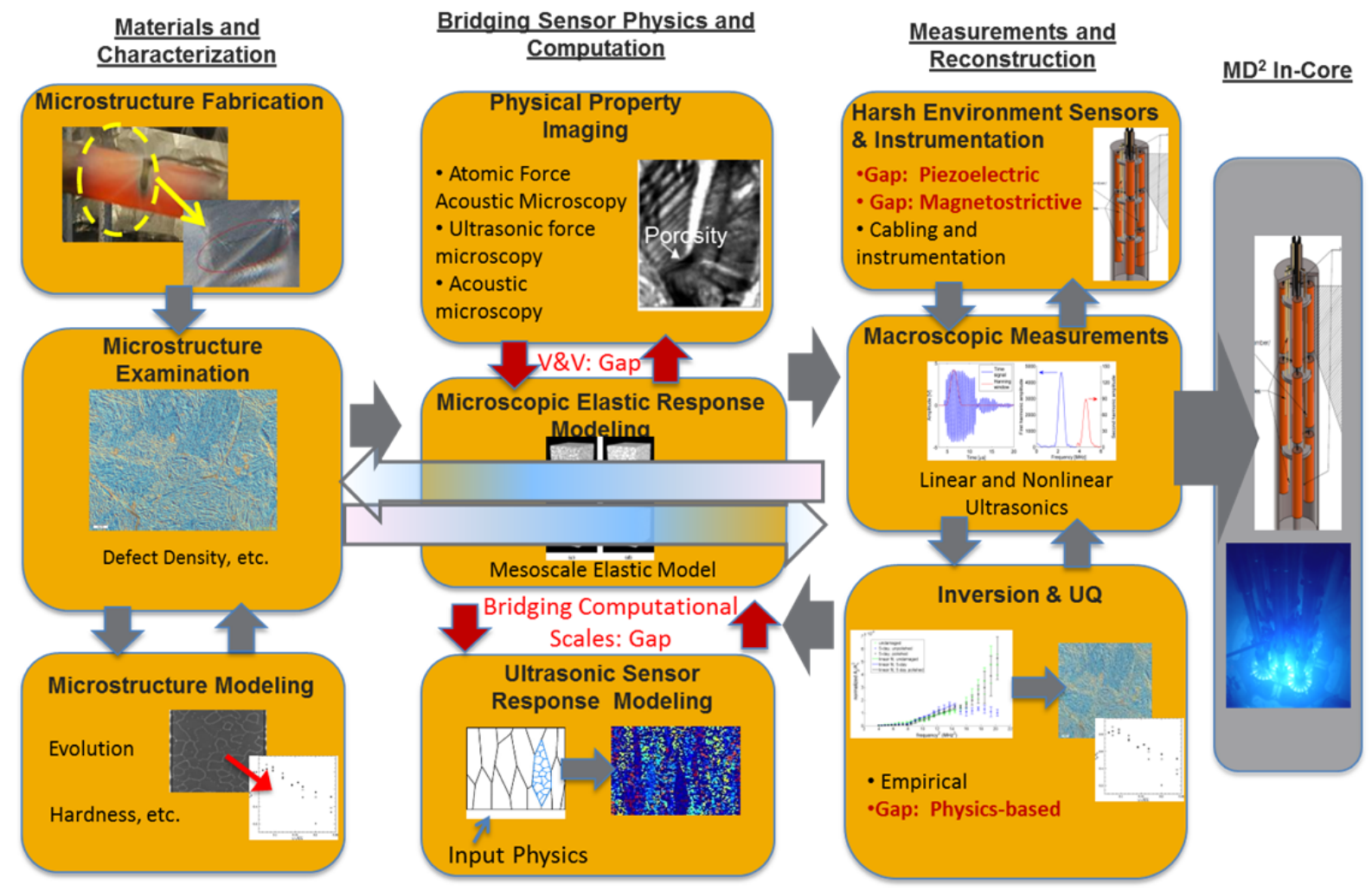

Figure 3. Schematic of approach for acoustic NDE sensor evaluation

1. Microstructure fabrication - Specimens are fabricated under known environmental conditions (known stress, neutron flux, temperature, etc.). Outcome: A set of specimens with different forms of microstructure, with and without degradation (used in steps 2 and $8)$.

2. Microstructure examination - Microscopy (imaging) used to characterize the microstructures. Tools to include APT, TEM, Environmental TEM, etc. Outcome: set of parameters defining the microstructure. Should also include thermodynamic and kinetic data (of use in steps 3 and 4).

3. Microstructure Modeling: Atomistic/phase field models of microstructure evolution. Outcome: Basic quantity such as hardness. 
4. Microscopic response modeling: Phase field model providing the response to applied stress at meso-scale. Outcome: Elastic modulus tensor $\mathrm{C}_{\mathrm{ijkl}}$ or magnetic hysteresis loop (or other relevant quantity).

5. Physical Property Imaging: Microscale imaging of elastic moduli variation (or magnetic permeability variation). Tools include MFM, AFAM, UFM, AM, etc. Data used to validate phase field models. Gap: V\&V at these length scales. The tools identified above are likely to provide the necessary validation data for mesoscale models.

6. Sensor Response modeling: Computational Models of applied energy interaction with material at bulk scales. For instance, modeling of ultrasonic wave propagation in the bulk material. Models need to be coupled to mesoscale models (Step 4) to integrate results from mesoscale models for bulk-scale predictive modeling. Tools for macroscale modeling include FEM, BEM, etc. to solve wave equation in anisotropic media. Outcome: Bulk-scale computational model of sensor physics. Gap: Bridging computational scales (from meso to macro). Multiscale modeling approaches may offer a route to bridging this gap.

7. Gap: Harsh environment sensors and instrumentation: Combination of modeling and experiment to characterize and develop sensor materials, sensors and instrumentation (piezoelectric, magnetostrictive, etc.) for harsh environment operation (high temp/rad). Tools include computational models and materials characterization systems being investigated currently. AFAM, etc. are useful tools to examine piezoelectric materials at microscopic scales during sensor operation. Outcome: If successful, a method to characterize sensor materials for performance in different environments, and design robust sensors. Used in step 8.

8. Macroscopic measurements: Macroscopic measurements on different microstructures (step 1) using sensors (step 7). Outcome: Data sets for use in bulk-scale model (step 6) $\mathrm{V} \& \mathrm{~V}$ as well as microstructure reconstruction (step 9).

9. Inversion and uncertainty quantification (UQ): Using sensor data at bulk scale, determine state of material and associated uncertainty. Tools include computational inverse models and characterization tools from previous steps, signal processing tools. Outcome: Robust approaches to fieldable inversion and UQ tools. Gap: Inversion to determine material state with minimal historical (trending) information. Gap: Uncertainty quantification.

\subsection{Material degradation modes in LWR primary coolant systems}

The majority of the structural components used in the primary system of LWRs are fabricated from the family of $\mathrm{Fe}-\mathrm{Cr}-\mathrm{Ni}$ metals often employed in many high-temperature 
corrosive environments. Several varieties of these materials are implemented including, carbon steels (e.g., A553B), stainless steels (e.g., 304 and 308), and nickel-based alloys (e.g., Alloy 600 and X750) and the corresponding weld materials used to join them. In general, these materials have exhibited excellent performance in high temperature and pressure water and steam systems. However, the unique combination of high temperature, corrosive water chemistry, and neutron flux leads to a harsh environment and activates materials degradation processes that reduce the capacity of these components to perform their desired operating and safety functions. The material degradation modes active in LWR primary coolant systems can be grouped into the following categories: generalized corrosion, localized corrosion, and mechanical. Table II summarizes the major types of material degradation mechanisms and the materials most susceptible in LWR systems.

The most impactful of the degradation modes shown in Table II is stress corrosion cracking (SCC), which has several different variants, including intergranular (IGSCC), transgranular (TGSCC), and irradiation-assisted (IASCC). Substantial research has been performed to identify the underlying causal factors that result in SCC failure in the $\mathrm{Fe}-\mathrm{Cr}-\mathrm{Ni}$ system. The research has found that SCC can become active once the conditions of environment (temperature, chemistry, neutron radiation, etc.), material susceptibility (microstructure, impurities, surface conditioning), and stress (residual, applied, etc.) align into a unique combination. Because of the large number of factors that influence SCC, quantitative predictions of the progression of the degradation process have been difficult. However, a qualitative understanding of the process has been developed and has been described by Staehle (Staehle 2012). While the progression given below is for the SCC mechanisms, the overview is general and applies to most material degradation processes.

The process of material degradation by SCC can be separated into 5 distinct stages (Staehle 2012). These stages are: (1) Stage 1: Initial condition - This stage represents the asmanufactured state of the material before exposure to the environment. The as-manufactured state includes surface characteristics such as finish (polishing, etching, oxidation, etc.), grain orientation/texture, second phase particles, and residual stresses. (2) Stage 2: Precursors - The precursor stage characterizes the exposure of the material to the operating environment. Upon exposure, certain processes may occur that promote the occurrence of SCC, such as surface pitting, depassivation of surface oxides, and buildup of irradiation damage (dislocations, amorphization of second phase particles, etc.). (3) Stage 3: Incubation - Progression from the precursor to the incubation stage represents the start of the active SCC process. During this stage the surface and microstructural changes occur that lead to crack initiation at the surface of the material. These changes include dislocation buildup, entry of oxygen or hydrogen, grain boundary migration of impurities, void formation, etc. (4) Stage 4: Proto-cracks - The formation of proto-cracks (cracks less than a few microns) results from vacancy coalescence, intergranular corrosion, etc. Proto-cracks start out as non-interacting with the applied or residual stress field, unlike the propagating cracks in Stage 5. (5) Stage 5: Propagation - This stage 
represents the process in which the crack interacts both with the local stress field and the local chemical/irradiation conditions. Crack advance is influenced by the electrochemical potential within the crack environment, the metallurgical chemistry at the crack tip, the stress state, etc. Stable crack growth rates are observed in experiments designed to simulate the coolant chemistry and strain rates.

Table II. Degradation mechanisms and susceptible materials in LWR primary coolant systems

\begin{tabular}{lll}
\hline Mode & Degradation mechanism & Susceptible material/component \\
\hline General corrosion & Boric acid corrosion & Carbon steel \\
& Erosion corrosion & Carbon steel, Alloy 600 \\
& Flow-accelerated corrosion & Carbon steel, Alloy 600 \\
& General corrosion & \\
Localized corrosion & Crevice corrosion & Carbon steel, Alloy 600 \\
& Galvanic corrosion & \\
& Pitting corrosion & Carbon steel \\
& Stress corrosion cracking (IGSCC, & Carbon steel, SS 304/316/308/309 CF8, Alloy \\
& TGSCC, IASCC, etc.) & 600, Alloy 82/182 \\
& Thermal/mechanical fatigue & Carbon steel, SS 304/316/308/309 CF8, Alloy \\
& & 600, Alloy 82/182 \\
Mechanical & Thermal embrittlement & SS 308/309 CF8, Alloy 82/182 \\
& Irradiation Embrittlement & Carbon steel, SS 304/316/308/309 CF8, Alloy \\
& & 600, Alloy 82/182 \\
& Irradiation/thermal creep & Carbon steel, SS 304/316/308/309 CF8, Alloy \\
& & 600, Alloy 82/182 \\
\hline
\end{tabular}

Current practices to manage the material degradation of primary system components in LWRs use periodic in-service inspection techniques to identify components that are in Stage 5 of the SCC process (Meyer et al. 2012). These practices characterize the presence of a crack and monitor the crack growth rate to ensure that actions are introduced prior to component failure. Because of the accelerating nature of crack growth, conservative actions are usually implemented (component repair or replacement) to ensure that rapid crack growth is prevented between inspection periods.

The goal of real-time monitoring of materials degradation is to provide a better understanding of the surface and volumetric material changes during Stage 3 (Incubation) and Stage 4 (Proto-cracks). By detecting the presence of the conditions conducive to SCC at an early stage in the process, better insights are gained about the state of the material that can be used to introduce actions to mitigate further progression of the degradation mechanisms or understand the margin to failure. 
A critical step in achieving this objective is identifying a methodology that relates the changes in underlying microstructural characteristics caused by the degradation process to detectable variations in the response of the material to the external fields applied using NDE techniques such as acoustic, magnetic, and electrical methods designed to probe material structure. One approach to develop this capability is to couple the advances in meso-scale modeling of material microstructure behavior with recent advances in micro-property measurement techniques to correlate local microstructure changes to external field responses. The study underway at PNNL is centered on identifying the science and technologies required in this approach and the challenges to this development are outlined below.

\subsection{Multi-scale computational modeling}

Atomistic, meso-, and macro-scale modeling methods have been developed during the past few decades to study microstructure and property evolution in irradiated materials. The challenge in multi-scale modeling of material behavior is the development of physics-based modeling approaches that enable prediction of the three-dimensional microstructure evolution at the meso-scale, where time and length scales are larger than that of atomistic simulations, but smaller than that of macro-scale methods. The temporal range for typical meso-scale methods is seconds to a few hours, and the typical length scale is 10's of nanometers to tens of micrometers. The phase-field approach (Figure 4) is one meso-scale method that has been successfully used in calculating the 3D microstructure evolution such as solidification, grain growth, martensitic transition, precipitation, ferroelectric/ferromagnetic transition, dislocation dynamics, deformation twin, and sintering (Chen 2002; Wang et al. 2001; Karma and Rappel 1998; Artemev et al. 2001; $\mathrm{Hu}$ et al. 2010). Atomistic simulations and experiments provide the thermodynamic and kinetic properties of the system that the phase-field approach requires for evaluating the microstructure behavior. The advantages of the phase-field approach are 1) the limited assumptions on microstructure morphology, 2) the ability to use a diffuse interface and topological changes instead of the difficulties of representing sharp interfaces, and 3) the continuous description of the energy landscape to take into account both short-range and long-range interactions.

At the macro-scale, an important application of simulation modeling is to understand the response of measurement sensor fields (e.g., acoustic, magnetic, and electric) to material damage. Most nondestructive evaluation measurements use the physics of stress wave propagation in materials, or the interaction of electric and magnetic fields with the material. Methods to model these interactions at the macro-scale include finite element models (Ludwig and Lord 1988; Chen and Konrad 1997), finite difference methods (Kunz and Luebbers 1993), and the method of moments (Jin 2002). In addition, semi-empirical models are also often used. Challenges in applying these methods include material inhomogeneity, anisotropy, and the stochastic nature of microstructural variation in materials (e.g., thermodynamic processes which are by nature statistical, such as Boltzmann's distributions). Most of the macro-scale sensor 
models are based on material property variations that are on much larger length scales than typical microstructural changes that control the onset of degradation. To gain a better understanding of the early stages of material degradation, additional and more refined information about the microstructural characteristics must be obtained from macro-scale methods. The current macro-scale/empirical methods lack the capabilities to provide this information alone and must be adapted to address the accumulation of microstructural damage at the meso-scale. A potential approach to addressing this issue is to couple meso-scale and macroscale modeling methods to achieve a multi-scale physical model of the interaction of the sensor field with the microstructure.

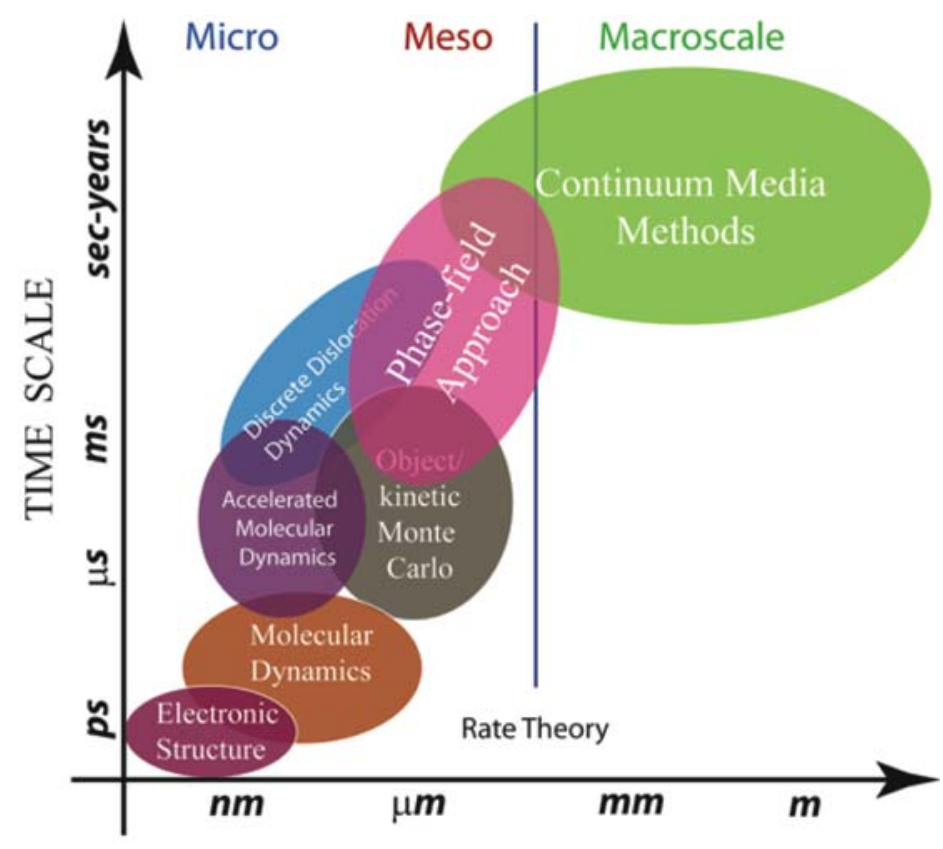

LENGTH SCALE

Figure 4. Rigorous meso-scale modeling of materials, phase field modeling (Hu et al. 2010)

A major difficulty in the area of computational modeling of material behavior is the ability to link simulations across length scales from a few microns to thousands of microns and higher. A number of approaches have been investigated to bridge the temporal and spatial scales from atomistic to macro-scale modeling methods. At one end of the bridging spectrum are indirect coupling methods that separately model at the meso- and macro-scales, and transfer information from one scale to the other with a passive process, using the results from lowerlength scale models to inform macro-scale models. Alternatively, fully coupled simulations have been developed that use such tactics as algebraic multi-grid methodologies (Brandt 2001). The challenge in either of these cases is the ability to scale the physical processes in an accurate enough fashion to retain the appropriate level of information for diagnostic evaluations. The initial effort to enhance the modeling of sensor physics to gather higher fidelity information will 
use the passive coupling approach to simplify the process while ensuring that only relevant information is passed from one scale to the next.

\subsection{Microscopic physical property imaging}

The processes that cause material degradation begin to occur in the microstructure at the atomic level as the atoms, ions, point defects, dislocations, grain boundaries, and second-phase particles respond and interact with the external chemical, thermal, mechanical, and irradiation environment. The ability to detect the microstructural evolution occurring in the early phases of material degradation requires identifying the impact of lower-length scale changes on key material properties at the sub-micron range. The capacity to characterize the microscopic physical properties (e.g., coercivity, elastic constants, and electrical conductivity) at the submicron/micron scale allows for 1) identifying the impact of microstructural changes during early stage degradation processes and 2) providing validation data to meso-scale modeling methods used to simulate the microstructure evolution during the degradation mechanisms.

Several microscopic physical property imaging techniques are derived from scanning probe microscopy capabilities, including magnetic force microscopy (MFM), atom force acoustic microscopy (AFAM), and piezoresponse force microscopy (PFM). These methods are able to resolve the impact of microstructure characteristics on nano-scale magnetization behavior (i.e., domain wall motion) and the nano-scale elastic material response. Other similar imaging methods which have somewhat lesser resolution include scanning Hall probe microscopy (SHPM), scanning SQUID microscopy (SSM), and scanning acoustic microscopy (SAM). By coupling the capabilities of these measurements with classical analytical microscopy methods, for example, transmission electron microscopy (TEM) and integrated, focused ion beam milling, scanning electron microscopy (SEM), electron backscatter diffraction (EBSD), energy dispersive spectroscopy (EDS), and atom probe tomography (APT), it now becomes possible to construct three-dimensional micro-property, micro-chemistry, and micro-crystallographic information that can be used to identify important relationships between microstructure evolution and material response. Figure 5 illustrates how the combination of structural imaging (optical and electron microscopy), chemical imaging (with microscope attachment such as EDS), and property imaging (magnetic, acoustic, and eddy current/ electrical conductivity) can combine to provide powerful diagnostic information about material degradation processes.

As mentioned, a key element in understanding the response of the microstructural characteristics (e.g., defect structure, second-phase particles, grain boundary evolution) to applied fields is the meso-scale phase-field modeling. The construction of micro-scale information that can be used to establish initial conditions for the analysis models is the first step in identifying the precursor signatures of material degradation. The second step uses microscopic physical property imaging to obtain the detailed response spectrum of characterized microstructures to applied fields. 
Validation of the meso-scale phase field models is necessary to ensure that the physics of microstructural behavior is being modeled accurately. One example in the literature of validating phase-field models using micro-property measurements has been performed with ferroelectric materials. A phase field model of $\mathrm{PbZr}_{0.2} \mathrm{Ti}_{0.8} \mathrm{O}_{3}$ films ( $\mathrm{Li}$ et al. 2005) has been compared to images of the same material taken using PFM (Ganpule et al. 2002), showing agreement between experimental and calculated material response.

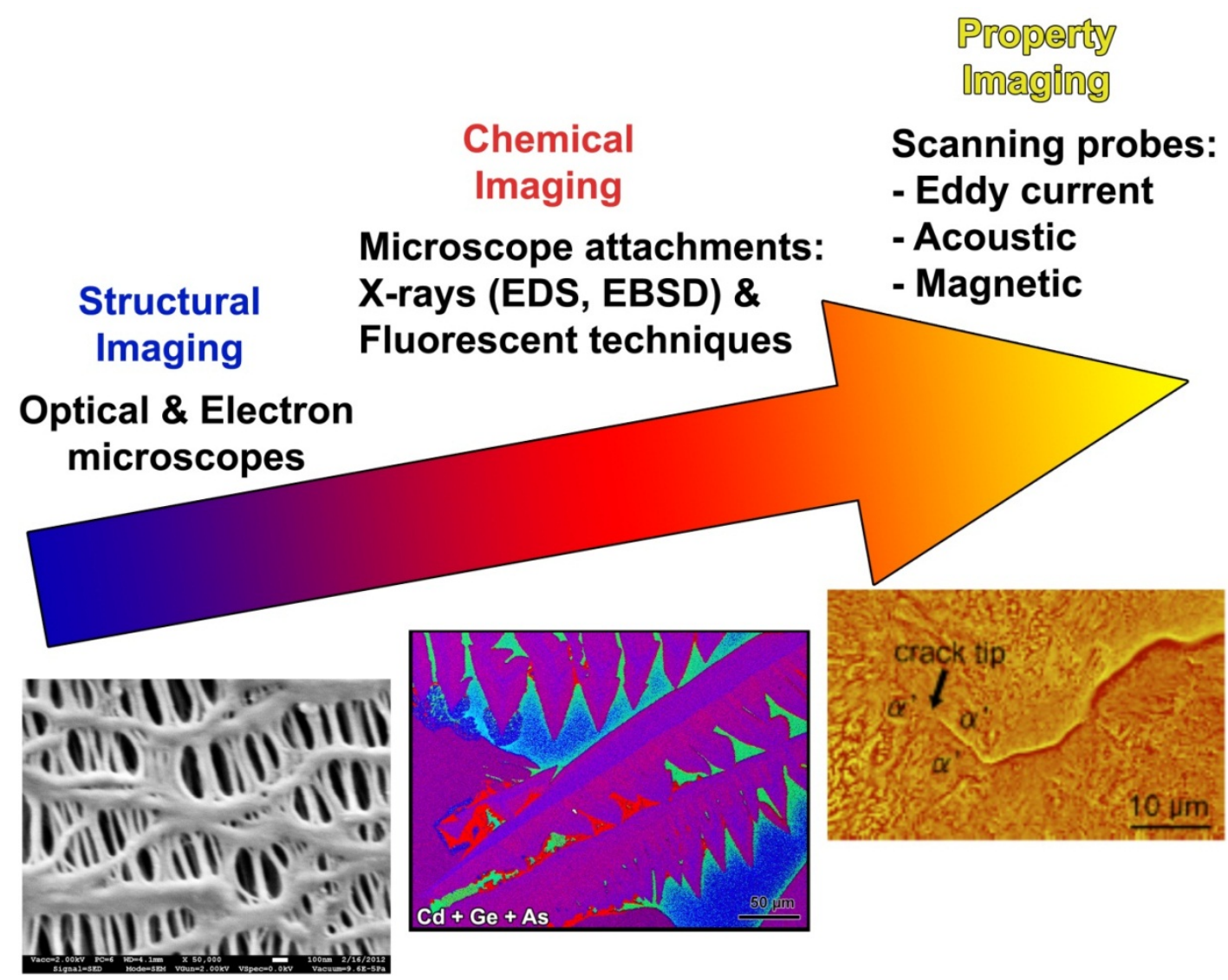

Figure 5. Illustration of the combined power of structural, chemical, and physical property imaging techniques

\subsection{Engineering-scale degradation measurements - NDE}

There are many possible NDE techniques which could be used to detect degradation and changes in material properties (see Figure 6). The main classes (and subclasses) of detection methods of interest are acoustic (linear and harmonic/nonlinear, with measurements of velocity/attenuation/scattering/nonlinear parameters), magnetic (Barkhausen, DC hysteresis, leakage flux), and electrical (eddy current, AC/DC potential drop, impedance tomography, impedance spectroscopy, etc.). Each detection method can be realized by multiple sensor types (e.g., magnetic: coils, Hall sensors, magneto-optic, giant magnetoresistance (GMR), anisotropic magnetoresistance (AMR), superconducting quantum interference device (SQUID); acoustic: 
piezoelectric, magnetostrictive, EMAT=electromagnetic/acoustic). These NDE methods have been reviewed by many authors regarding their applicability for use in nuclear reactor plant degradation management. PNNL researchers have been engaged in the Nuclear Regulatory Commission's Proactive Management of Materials Degradation (PMMD) program and have assessed various technologies for NDE of different reactor components (Bond et al. 2009, 2011). NDE techniques for assessing creep damage in power plant steels have also been recently reviewed (Sposito et al. 2010), where the various techniques are compared for their utility in detecting flaws as a function of crack progression, building on earlier reviews (Dobmann 2006; Dobmann et al. 1992).

The relationship between conventional materials science investigation tools such as SEM/TEM, optical microscopy, and field NDE is shown in Figure 7. This figure highlights the trade-off that exists between volumetric sampling capability and scale of phenomena that the technologies may be sensitive to. The development of non-destructive material examination methods sensitive to the phenomena of degradation at early stages requires the identification of suitable observable signatures that correlate with changes in material condition indicative of damage (precursors). Such signatures could be local changes in electrical, mechanical, or thermal properties that "localize" before initiation of a macro-defect such as metal loss or crack formation. Material degradation manifests at the microstructural level in several ways and the influence of such microstructural phenomena on measurable bulk magnetic and elastic properties is described in the extensive review by Raj et al. (Raj et al. 2003). This review also highlights the important length scales for measuring some forms of degradation, and applicable NDE techniques to investigate these length scales (see Figure 8).

For a given technique, determining resolution and minimum detectable flaw size is a complex process. In general, higher frequency measurements will give better feature resolution, lower penetration (higher attenuation), be more surface sensitive, sample a smaller volume, and have a smaller signal-to-noise ratio. Physical constrains, such as skin depth for electromagnetic waves and impedance matching for acoustic waves, will also play a part in determining the best frequencies for measurement. In the reality of field measurements, as opposed to laboratory measurements, it is quite difficult to control environmental noise, so electronics noise must be decreased to the lowest level possible, and higher powers are required to increase signal levels. Ultimately, therefore, the resolution of a particular technique should not be confounded with its sensitivity (or detectability) to a particular length scale defect or feature. Additionally, having increased sensitivity does not necessarily imply increased selectivity for detecting features of interest. That being said, it is desirable to detect flaws in the pre-crack stage (Bond et al. 2011), before they have become large enough for detection using conventional NDE techniques (see Figure 7). 


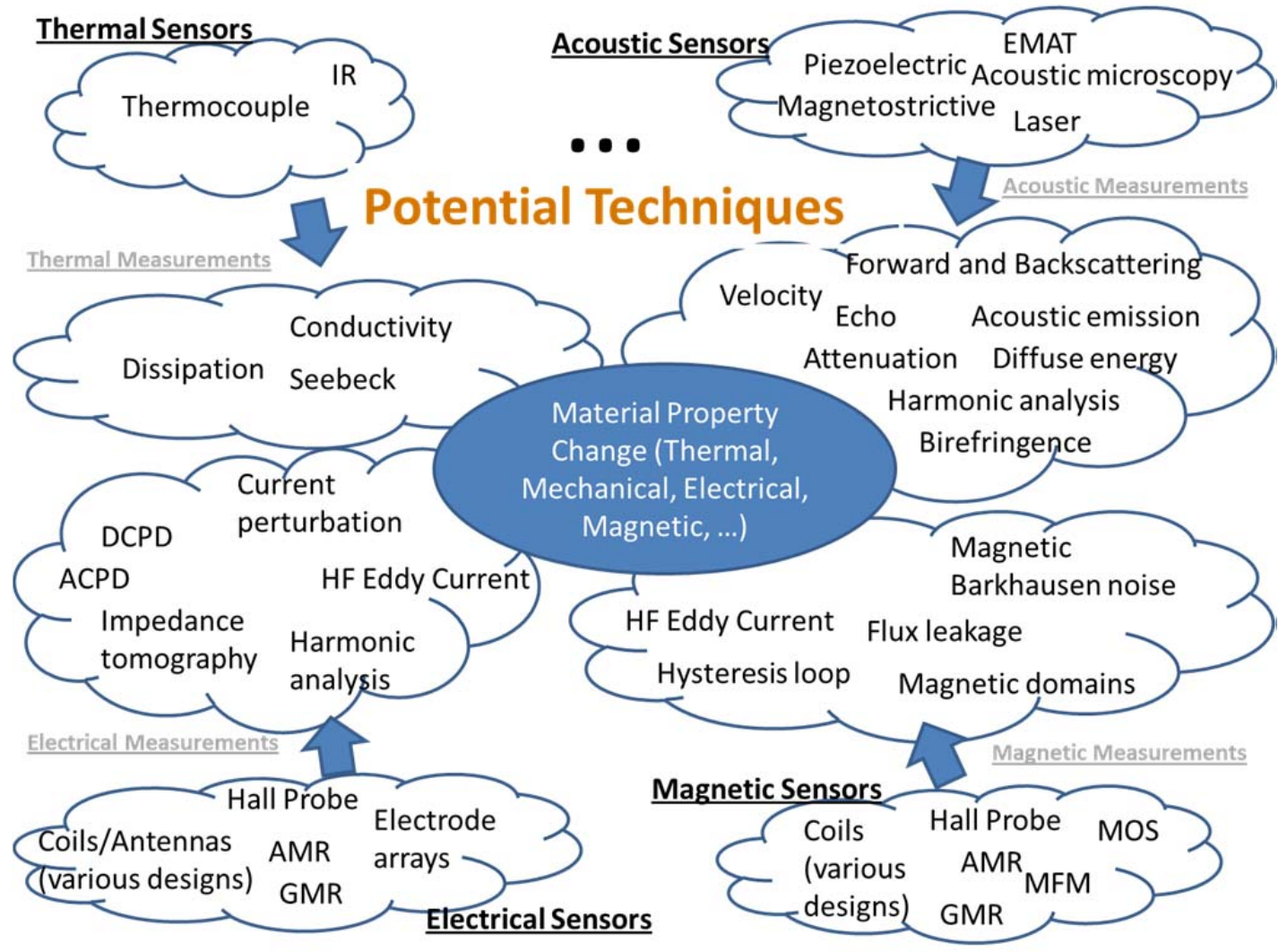

Figure 6. Potential NDE technologies and techniques (see acronym list)

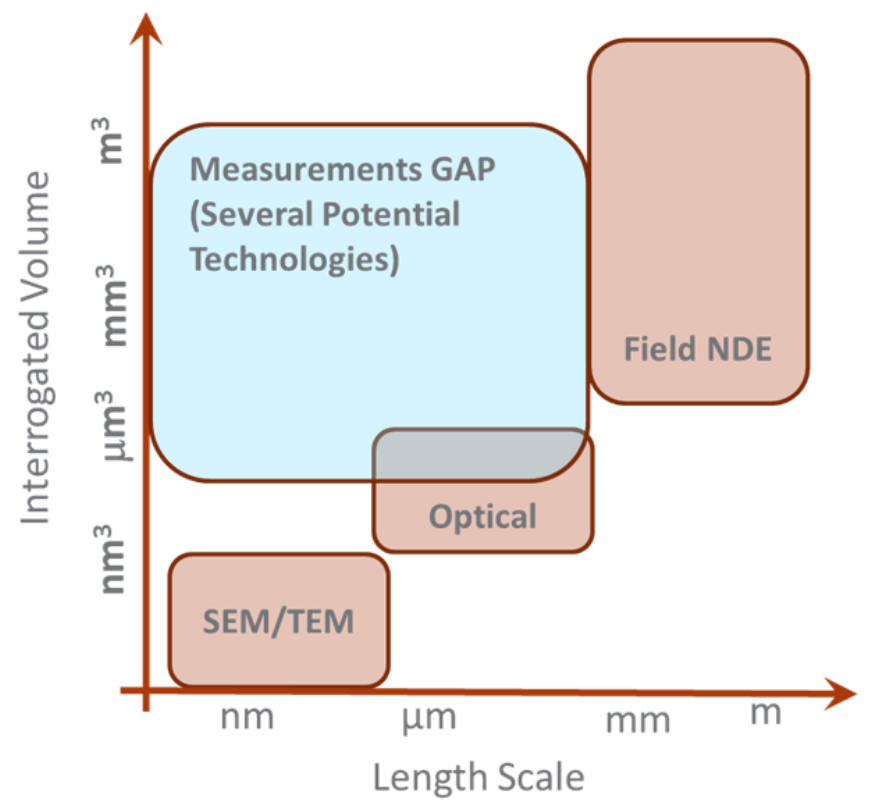

Figure 7. Conceptual description of current state of art in field NDE and the gap towards which the present program is geared 


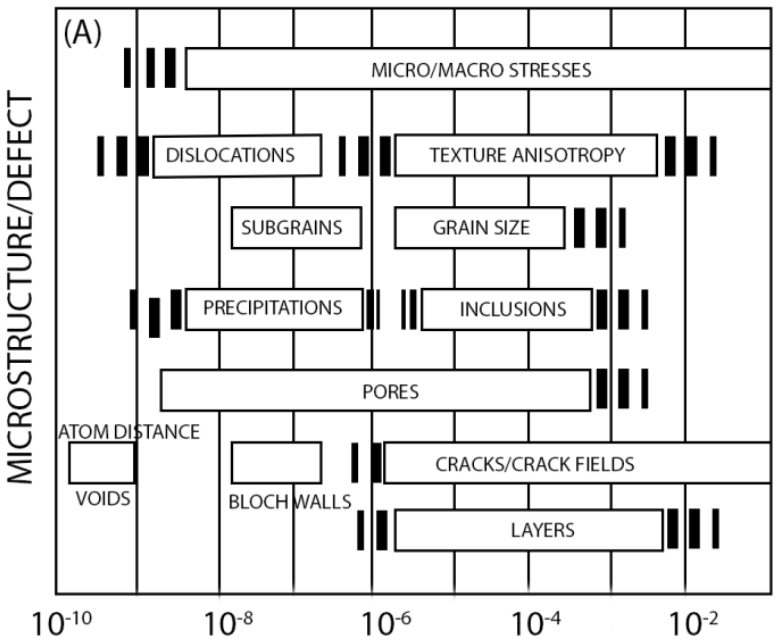

$(\mathrm{m})$

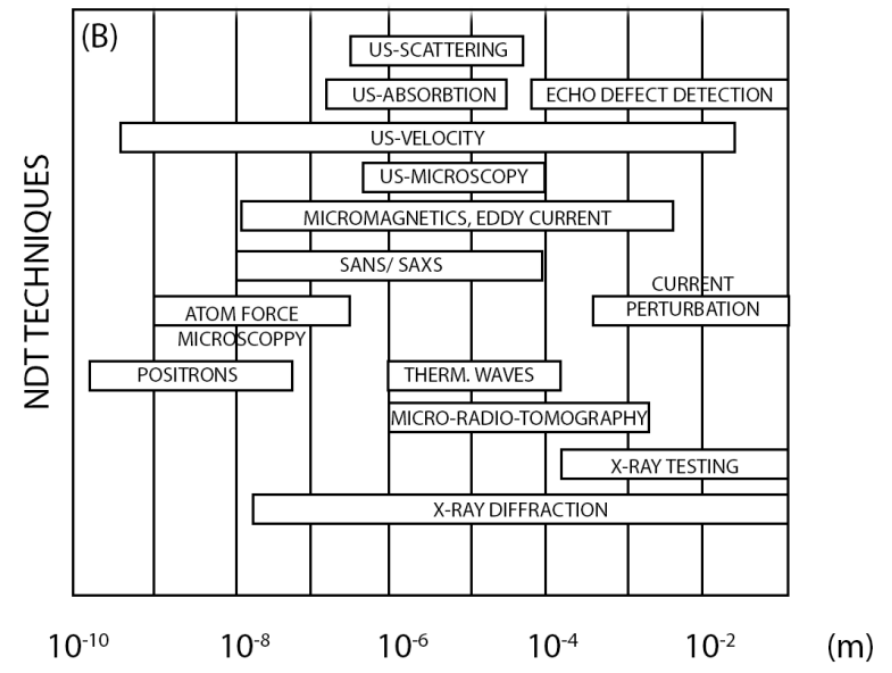

Figure 8. Microstructural defect length scales and applicable NDE techniques, after (Raj et al. 2003)

An added dimension to increasing sensitivity is the potential aging and degradation of the sensor itself, over long time periods. While this is generally not an issue for periodic in-service inspection technologies (differences in response due to sensor change-out can usually be calibrated out), the use of sensors for long-term condition monitoring in harsh environments is likely to result in a gradual change in the sensor response and sensitivity due to aging and degradation especially in regions of high temperatures and irradiation (neutron and gamma). Application of in-situ monitoring in nuclear reactors can conceptually be divided into two broad areas: (1) fuel and other in-pile materials and (2) external structural materials such as the reactor pressure vessel (RPV). The requirements on the sensor materials are quite different in 
these two cases, as temperatures and radiation fields for in-pile materials are much higher. Aging effects in sensor materials may be compounded by similar effects in the cabling and instrumentation used for measurement. The level of drift and reduction in sensitivity is likely to be a function of the type of sensor (acoustic vs magnetic vs electrical) and the specific material used (for instance, PZT vs AlN for piezoelectric sensors (Parks and Tittmann 2011)). Gamma and/or neutron testing has been conducted for the production of radiation-hardened magnetic sensors for space applications, fusion reactors, and other nuclear applications. Similar studies have been conducted, though on a limited scale, for piezoelectric materials commonly used for ultrasonic measurements. While recent advances (Coble et al. 2012) may be used to monitor sensor drift, techniques to compensate for decreasing sensitivity may be needed to maintain the ability to monitor the materials/components over the long term. An assessment of the current state-of-the-art (SOTA) for detection of degradation and degradation precursors in various materials of interest to nuclear plants is shown in Table III. This table focuses on $\mathrm{FeCr} / \mathrm{Ni}$ alloys, $\mathrm{Zr}$-alloys, oxide dispersion strengthened (ODS) steels, and $\mathrm{UO}_{2}$, as these constitute the dominant structural and fuel materials used (or planned for use) in current and future reactor designs. Listed are some phenomena of interest for degradation, field NDE SOTA, and microstructure changes of interest. Also listed are some examples of property changes of interest, such as magnetization $(M)$, thermal conductivity $(K)$, volume $(V)$, oxygen level $(O x)$, and ductile-brittle transition temperature (DBTT).

Several NDE technologies have emerged as potential candidates to meet the requirements for early material degradation measurement. These include micromagnetic techniques such as magnetic Barkhausen noise and magnetic loop measurements. Substantial efforts to relate thermal, mechanical, and radiation embrittlement degradation to micro-magnetic responses are described by Raj et al. (Raj et al. 2003) and Dobmann et al. (Dobmann 2006). Nonlinear acoustic/ultrasonic techniques have been shown to be more sensitive to micro-damage than conventional linear ultrasonic techniques (Jhang 2009). The development of practical NDE technologies for early degradation monitoring is in its infancy and one critical gap is the ability to interpret the resulting measurement signals. Empirical correlative analysis (e.g., Figure 9) is often performed on signals obtained over a range of conditions to relate measurements to material condition. The development of physical-based models to allow determination of material state without knowledge of initial state and stressor history is an important need; addressing this need will allow more robust interpretations of material condition from engineering scale measurements. The insights gained from the multi-scale computational models described earlier can be used to address the needed inverse analysis to aid in characterizing the microstructural state of the material. 
Table III. Candidate property changes for NDE monitoring of nuclear materials (see acronym list)

\begin{tabular}{|c|c|c|c|c|}
\hline & $\mathrm{FeCr} / \mathrm{Ni}$-Alloy & Zr-Alloy & ODS & $\mathbf{U O}_{2}$ \\
\hline Microstructure & $\begin{array}{l}\text { Gas bubble, Grain } \\
\text { boundary segregation, } \\
\text { Dislocation loop, Oxide } \\
\text { film. }\end{array}$ & $\begin{array}{l}\mathrm{SSP}, \mathrm{ZrH}_{2} \text {, Dislocations, } \\
\text { Oxide film }\end{array}$ & $\begin{array}{l}\text { Gas bubble, Grain } \\
\text { boundary segregation, } \\
\text { Dislocation loop, } \\
\text { Oxide film; Stability } \\
\text { of nano-particles and } \\
\text { the impact on } \\
\text { microstructure }\end{array}$ & $\begin{array}{l}\text { Gas Bubble, } \\
\text { Porosity, } \\
\text { Grain coalescence, Re- } \\
\text { crystallization }\end{array}$ \\
\hline $\begin{array}{l}\text { Property } \\
\text { Changes }\end{array}$ & $\Delta \mathrm{H}, \Delta \mathrm{V}, \Delta \mathrm{DBTT}$ & $\Delta \mathrm{H}, \Delta \mathrm{Ox}, \Delta \mathrm{V}, \Delta \mathrm{DBTT}$ & $\begin{array}{l}\Delta \mathrm{H}, \Delta \mathrm{Ox}, \Delta \mathrm{V}, \\
\Delta \mathrm{DBTT}\end{array}$ & $\Delta \mathrm{K}, \Delta \mathrm{Ox}, \Delta \mathrm{V}, \Delta \mathrm{DBTT}$ \\
\hline$\Delta \mathrm{M}(\Delta \mathrm{Oe})$ & Precipitate growth & $\begin{array}{l}\text { Second phase particle } \\
\text { behavior }\end{array}$ & & $\mathrm{N} / \mathrm{A}$ \\
\hline$\Delta \mathbf{E}(\Delta \mathbf{M P a})$ & $\begin{array}{l}\text { Precipitate Growth, } \\
\text { Void Growth, }\end{array}$ & Dislocations, hydrogen & & \\
\hline ( $\triangle \mathrm{MPa})$ & $\begin{array}{l}\text { Oxide film thickness } \\
\text { growth }\end{array}$ & Oxide film thickness growth & & \\
\hline $\begin{array}{l}\text { Phenomena/ } \\
\text { Degradation } \\
\text { Mechanisms }\end{array}$ & $\begin{array}{l}\text { SCC } \\
\text { Irradiation Hardening } \\
\text { DBTT }\end{array}$ & $\begin{array}{l}\text { Material Loss } \\
\text { Irradiation Hardening } \\
\text { Hydrogen Pickup } \\
\text { SCC } \\
\text { DBTT }\end{array}$ & $\begin{array}{l}\text { DBTT } \\
\text { SCC }\end{array}$ & $\begin{array}{l}\text { Cracking, Swelling, } \\
\text { Porosity } \\
\text { Fission Products }\end{array}$ \\
\hline $\begin{array}{l}\text { Field NDE: } \\
\text { Detection SOTA }\end{array}$ & $\begin{array}{l}\text { Cracking: } 0.1-1 \mathrm{~mm} \\
\text { (acoustic, eddy current) } \\
\text { best case in the field } \\
\text { Hardening: Usually ABI } \\
\text { or microindentation used } \\
\text { DBTT shifts - not } \\
\text { measured in field, } \\
\text { surveillance specimens } \\
\text { used to assess DBTT }\end{array}$ & $\begin{array}{l}\text { Crack: } \sim 0.1 \mathrm{~mm} \text { (eddy } \\
\text { current) } \\
\text { Data on fabrication inspection } \\
\text { capability difficult to locate. } \\
\text { Field inspections (ISI) not } \\
\text { done. } \\
\text { Literature usually focused on } \\
\text { hydriding and other impurity } \\
\text { detection - research phase } \\
\text { only currently. }\end{array}$ & $\begin{array}{l}\text { N/A (material not } \\
\text { used in current } \\
\text { LWRs) } \\
\text { Literature not very } \\
\text { widespread on } \\
\text { SCC/DBTT } \\
\text { measurement }\end{array}$ & $\begin{array}{l}\text { N/A - field NDE (ISI) } \\
\text { methods not used } \\
\text { Degradation detection } \\
\text { PIE demonstrated in } \\
\text { literature for porosity + } \\
\text { fission gases. } \\
\text { Cracking and swelling } \\
\text { not measured in field }\end{array}$ \\
\hline
\end{tabular}

\section{NOTES:}

- $\mathrm{H}$ - magnetic field; V - volume; DBTT - ductile-brittle transition temperature; Ox oxidation; SCC - stress-corrosion cracking; ISI - in-service inspection; PIE - post irradiation evaluation; $\mathrm{ABI}$ - automatic ball indenter 


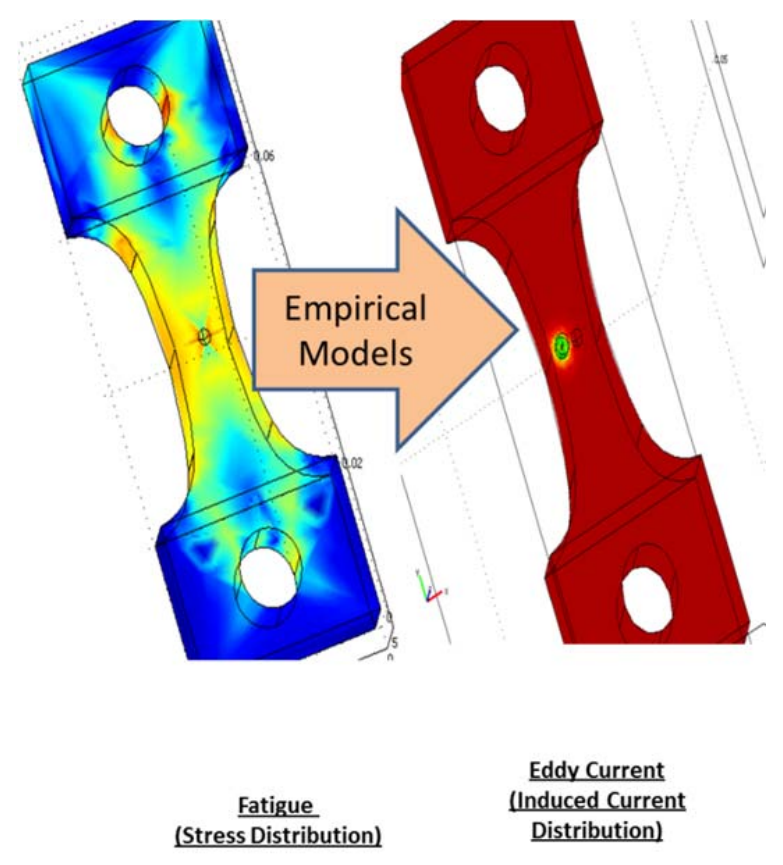

Figure 9. Sensor modeling through empirical correlations between fatigue stress and induced eddy currents

In summary, general detection technology gaps involve 1) measurement signal: robustness of measurement signal to noise, sensitivity to small-scale changes, and selectivity minimally impacted by other factors; 2) sensor technologies: robustness and long-term stability to harsh temperature, radiation, and chemical environments; high sensitivity over large bandwidths; and integrated sensors in structural materials; 3) electronics and instrumentation: robustness to harsh environment, low power or power-harvesting capable; and 4) analytics: multiscale multiphysics computational modeling to guide interpretation of measured data. Barriers to detection do not lie in the physics of the material being inspected; in other words, the relevant phenomenology is not too small. The main issues are the ability to sample large enough volumes to find rare features such as defects and crack precursors (impacts the fieldability of the NDE technique), the ability to generate models of microstructures with spatially varying electromagnetic and acoustic properties (impacts the development of the NDE technique), and the ability to generate sensor models which statistically predict detection based on spatially differing electromagnetic and acoustic properties (impacts interpretation of the measurement). Secondary issues include sensor- or probe-specific limitations regarding radiation hardness, high temperature performance, and frequency limitations.

A summary of the state of the art in in-pile and ex-core measurements is provided below, as a starting point for the gaps assessment. 


\subsubsection{In-pile measurements}

Improved safety and reliability of nuclear fuels are important for the development of Gen IV systems and to the competitiveness of existing nuclear plants. The performance of these fuels must be verified prior to licensing under operating conditions in a fuel cycle test program using test reactors such as Idaho National Laboratory's Advanced Test Reactor (ATR). It has been determined that this fuel cycle test program should include in-pile instrumentation that allows real-time three-dimensional characterization of fuel during irradiation (Rempe et al. 2011). Characterization needs include dimensional changes in fuel pellets, microstructural changes (such as porosity and cracking), as well as characterization of fission gasses. Several recent reviews have focused on in-pile instrumentation for reactor monitoring (Kim et al. 2011; Solstad and Van Nieuwenhove 2011; Villard and Schyns 2011; Rempe et al. 2010). On-line continuous monitoring of in-pile materials requires radiation-hardened sensor materials. Gamma and/or neutron testing has been conducted for the production of radiation-hardened magnetic sensors for space applications, fusion reactors, and other nuclear applications.

Some of the key enabling sensor technologies identified for in-pile monitoring are acoustic-based. Typical acoustic transducer elements are composed of piezoelectric ceramics, most of which are known to degrade severely at high temperatures and in high neutron flux, resulting in loss of signal. High Curie temperature $\left(T_{\mathrm{C}}\right)$ is important for in-pile sensor applications, as predictions for fuel cladding temperatures are $\sim 400^{\circ} \mathrm{C}$ for light water reactors and $\sim 650^{\circ} \mathrm{C}$ for sodium fast reactors (Rempe et al. 2011). Radiation-induced thermal spikes in neutron irradiated permanent magnets in the Ohio State University Research Reactor (OSURR) have been estimated to reach $275^{\circ} \mathrm{C}$ or higher for only $2 \times 10^{13} \mathrm{n} / \mathrm{cm}^{2}$ fluence (Liu et al. 2007). For reference, Curie temperatures of conventionally used ferroelectrics for piezoelectric acoustic transducers are $\sim 365^{\circ} \mathrm{C}$ (PZT5A) (Zhang and Yu 2011), while that of more advanced noncommercial ones can reach only $570^{\circ} \mathrm{C}\left(\mathrm{PbNb}_{2} \mathrm{O}_{6}\right)$ (Holbert et al. 2003). $\mathrm{LiNbO}_{3}$, while having a high $T_{\mathrm{C}}$ of $1145^{\circ} \mathrm{C}$, suffers from oxygen loss and activation of ${ }^{6} \mathrm{Li}$ making it less useful than other piezoelectric ferroelectrics. Higher $T_{\mathrm{C}}$ piezoelectrics tend to have lower electromechanical conversion factors. Some non-ferroelectric materials have been considered as very high temperature piezoelectrics, such as AlN and $\mathrm{GaPO}_{4}$, but these materials typically have very low intrinsic transduction capability (Zhang and $\mathrm{Yu}$ 2011).

An alternative technology for acoustic transduction relies on magnetostrictive elements to create the acoustic wave in the material to be inspected (e.g., fuel cladding) by NDE. Ultrasonic magnetostrictive transducers have been developed for a number of products, including surgical tools, underwater sonar, and chemical and materials process monitoring. Magnetostrictive devices are numerous and include ultrasonic cleaners, adaptive optics positions, active vibration control, and linear motors. Proposals for in-core diagnostics using magnetostrictive transducers have thus far relied on propagating acoustic signals, such as with guided wave modes, from outside the core, thus shielding the transducer from the highest temperatures and neutron fluxes (Guers 2010). Currently available magnetostrictive acoustic 
sensors are limited to low acoustic frequencies $(<500 \mathrm{kHz}$ and normally $\sim 10 \mathrm{kHz})$ due to induced eddy currents in conductive metallic magnetostrictive materials. These low frequencies limit the resolution of acoustic measurements below $\sim 10 \mu \mathrm{m}$ necessary for inspecting fuel porosity, where acoustic frequencies of $\sim 10 \mathrm{MHz}$ are required. Magnetostrictive transducer materials with high $T_{\mathrm{C}}$ should at least be able to compete with ferroelectric piezoelectric transducers for thermal stability, and may offer superior transduction to current materials considered for hightemperature piezoelectric acoustic transducers.

One important issue constraining in-pile measurement methods is that sensor materials may become altered with radiation such that their transduction function is changed. Experiments are needed to assess real-time transient changes in the sensor materials, such that the change in the sensor itself can be decoupled from the changes of the acoustic signal of the fuel bundle or other component under investigation.

\subsubsection{Ex-core measurements}

Monitoring of ex-core structural components such as the RPV, on the other hand, allows the introduction of many other types of sensors because the materials used for ex-core components are metallic and therefore allow a wider range of measurement physics. In addition, the environmental conditions are often less severe than in-core conditions. Acoustic, ultrasonic and magnetic sensors are of primary interest when dealing with metallic pressure boundary components. In this case, magnetic sensors measure magnetic field changes near degradation and cracking by means of flux leakage or the Barkhausen effect caused by the discontinuous jump of magnetization due to pinned domain wall movement. These methods have shown great promise in other, less demanding, applications related to inspection of metallic components. Acoustic and ultrasonic measurements could potentially be implemented using a variety of sensors including those based on piezoelectric, magnetostrictive, and electromagnetic acoustic transduction (EMATs). Laser excitation of ultrasound may also be a possible means for inspecting components when access to the surface is available.

In addition to environmental factors, sources of noise due to reactor operation pose a challenge to real time monitoring of structural components. For instance, acoustic noise caused by the flow of reactor coolant has a significant impact on the ability to monitor component degradation via acoustic emission. Electrical noise issues caused by running pumps and motors may cause similar issues for magnetic or electrical based measurements.

Achieving sufficient coverage is another challenge posed by real time monitoring of early degradation in structural components in nuclear reactors. Achieving full component coverage is not practical for the near term and the detection of damage precursors requires detection in the earliest stages of degradation. Hence, optimal placement of sensors for real time monitoring of damage precursors in structural components is a significant challenge to overcome. 


\section{Magnetic Case Study}

The overall goal of expanded capability is to 1) image the relevant NDE property at a relevant length scale to the degradation phenomena, 2) cross-correlate static computational microstructures with physical and NDE property images acquired with advanced characterization techniques, 3) predict microstructural evolution of radiation-induced degradation of a particular type, 4) design and characterize radiation-hardened sensors materials, 5) perform in-situ measurements of NDE properties in a representative radiation environment, 6) interpret NDE measurements with the aid of physics-based models of signal development (sensor model), and 7) estimate the remaining life of the component based on interpreted NDE signals and models.

In the case of magnetic sensors, the primary signal is based on magnetization of the sample (e.g. structural steel component such as RPV) as a function of applied current/magnetic field. Magnetization occurs via various processes, among them movement of magnetic domain walls. Domain wall motion is impeded by defects such as dislocations, precipitates, voids, and second phases (Bida 2004). Irradiation produces and/or destroys these types of defects, thus changing the local coercive fields of the material. Analogous to the paragraph above, it is desirable to 1) image defects impeding domain wall motion, 2) compute the effects of defects on domain wall motion and compare these results to bulk measurements like major loop hysteresis and NDE measurements like Barkhausen noise, 3) compute the evolution of these defects as a function of irradiation, 4) produce radiation-hardened Barkhausen noise or other magnetic sensors, 5) test these rad-hard sensors in a representative neutron environment, and 6) show that the measured Barkhausen signals can be interpreted in terms of a nano/micro-scale distribution or density of defects of a certain type, and 7) predict the remaining life of the monitored component based on measured current state and models of defect evolution. A schematic of this process is shown in Figure 10. Some components of this approach have been shown in the literature, as will be discussed below. For the purposes of pedagogical illustration, the following discussion will begin at the sensor and phenomenological level and proceed toward the nanoscale fundamental level.

\subsection{Signal interpretation and sensor modeling}

This section will focus on only one type of magnetic sensor, the Barkhausen noise sensor. Other candidate magnetic NDE sensors are possible, but Barkhausen sensors are sufficiently developed such that much of the physics is well-understood and many steel alloys, including irradiated alloys, have been at least preliminarily investigated. First, the physics of the Barkhausen effect and related magnetic properties are reviewed. Second, the literature on the effects of radiation on magnetic properties of steels is reviewed. 


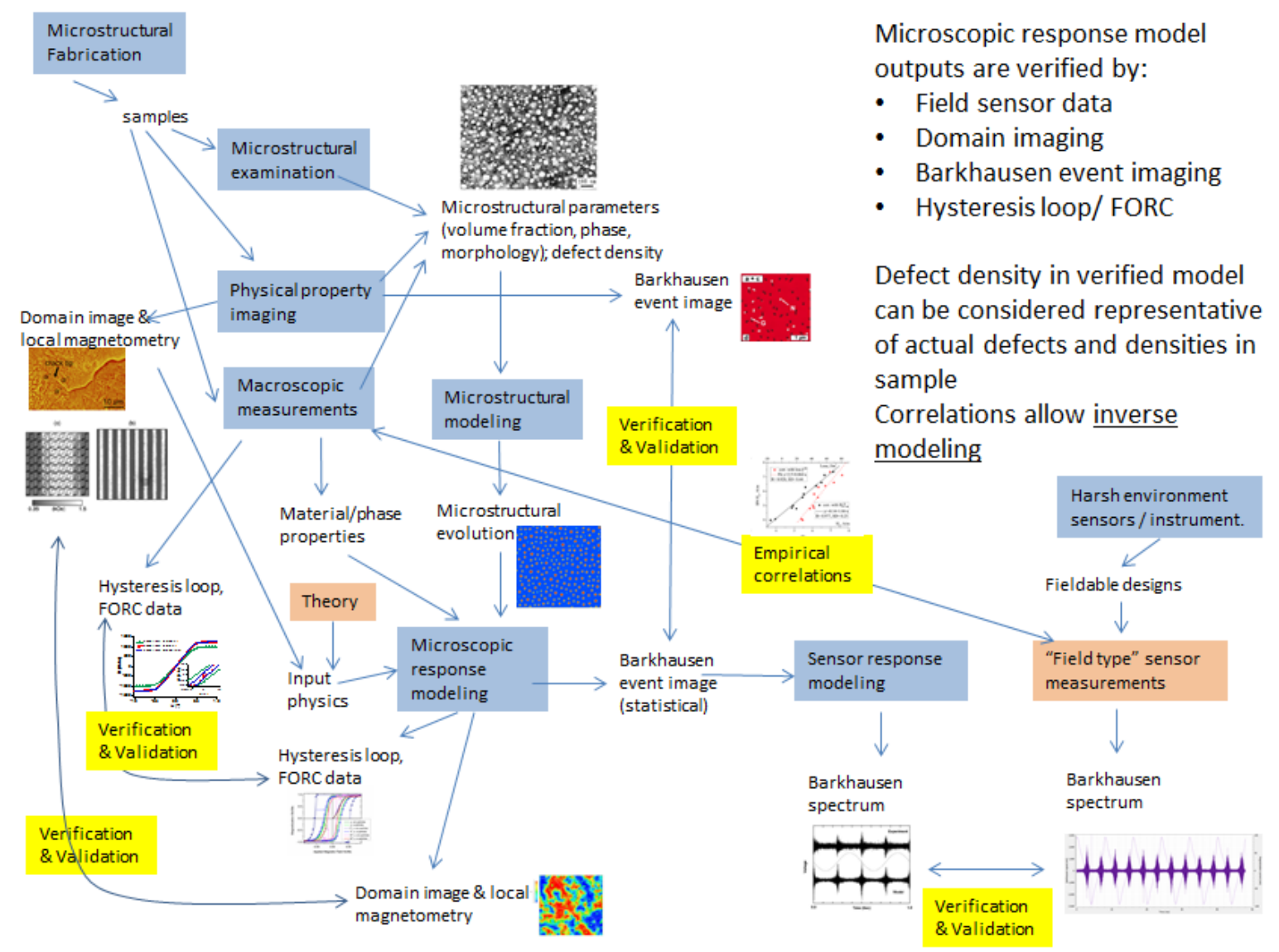

Figure 10. Conceptual relationships among components of mesoscale modeling and measurement for magnetic sensing

\subsubsection{Barkhausen noise}

Barkhausen noise is a result of the magnetic hysteresis in ferromagnetic materials (Jiles and Atherton 1986; Jiles 2000; Stupakov et al. 2008). The magnetic flux density (B) in ferromagnetic materials placed in an externally applied magnetic field is a function of the applied magnetic field intensity $(H)$ and the magnetic permeability $(\mu): B=\mu H$. For ferrous materials, the $B-H$ (or magnetization) curve is sigmoid in shape. Close inspection of the $B-H$ curve reveals that changes in the induced magnetization are not continuous. Instead, they manifest as discrete steps arising from the movement of magnetic domain walls as the applied magnetic field intensity is increased. The magnetic Barkhausen effect is caused by abrupt changes in magnetization with imposed magnetic field, principally due to interactions of $180^{\circ}$ domain walls with dislocations (Ranjan et al. 1987b; Ranjan et al. 1987a; Krause et al. 1994). As the imposed magnetic field strength $(H)$ increases, larger numbers of magnetic domains align in the applied field direction. This realignment is, however, not a continuous process since the presence of dislocations, voids, inclusions or other microscopic damage sites results in domain wall pinning. 
Increasing the applied field strength results in abrupt realignment of some domains, and is accompanied by a release of energy which may be detected using a sensing coil or piezoelectric sensor. The magnetic signal from a sensing coil is known as magnetic Barkhausen noise (MBN) while the acoustic signal from a piezoelectric sensor is known as magnetic acoustic emission (MAE). MBN signals are detected only from near-surface regions, and are sensitive to $180^{\circ}$ domain wall motion which is the largest change in magnetic moment. MAE, on the other hand, originates from the bulk material and is sensitive to $90^{\circ}$ domain wall motion which has magnetostrictive strain (Park et al. 1999d; Ranjan et al. 1987a).The number of Barkhausen counts is given by (Ranjan et al. 1987b)

$$
N_{M B}=c^{\prime} \int \rho_{180}(H) \bar{V}_{180}(H) \overline{\overline{\bar{\Delta}} B} d H
$$

where $c^{\prime}$ is a constant which depends on the time constant of the pickup coil, permeability, and conductivity of the sample; $\rho_{180}(H)$ is the density of $180^{\circ}$ domain walls at field $H ; \bar{V}_{180}(H)$ is the average critical velocity of a $180^{\circ}$ domain wall when it is released from pinning sites; and $\overline{\overline{\bar{\Delta} B}}$ is the average change in the local magnetic induction due to unit displacement per unit area of domain walls. Note that two Barkhausen bursts are present - one for the positive magnetization and the other for negative magnetization. Numerous models have been developed to predict Barkhausen response to microstructural defects in steels such as grain boundaries and second phase precipitates (Pérez-Benitez et al. 2005; Kameda and Ranjan 1987; Moorthy et al. 1997).

The magnetic Barkhausen method is predominantly a near-surface measurement, with the skin depth, $\delta$, decreasing with increasing frequency defined as $\delta=1 / \sqrt{\pi f \mu \sigma}$, where $f$ is the Barkhausen jump frequency, $\mu$ is the magnetic permeability of the material, and $\sigma$ is the electrical conductivity. For low magnetization frequencies $(<10 \mathrm{~Hz})$, magnetization is nearly uniform throughout the sample volume. Barkhausen jumps arising from distances greater than the skin depth will be severely attenuated because the pickup coil is positioned on the sample surface. For non-ferritic steel (such as 316L), the skin depth at $1 \mathrm{kHz}$ is about $13.1 \mathrm{~mm}$.

The Barkhausen method has found wide application including as a nondestructive tool for characterizing microstructural changes, tensile properties and fracture toughness in a variety of steels (Ranjan et al. 1987b; Kameda and Ranjan 1987; Moorthy et al. 1997; Wilson et al. 2009; Gurkunov 2000; Dobmann et al. 2001; Raj et al. 2003).

MBN can be used for studying the effects of heat treatments and defects. In some instances, MBN increases due to an increased number of domain walls moving at a given time and/or increased mean free path of movement due to reduction in dislocation density (Kim et al. 1999). The shape and volume fraction of carbide precipitates, for instance, may result in increase or decrease of MBN depending on the thermal treatment, since large carbides create spike domains and decrease $\mathrm{MBN}$, yet larger precipitates, even if they are fewer in number, have increased MBN compared to systems with smaller and fewer pinning sites (Kim et al. 1999). Thus MBN measurements tied to microstructural evidence can provide detailed NDE 
information about precipitates in irradiated and heat treated steels. In some cases, multiple peaks in the MBN spectrum indicate domain wall pinning sites of different character, such as grain boundaries and precipitates (Moorthy et al. 1997). It has been demonstrated that the main microstructural influences on MBN is due to nucleation and annihilation of $90^{\circ}$ domain walls at grain boundaries and jumps of $180^{\circ}$ domain walls pinned by precipitate particles (Pérez-Benitez et al. 2005). Additionally, position and peak of the MBN signal has been correlated to martensite volume fraction in ferrite-martensite steels (Kleber et al. 2004). Peaks due to ferrite versus martensite can also be distinguished in some cases (Vincent et al. 2005).

\subsubsection{Other magnetic methods}

It is desirable to be able to distinguish different pinning methods of domain walls, in order to assess radiation-induced damage mechanisms non-destructively. Barkhausen techniques have been shown to offer this distinction, provided that the average critical fields for irreversible domain wall motion for different defects are sufficiently separated (Moorthy et al. 1997). Other micromagnetic methods sensitive to domain wall pinning over a wider range of applied magnetic fields are needed to further refine understanding of the reversible and irreversible processes affecting bulk measurements like Barkhausen noise emission. First-order reversal curve (FORC) measurements appear to be a suitable for generating additional information that can be used to probe the details of these domain wall pinning effects.

While it has been frequently shown that mechanical changes in steels, such as those resulting from neutron irradiation, have effects on the major loops of magnetization (e.g., (Park et al. 2003; Park et al. 2004a; Park et al. 1997a)), Barkhausen noise (e.g., (Chang et al. 2002; Altpeter et al. 2001; Park et al. 1999d; Park et al. 1999b; Sipahi et al. 1994)), impedance spectroscopy (Park et al. 2004b; Park et al. 2004a), and ferromagnetic resonance (Park et al. 2004b; Park et al. 2003), only one group has looked at the effects of mechanical changes and precipitation on minor hysteresis loops where the magnetic history is not merely between positive and negative saturations (Takahashi et al. 2006; Kobayashi et al. 2009, 2008; Takahashi et al. 2005). First order reversal curves (FORCs) are similar to minor loops but consist of only part of the loop. Each FORC is obtained by 1) saturating at a positive field, 2) ramping down to a reversal field $H_{\mathrm{r}}$, and 3) measuring magnetization $M$ at increasing fields $H$ starting from $H_{\mathrm{r}}$ and increasing (see Figure 11).

By choosing a series of reversal points $\left(H_{\mathrm{r}}\right)$ with appropriate spacings, a major loop hysteresis curve can be "filled in" by a series of FORC curves which can then be transformed using the FORC function (below) to represent a density function which depends on magnetic switching behavior. As described below, it is typically plotted as a function of microcoercivity $\left(H_{\mathrm{c}}\right)$ and bias field $\left(H_{\mathrm{b}}\right)$. As explained recently, the FORC function can describe the distribution of pinning strengths for magnetic domain wall motion and hence be a sensitive measure of defect population (McCloy et al. 2012). 


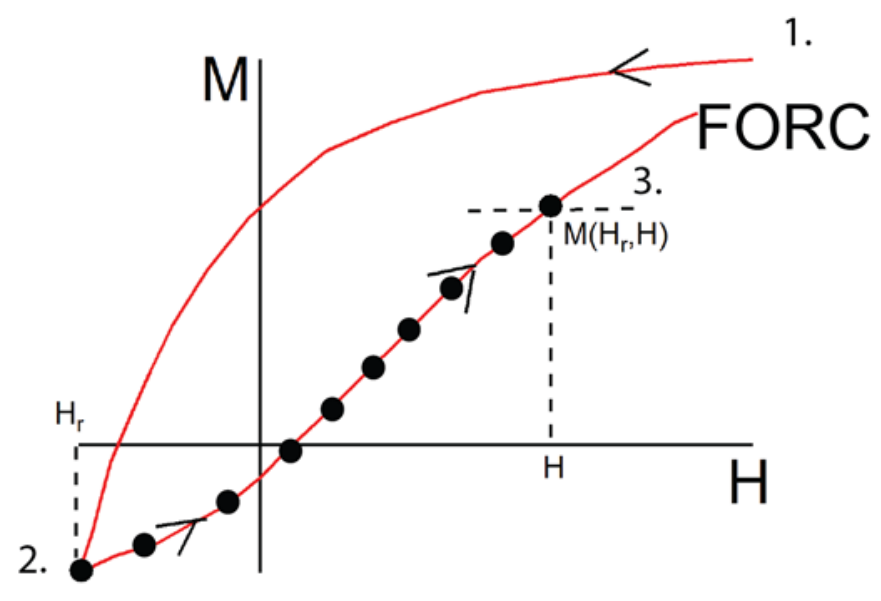

Figure 11. Schematic of First Order Revers Curve (FORC) measurements

The FORC function can be described for FORCs taken increasing after saturation at positive field as (Newell 2005)

$$
\rho\left(H_{r}, H\right)=-\frac{1}{2} \frac{\partial^{2} M\left(H_{r}, H\right)}{\partial H_{r} \partial H},
$$

where this function, which can take on positive or negative values, is well-defined for $H>H_{\mathrm{r}}$. In processing the raw data, a smoothing factor is used to create a polynomial surface of the magnetization as a function of the two field parameters $\left(H, H_{\mathrm{r}}\right)$ (Pike et al. 1999).

As a first approximation, the FORC distribution can be thought of as a Preisach diagram which deconvolves the hysteresis loop into a series of "hysterons" or square loops each with a "local coercivity" $\left(H_{\mathrm{c}}\right)$ (also called a pinning field (Durin et al. 2000)) and a "local bias field" or interaction field $\left(H_{\mathrm{b}}\right)$ (Roberts et al. 2000). In practice, many features observed in FORC diagrams do not fit the Preisach model, but it is still useful to conceive of the FORC diagram this way (Stancu et al. 2003a; Newell 2005). In a FORC diagram, $H_{\mathrm{c}}$ is plotted on the $x$-axis from zero to $H_{\mathrm{c}, \max }$, and $H_{\mathrm{b}}$ is plotted with both positive and negative values. $H_{\mathrm{c}}$ and $H_{\mathrm{b}}$ are obtained by coordinate transform of the $H$ and $H_{r}$ data as:

$$
H_{c}=\frac{H-H_{r}}{2} \text { and } H_{b}=\frac{H+H_{r}}{2} \text {. }
$$

Any hysteretic phenomenon can be described using a FORC diagram. FORC has been much used for studying the magnetization behavior of geological samples (Chen et al. 2007; Acton et al. 2007), nano-magnets (Pike et al. 2005; Davies et al. 2004; Kou et al. 2011), and spin transitions (Katzgraber et al. 2002; Davies et al. 2005; Katzgraber et al. 2004), but has also been used to examine magnetoresistance (Pomeroy et al. 2009), ferroelectric switching (Stancu et al. 2003b; Fujii et al. 2010), and metal-insulator transitions (Ramírez et al. 2009) by considering a different set of input (e.g., electric field, current) and response (e.g., capacitance, voltage). 
It has been shown that FORC diagrams can be modeled as collections of components (Stancu et al. 2003a; Pike et al. 2005; Carvallo et al. 2003), suggesting that the individual contributions of multiple phases could be distinguished. Distinguishing between single domain and multi-domain behavior is straightforward using FORC diagrams (Pike et al. 2001). A Day plot (Roberts et al. 2006; Day et al. 1977) is frequency used in geology to display this data, where $M_{\mathrm{rs}} / M_{\mathrm{r}}$ is plotted versus $H_{\mathrm{cr}} / H_{\mathrm{cv}}$ where $M_{\mathrm{rs}}$ is the remnant magnetization after saturation, $M_{\mathrm{r}}$ is the saturation magnetization, $H_{\mathrm{cr}}$ is the coercivity of remanence, and $H_{\mathrm{cv}}$ is the major loop coercivity (distinguished here from $H_{\mathrm{c}}$ the local coercivity) (McCloy et al. 2012).

\subsubsection{Irradiated steels - Barkhausen and other magnetic properties}

It is the purpose of this section to review some of the published results on Barkhausen and other magnetic measurements of neutron-irradiated steels.

As far back as 1953 the use of Barkhausen noise and coercive force measurements were used to interrogate steels and other alloys in terms of microstructural state, particularly with regard to composition and strengthening precipitates (Anon 1953; Geisler 1953; Gordon 1953). Early work on the effects of irradiation and radiation damage on magnetics and micromagnetics of materials demonstrated that the majority of materials were sensitive in some degree to the changes in microstructure due to irradiation (Anon 1959), in one case demonstrating a linear response to neutron dose (Alley 1959). More recently, concerns regarding embrittlement of RPV steels encouraged research into NDE methods for mechanical property changes due to neutron irradiation and magnetic measurements were explored with some success. One of the first investigations used MAE and MBN to investigate radiation-induced changes in A302B plate and A533B weld steels (Kwon et al. 1988). The analysis concluded that MAE waveform analysis was a promising NDE technique for monitoring the microscopic changes in the steel components subjected to neutron irradiation. Other magnetic measurements, including remanence, coercivity, and permeability were also used to study radiation damage in these same steels. Magnetic remanence and maximum permeability were found to be highly sensitive to neutron dose (Stubbins et al. 1993). It was hypothesized that atomic disorder due to neutron irradiation caused large-scale magnetic domains to breakdown, while the resulting smaller domains more easily rotated to form closed flux loops, thus, decreasing remanence. The magnetic signals were more sensitive to these microstructural changes than mechanical properties, such as microhardness, in this study (Shong et al. 1993).

Others realized that micromagnetics could be used for NDE of both nuclear pressure vessel steels (Hsu and Chang 1996; Blaszkiewicz 1996; Ara et al. 1996; Dobmann 1994; Kee-Ok et al. 1999; Park et al. 1999a; Park et al. 1999c; Sukegawa et al. 2000; Park et al. 2000; Kikuchi et al. 2006; Park et al. 1999d; Park et al. 1999b) and power plant steels (Ginsztler et al. 1994). Consequently, these steels were soon being routinely investigated using these methods and correlations were developed for hardening and aging. The use of Barkhausen signals for 
monitoring stress relief of welds was also pioneered during this time (Rodriguez and Raj 1997), as was thermal recovery monitoring of RPV steels. At the same time, some innovations in these magnetic methods were also being explored, such as the Pulse MAE method (Maeda et al. 1999), which demonstrated signatures increasing monotonically with neutron dose. In another study, a SQUID sensor was used to demonstrate that magnetic coercivity could be used as a signature for radiation hardening with good sensitivity (Otaka et al. 1999). Giant magneto-impedance measurements were also shown to revels similar signatures (Kim et al. 2002). More general uses for micromagnetics measurements were also emerging, such as monitoring tensile and fatigue strain as a measure of degradation (Sukegawa and Uesaka 2001). Strong correlations are realized between neutron irradiation mechanical property changes and micromagnetic signatures when multiple methods are combined using statistical techniques (Dobmann et al. 2006b; Dobmann et al. 2006a). These methods are also extended to fatigue and tensile damage correlations (Dobmann et al. 2006b; Dobmann et al. 2006a). More recently, these methods have almost become routine for RPV materials in terms of monitoring hardening and recovery (Takaya et al. 2010; Baek et al. 2009; Park et al. 2008; Kikuchi et al. 2007). However, such micromagnetic methods cannot address all such embrittlement problems, such as phosphorus segregation when no hardening is involved (Debarberis et al. 2007).

The trends with regards to hardening and neutron irradiation effects are clear, however, and magnetic methods that are sensitive to domain wall pinning are suitable for NDE of magnetic materials. Regardless of the alloy, magnetic Barkhausen noise is almost always decreased with irradiation (Sipahi et al. 1994; Park et al. 1997b) due to domain wall pinning, and typically coercivity and permeability are increased, though not always (Park et al. 1997a; Park et al. 1999b). Irradiation processes that produce point defects and small defect clusters can be effectively probed as a function of dose for small doses using these methods and linear responses are found initially. Embrittlement thresholds can be determined using statistical regression methods and calibrated samples. However, these methods cannot distinguish between hardening events and researchers often suggest that additional work is required to sort out complex effects.

\subsection{Magnetic sensor materials and in-situ measurements}

Compared with piezoelectric materials, very little is known about the effects of radiation, particularly neutron irradiation, on the properties of magnetic sensor materials. Neutron damage studies of magnetic sensor materials are few and far between (see Appendix for an incomplete summary), and results indicate a wide range of behaviors, including amorphization (Chukalkin et al. 1983), cation site mixing (Chukalkin et al. 1975), superparamagnetism (Parkhomenko et al. 1976), anisotropy change (Chukalkin et al. 1981), loss of remnance (Anderson et al. 2005), or complete loss of magnetization due to radiation-induced thermal spikes (Liu et al. 2007). In addition to their use in magnetostrictive transducers, magnetic materials are integral to the operation of linear variable differential transformers (LVDTs), which will also find future use as in-pile diagnostic instruments (Rempe et al. 2011). 
Some magnetic sensor types have been shown to be relatively rad-hard, including Hall (Bolshakova 1999; Bolshakova et al. 2009), SQUID (Nagaishi et al. 2003), magnetoresistive (anisotropic magnetoresistance, AMR (Díaz-Michelena 2009; Sanz et al. 2012); giant magnetoresistance, GMR (Carroll 2010); and magnetic tunnel effect magnetoresistance, TMR (Persson et al. 2011) type), coils (Nemoto et al. 2011), and fluxgate (Nielsen et al. 1997) sensors. These effects are, of course, temperature, dose, dose rate, flux, and radiation-type dependent.

Based on existing research on the characteristics of radiation-tolerant ceramics (Sickafus et al. 2007; Sickafus et al. 2000), it may be possible to find magnetic oxides or other magnetic ceramic materials which possess the tolerance for lattice disorder necessary for radiationtolerance, in addition to good high temperature properties and good magnetostriction. Since one limitation of current magnetostrictive materials (see 3.5.1) is high electrical conductivity and hence large eddy currents, low conductivity oxide materials are candidates for this application.

A list of magnetostrictive materials is shown in Table IV. The materials currently considering as "conventional" magnetostrictive materials include $\mathrm{Ni}, \mathrm{Co}, \mathrm{CoFe}_{2} \mathrm{O}_{4}$, $\mathrm{Fe}_{81} \mathrm{Si}_{3.5} \mathrm{~B}_{13.5} \mathrm{C}_{2}$ (Metglas), and $\mathrm{Tb}_{0.3} \mathrm{Dy}_{0.7} \mathrm{Fe}_{1.92}$ (Terfenol-D). Terfenol-D is a giant magnetostrictive material used in sonar. A related Fe-Ga alloy, known as Galfenol, having somewhat smaller magnetostriction but much higher Curie temperature, is under current development. Next-generation, rad-hard magnetostrictive materials will likely come from the class of materials that is very tolerant of disorder, or is already disordered itself. For example, bulk metallic glasses (BMG) such as FeDyBSiNb (Li 2011) as well as commercial "Metglas" FeSi-B based amorphous metals have been shown to have reasonable magnetostriction coefficients. Usually these materials are used for mechanical applications or as soft magnets, and optimization for magnetostriction and radiation damage is possible.

Some work has been conducted on radiation damage of Metglas alloys. Reduction of permeability with neutron irradiation is much slower than with conventional crystalline magnetic materials such as Permalloy (Brown et al. 1984). Decrease in permeability for Metglas appears to be a result of a short-range ordering due to defect accumulation at low fluences and pinning of domain walls at higher fluences (Brown et al. 1984). Neutron irradiation decreases permeability at low frequencies due to impeding of domain wall motion, but increases permeability at higher frequencies due to increased importance of rotational magnetization (Kim et al. 2000). Metglas alloys crystallized to a nanograin structure are known as FINEMET (Škorvánek and Gerling 1994). These have an order of magnitude lower magnetostriction than Metglas. It has been shown that neutron irradiation results in residual stress centers which react with domain walls through magnetostriction. Thus FINEMET alloys have lower sensitivity to radiation damage than do the chemically similar Metglas alloys due to magnetostriction, even when neutron irradiation partially amorphizes the FINEMET alloys (Škorvánek and Gerling 1994). In a similar study using pulsed laser irradiation, it was shown that laser-induced crystallization of amorphous alloys was strongest in materials with larger magnetostriction constants (Sorescu 1998). Ion irradiation studies have shown the importance of in-plane versus out-of-plane anisotropy in 
determined the magnetic properties of amorphous magnetic alloy films (McCord et al. 2005; Kopcewicz and Dunlop 2001). On the other hand, neutron irradiation can restore ductility in thermally-embrittled amorphous Metglas, while nanocrystalline FINEMET do not undergo such radiation-induced annealing (Šk korvánek and Gerling 1994). Thus it is not immediately clear whether amorphous magnetostrictive alloys necessarily be advantageous for radiation hardened sensors, as there appear to be some disadvantages associated with high magnetostriction. Recent work studying electron-induced crystallization has shown that stability against crystallization can be assessed from standard thermal tests (Nagase et al. 2012). Driving force for defect-induced crystallization in amorphous metallic alloys is based on free energy considerations, local atomic structure due to radiation-induced defects, and radiation enhanced diffusion (Nagase et al. 2012). There appears to be more room for material tailoring in these systems, and thus more work is warranted in this area.

Crystalline metallic systems known as "high entropy alloys," (Zhang et al. 2008) have been recently identified as candidates for radiation-tolerant components due to their potential for "self-healing" through recrystallization via a glassy state. The magnetostriction properties of these alloys (e.g., $\mathrm{Al}_{\mathrm{x}} \mathrm{CoCrFeNi}$ ) are virtually unexplored, and at least some compositions are suggested to have Curie temperatures as high as $\sim 600{ }^{\circ} \mathrm{C}$ (Chou et al. 2009). Additionally, some room-temperature ferromagnetic oxides in the double perovskite family have been shown to be very tolerant to disorder in their cation sites (Serrate et al. 2007), and may be additional candidates for rad-hard magnetic materials if materials with high enough $T_{\mathrm{c}}$ can be found. The saturation magnetostriction and Curie temperatures from the literature for some of these materials are listed in Table IV. Galfenol, high entropy alloys, and double perovskites are not commercially available materials.

Table IV: Magnetostrictive materials

\begin{tabular}{|c|c|c|c|c|c|}
\hline Material & Alternative name & $\begin{array}{c}\text { Magnetostriction } \\
\text { (ppm) }\end{array}$ & $\mathbf{T}_{\mathrm{c}}\left({ }^{\circ} \mathrm{C}\right)$ & 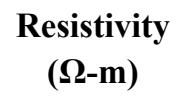 & Ref. \\
\hline $\mathrm{Fe}_{81} \mathrm{Si}_{3.5} \mathrm{~B}_{13.5} \mathrm{C}_{2}$ & Metglas 2605SC & +20 & 350 & $5.0 \mathrm{E}-3$ & 6 \\
\hline $\mathrm{Ni}$ & & -33 & 358 & $7.1 \mathrm{E}-8$ & 1 \\
\hline Co & & -62 & 1130 & $5.6 \mathrm{E}-8$ & 1 \\
\hline $49 \mathrm{Co}-49 \mathrm{Fe}-2 \mathrm{~V}$ & Rem/perm-endur & +70 & 932 & $4.2 \mathrm{E}-7$ & $1,7,12$ \\
\hline $\mathrm{CoFe}_{2} \mathrm{O}_{4}$ & & -110 & 520 & $1.0 \mathrm{E}+2$ & 1,10 \\
\hline $\mathrm{Tb}_{0.3} \mathrm{Dy}_{0.7} \mathrm{Fe}_{1.92}$ & Terfenol-D & +1640 to +2000 & 380 & $6.0 \mathrm{E}-7$ & $2,4,11$ \\
\hline $\mathrm{Fe}_{81.6} \mathrm{Ga}_{18.4}$ & Galfenol & +400 & 670 & $8.0 \mathrm{E}-3$ & 3,9 \\
\hline $\mathrm{Al}_{2} \mathrm{CoCrFeNi}$ & High entropy alloy & Unknown & 596 & $1.0 \mathrm{E}-2$ & 5 \\
\hline $\mathrm{Ca}_{2} \mathrm{FeReO}_{6}$ & Double perovskite & $\sim 200$ & 250 & $2.0 \mathrm{E}+0$ & 8 \\
\hline 1. $\quad$ (Lide 2006) & & 9. (Clark et al. 2002) & & & \\
\hline 2. (Zhang and Chen 2 & & 10. (Özgür et al. 2009) & & & \\
\hline (Staley and Flatau & & 11. http://www.etrema-u & a.com/core & nold/ & \\
\hline 4. (Moffett et al. 199 & & 12. http://www.hightem & netals.com/tec & lata/hitempPermen & Irdata.php \\
\hline 5. (Chou et al. 2009) & & & & & \\
\hline http://www.metgla & & & & & \\
\hline 7. (Pinnel and Bennet & 973) & & & & \\
\hline 8. (Serrate et al. 2005 & & & & & \\
\hline
\end{tabular}




\subsection{Characterization of magnetic microstructure and nanostructure}

Characterization of magnetic materials can generally be broken up into seven categories. It is beyond the scope of this report to review these techniques in detail, but the reader is referred to a recent review (Lau and Shaw 2011). Characteristics of some of the following potential methods are summarized in Table $\mathrm{V}$.

1) X-ray methods include $\mathrm{X}$-ray transmission microscopy plus $\mathrm{X}$-ray transmission microscopy + $\mathrm{x}$-ray circular dichroism (XMCD); and photoelectron emission microscopy (PEEM) + $\mathrm{XMCD}$ which can provide time-resolved imaging

2) Neutron methods such as neutron tomography, which provides 3-D imaging

3) Electron microscopy + polarization analysis includes scanning electron microscopy polarization analysis (SEMPA); spin-polarized scanning tunneling microscopy (SP-STM); ballistic electron magnetic microscopy (BEMM), which uses a variation of STM for thin films on semiconductor substrates; and Lorentz mode transmission electron microscopy (TEM)

4) Orthogonal fluxgate method (wires)

5) Magnetic particles/ Bitter patterns

6) Magnetic force microscopy (MFM), scanning Hall probe microscopy (SHPM), superconducting quantum interference device (SQUID) microscopy, and similar techniques

7) Magneto-optical techniques, including magneto-optical Kerr effect (MOKE) microscopy; Faraday effect (magnetic circular birefringence) on transparent materials; and magneto-optic versions of conventional optical microscopy, including confocal optical microscopy or scanning near-field optical microscopy (SNOM).

In comparing these methods, it is important to consider the components of magnetization of the sample under test for which the particular technique is sensitive. For example, some methods are sensitive to the magnetization of the whole sample (Lorentz TEM, Faraday effect). Other methods are only sensitive to surface magnetization (MOKE microscopy, SEMPA). Still others, particularly scanning methods, are sensitive to stray fields at the surface (MFM, Scanning SQUID, SHPM). Domain walls at surfaces tend to exert fields of $\sim 10 \mathrm{mT}$ and have a spatial extent of $20-50 \mathrm{~nm}$. Finally, some techniques are sensitive to individual atomic moments, such as synchrotron techniques of XMCD, which can assess site occupancy the ferromagnetic atoms $\mathrm{Fe}, \mathrm{Co}$, and $\mathrm{Ni}$.

Given the inherent spatial resolution and instrumental constraints, a subset of these methods was down-selected for further consideration, as shown in Table VI. Applicable materials that can be analyzed, details on the physical property measured, and bulk measurement equivalencies are listed. These bulk measurements are listed as a means of considering the correlation with bulk NDE methods. Table VII further assesses these techniques, examining pros and cons of each technique, applicable temperature ranges, and equipment manufacturers, if applicable. 
The bottom line of this exercise was that the magnetic imaging techniques of most interest for near-term work on steels are magnetic force microscopy (MFM), magneto-optical Kerr effect (MOKE), and possibly scanning Hall probe microscopy (SHPM). Of the three, MFM gives the best spatial resolution, $\sim 25 \mathrm{~nm}$, sufficient for imaging domain walls. The disadvantage is that only a small area can be scanned at any one time. MOKE, on the other hand, has much lower resolution, $\sim 300-500 \mathrm{~nm}$, as it depends on visible light; however, MOKE can image large areas simultaneously and can thus illustrate grain texturing and magnetic domain structure. SHPM has similar resolution to MOKE, $\sim 300 \mathrm{~nm}$, but in theory is more reliable than MFM for true magnetization measurements since it measures stray fields directly, not through interaction of a tip with the sample fields as does MFM.

\subsubsection{Magnetic imaging as input to microstructure simulations}

An additional advantage of the down-selected techniques is that point-by-point local hysteresis loops can be generated, showing differences in local magnetization behavior. This has the benefit of allowing direct comparison with meso-scale phase field computer models, which compute "voxel-by-voxel" magnetization. Magnetometry (or susceptometry) is obtainable from both MFM (Babcock et al. 1996; Zhu et al. 2003; Sorop et al. 2003) and MOKE microscopy (Choe et al. 2002; Sato and Ishibashi 2008) data. MOKE microscopy/magnetometry is routinely used for combinatorial screening of magnetic compounds (Zhao et al. 2004).

MFM and MOKE have also been used to elicit detailed information about the mechanisms of domain wall dynamics. Comparison of subsequent MFM images obtained as a function of magnetic field has been used to show the difference between Barkhausen jump volumes grown by domain wall motion or nucleated in isolated regions (Schwarz et al. 2004). A similar experiment using a MOKE microscope known as a magneto-optical microscope magnetometer (MOMM) has been used to plot probabilities of Barkhausen jump sizes as a function of $\mathrm{NiO}$ thickness on $\mathrm{Fe}$, showing that mechanisms of domain wall creep can be distinguished from domain wall pinning and depinning (Barkhausen) (Lee et al. 2011). Finally, MOKE magnetometry has been used to study the effects of AC magnetic fields on domain walls, allowing the differentiation between domain boundary creep, slide, and switching as a function of AC field excitation frequency, and allowing the accurate measurement of depinning fields and domain wall mobility (Kataja and van Dijken 2011). In summary, magnetic imaging methods such as MFM and MOKE provide a critical experimental tool to obtain numerical parameters (such as depinning fields, domain wall mobilities, etc.) for domain wall dynamics, as affected by defects, which can be put into microstructural models of magnetic materials to study the evolution of magnetic signatures as a function of changes of defect concentration and magnetic field. 
Table V. Summary of some magnetic imaging techniques

\begin{tabular}{|c|c|c|c|c|}
\hline Category & Technique & $\begin{array}{l}\text { Spatial } \\
\text { resolution }\end{array}$ & Time resolution & Notes \\
\hline Electron & Lorentz TEM & $100 \mathrm{~nm} / 1 \mathrm{~nm}$ & $\begin{array}{l}\text { ms to s, except } \\
\text { pump-probe }\end{array}$ & $\begin{array}{l}\text { Fresnel mode, For (u)ncorrected/ (c)orrected } \\
\text { aberrations }\end{array}$ \\
\hline Electron & Differential phase contrast & $20 \mathrm{~nm}$ & & STEM mode, uncorrected aberrations \\
\hline Electron & Electron holography & $0.5 \mathrm{~nm} / 0.1 \mathrm{~nm}$ & & For (u)ncorrected/ (c)orrected aberrations \\
\hline Electron & $\begin{array}{l}\text { SEM with polarized analysis } \\
\text { (SEMPA) }\end{array}$ & $20 \mathrm{~nm}$ & & \\
\hline Electron & $\begin{array}{l}\text { Spin-polarized low-energy } \\
\text { electron microscopy (SP- } \\
\text { LEEM) }\end{array}$ & $10 \mathrm{~nm}$ & & Good for in-situ spin reorientation (like LEED) \\
\hline Electron/ X-ray & $\begin{array}{l}\text { Photo-emission electron } \\
\text { microscopy (PEEM) }\end{array}$ & $50 \mathrm{~nm}$ & 100 ps & Circularly polarized x-ray incident on sample \\
\hline X-ray & $\begin{array}{l}\text { X-ray magnetic circular } \\
\text { dichroism (XMCD) }\end{array}$ & & $\begin{array}{l}>70 \text { ps for } \\
\text { synchrotron; poss. } \\
\text { better for other }\end{array}$ & $\begin{array}{l}\text { Generate with synchrotron, free-electron laser, or } \\
\text { high-harmonic generation laser; resolution in } \\
\text { principle much better than M-O due to smaller } \\
\text { wavelength of EUV/ soft x-ray }\end{array}$ \\
\hline $\begin{array}{l}\text { Magneto- } \\
\text { optical }\end{array}$ & $\begin{array}{l}\text { Magneto-optical Kerr effect } \\
\text { (MOKE) }\end{array}$ & $300-500 \mathrm{~nm}$ & & $\begin{array}{l}\text { Visible laser, spot size few } \mu \mathrm{m} \text { very easy; smaller } \\
\text { spots diffraction limited }\end{array}$ \\
\hline $\begin{array}{l}\text { Magneto- } \\
\text { optical }\end{array}$ & $\begin{array}{l}\text { Time-resolved MOKE (TR- } \\
\text { MOKE) }\end{array}$ & $\sim 50 \mathrm{~nm}$ & $<1$ ps & $\begin{array}{l}\text { pump-probe; Fourier transform time-resolved data to } \\
\text { get frequency-resolved }\end{array}$ \\
\hline Scanning probe & $\begin{array}{l}\text { Magnetic force microscopy } \\
(\text { MFM) }\end{array}$ & $25 \mathrm{~nm}$ & & $\begin{array}{l}\text { Mostly limited to perpendicular field with normal tip; } \\
\text { use in vacuum improves SNR 2-3 orders magnitude }\end{array}$ \\
\hline Scanning probe & $\begin{array}{l}\text { Ballistic electron magnetic } \\
\text { microscopy (BEMM) }\end{array}$ & & & Variety of STM \\
\hline \multirow[t]{2}{*}{ Scanning probe } & $\begin{array}{l}\text { Ferromagnetic resonance force } \\
\text { microscopy (FMRFM) }\end{array}$ & $\sim \mathrm{nm}$ & & $\begin{array}{l}\text { Resolution determined by FMR linewidth and field } \\
\text { gradient, not tip radius }\end{array}$ \\
\hline & $\begin{array}{l}\text { Micro-Brillouin light scattering } \\
\text { (BLS) + AFM near field } \\
\text { imaging }\end{array}$ & $\sim 85 \mathrm{~nm}$ & & \\
\hline
\end{tabular}




\section{Table VI. Down-select list of magnetic imaging methods relevant for NDE}

\begin{tabular}{|c|c|c|c|c|}
\hline Technique & $\begin{array}{c}\text { Spatial } \\
\text { resolution }\end{array}$ & Applicable materials & Physical parameter measured & Bulk property analogue \\
\hline $\begin{array}{l}\text { X-ray magnetic } \\
\text { circular dichroism } \\
\text { (XMCD) microscopy }\end{array}$ & $\sim 10 \mathrm{~nm}$ & $\begin{array}{l}\text { Those containing } \mathrm{Fe}, \mathrm{Co} \text {, } \\
\text { or } \mathrm{Ni}\end{array}$ & $\begin{array}{l}\text { Difference spectrum of x-ray absorption } \\
\text { taken in magnetic field with right-hand } \\
\text { and left-hand circularly polarized light } \\
(\mathrm{x}-\mathrm{ray}, 700-900 \mathrm{eV}) \text {; can look at } \\
\text { ferromagnetic atoms } \mathrm{Fe}, \mathrm{Co}, \mathrm{Ni} \text {; tune } \mathrm{x}- \\
\text { ray energy for atoms of interest }\end{array}$ & $\begin{array}{l}\text { Magnetic hysteresis loops, saturation, } \\
\text { coercivity, permeability/susceptibility; } \\
\text { can get element specific hysteresis data }\end{array}$ \\
\hline $\begin{array}{l}\text { Magneto-optical Kerr } \\
\text { effect (MOKE) }\end{array}$ & $300-500 \mathrm{~nm}$ & $\begin{array}{l}\text { ferro-, ferri-, and anti- } \\
\text { ferromagnetic materials }\end{array}$ & $\begin{array}{l}\text { Reflection of polarized light (UV, VIS, } \\
\text { or IR) by material sample subjected to } \\
\text { magnetic field (rotation, ellipticity, and } \\
\text { intensity change) }\end{array}$ & $\begin{array}{l}\text { Magnetic hysteresis loops, saturation, } \\
\text { coercivity, permeability/susceptibility }\end{array}$ \\
\hline $\begin{array}{l}\text { Magnetic force } \\
\text { microscopy (MFM) }\end{array}$ & $25 \mathrm{~nm}$ & $\begin{array}{l}\text { Ferritic steel, martensitic } \\
\text { steel, deformed austenitic } \\
\text { steel }(304,316) \text {, other } \\
\text { ferro-, ferri-, and anti- } \\
\text { ferromagnetic materials, } \\
\text { superconductors }\end{array}$ & $\begin{array}{l}\text { Magnetic force gradient by shift in phase } \\
\text { or resonant frequency of oscillating } \\
\text { cantilever probe; measures interaction } \\
\text { between sample and tip }\end{array}$ & $\begin{array}{l}\text { Magnetic hysteresis loops, saturation, } \\
\text { coercivity, permeability/susceptibility }\end{array}$ \\
\hline $\begin{array}{l}\text { Scanning Hall Probe } \\
\text { Microscopy (SHPM) }\end{array}$ & $300 \mathrm{~nm}$ & $\begin{array}{l}\text { ferro-, ferri-, and anti- } \\
\text { ferromagnetic materials, } \\
\text { superconductors }\end{array}$ & $\begin{array}{l}\text { Hall voltage in semiconductor sensor } \\
\text { induced by local magnetic field }\end{array}$ & $\begin{array}{l}\text { Magnetic hysteresis loops, saturation, } \\
\text { coercivity, permeability/susceptibility; } \\
\text { Provides true quantitative assessment of } \\
\text { local magnetic field of sample }\end{array}$ \\
\hline $\begin{array}{l}\text { Scanning SQUID } \\
\text { microscope (SSM) }\end{array}$ & $\sim 2.5 \mu \mathrm{m}$ & $\begin{array}{l}\text { ferro-, ferri-, and anti- } \\
\text { ferromagnetic materials, } \\
\text { superconductors }\end{array}$ & $\begin{array}{l}\text { Sample stray magnetic field effect on the } \\
\text { Josephson junction superconductor } \\
\text { circuit }\end{array}$ & $\begin{array}{l}\text { Magnetic hysteresis loops, saturation, } \\
\text { coercivity, permeability/susceptibility; } \\
\text { Provides true quantitative assessment of } \\
\text { local magnetic field of sample }\end{array}$ \\
\hline
\end{tabular}




\section{Table VII. Down-select trade study for magnetic imaging methods}

\begin{tabular}{|c|c|c|c|c|c|}
\hline Technique & Pros & Cons & $\begin{array}{l}\text { Temperature } \\
\text { ranges } \\
\end{array}$ & Notes & Manufacturers \\
\hline $\begin{array}{l}\text { X-ray magnetic circular } \\
\text { dichroism (XMCD) } \\
\text { microscopy }\end{array}$ & $\begin{array}{l}\text { Can obtain individual atomic } \\
\text { moments; Get chemical } \\
\text { environment "for free" with XAS; } \\
\text { some leverage with chemical } \\
\text { imaging initiative; some in-house } \\
\text { expertise (C. Pearce); can get } \\
\text { tomography }\end{array}$ & $\begin{array}{l}\text { Currently need synchrotron; } \\
\text { in-house capability } \\
\text { probably } 5 \text { years out }\end{array}$ & LT/RT/HT? & $\begin{array}{l}\text { May eventually } \\
\text { be feasible with } \\
\text { compact x-ray } \\
\text { light source }\end{array}$ & $\begin{array}{l}\text { N/A Everything is } \\
\text { custom }\end{array}$ \\
\hline $\begin{array}{l}\text { Magneto-optical Kerr effect } \\
\text { (MOKE) - scanning }\end{array}$ & In-house expertise in optics & $\begin{array}{l}\text { Only near surface } \\
\text { information; resolution not } \\
\text { great }\end{array}$ & $\mathrm{LT} / \mathrm{RT} / \mathrm{HT}$ & $\begin{array}{l}\text { Use low-cost } \\
\text { lasers and } \\
\text { optical table }\end{array}$ & $\begin{array}{l}\text { Durham Magneto } \\
\text { Optics (through } \\
\text { Quantum Design) }\end{array}$ \\
\hline $\begin{array}{l}\text { Magnetic force microscopy } \\
\text { (MFM) - PPMS based }\end{array}$ & $\begin{array}{l}\text { Takes advantage of existing } \\
\text { equipment for low T and high field } \\
\text { measurements; can get Hall probe } \\
\text { sensor as well for low incremental } \\
\text { cost }\end{array}$ & \multirow{2}{*}{$\begin{array}{l}\text { Only near surface } \\
\text { information; data relies on } \\
\text { interaction between tip and } \\
\text { sample; only sees domain } \\
\text { walls; applied fields } \\
\text { influence tip and sample; tip } \\
\text { magnetization may affect } \\
\text { sample }\end{array}$} & LT/RT only & $\begin{array}{l}\text { Can get various } \\
\text { sensor heads to } \\
\text { upgrade probe }\end{array}$ & $\begin{array}{l}\text { Nanomagnetics } \\
\text { (through Quantum } \\
\text { Design) } \\
\text { Attocube }\end{array}$ \\
\hline $\begin{array}{l}\text { Magnetic force microscopy } \\
\text { (MFM) - stand alone }\end{array}$ & $\begin{array}{l}\text { Easy to perform low and high T } \\
\text { measurements in modest fields }\end{array}$ & & $\mathrm{LT}$ ?/RT/HT & & \begin{tabular}{|l|} 
Nanomagnetics \\
instruments, Asylum \\
\end{tabular} \\
\hline $\begin{array}{l}\text { Scanning SQUID } \\
\text { microscope (SSM) }\end{array}$ & $\begin{array}{l}\text { Can detect very small transition } \\
\text { metal impurities in insulators; the } \\
\text { most sensitive of the instruments }\end{array}$ & $\begin{array}{l}\text { Overkill in sensitivity for } \\
\text { steels }\end{array}$ & LT/RT/HT? & $\begin{array}{l}\text { Could get } \\
\text { widespread use } \\
\text { in FCSD to } \\
\text { characterize } \\
\text { substrates }\end{array}$ & Neocera Magma C20 \\
\hline
\end{tabular}

NOTES: LT - low temperature, RT - room temperature, HT - high temperature 


\subsubsection{Existing literature on magnetic imaging of steels}

It is worthwhile to review a few relevant studies on defects in steels using magnetic imaging methods, in order to assess what is possible from an experimental point of view for studying defects in steel.

Stress-corrosion cracking susceptibility of 304 stainless steel was evaluated by MFM (Takaya et al. 2004). It was shown that transformation from austenite to martensite due to chromium depletion along grain boundaries caused the magnetic phase seen with MFM and corroborated with phase identification by electron backscatter diffraction (EBSD). Straininduced martensite forming at crack tips of 304 and $310 \mathrm{~S}$ austenitic steels has been imaged using MFM (Zhang et al. 2010). Fatigue crack tips have also been imaged in bearing steel using SHPM since the magnetic flux density is different at the crack tip (Kida et al. 2012).

A related force microscopy technique has been developed, in which it is the electrical conductivity which is measured by means of eddy currents (Nalladega 2009). So-called eddy current force microscopy (ECFM) allows the simultaneous probing of skin depth changes due to changes in conductivity and magnetic permeability.

Perhaps most relevant is the very recent work from the German group (Batista et al. 2012) showing the changes in structure and phase of austenitic twinning induced plasticity (TWIP) steels as a function of tensile stress. Additionally, these authors show the evolution of the domain structures of cementite particles in Fe- $0.8 \% \mathrm{C}$ unalloyed steel using MFM, and correlate their orientations with EBSD. These methods could be used to understand the growth habits of radiation-induced precipitates (Maziasz 1989) and their behavior under applied magnetic fields such as used in NDE methods.

\subsection{Phase field modeling of the effect of microstructures on magnetic response}

Irradiation causes microstructure evolution such as grain boundary solute segregation, precipitation, void formation, dislocation networking, and grain growth, hence, the material property degradation. To monitor the material property degradation, we need a fundamental understanding of the effect of microstructures on material responses, i.e., signal physics. In this case study, we present a phase-field model for simulating the effect of nonmagnetic particles/precipitates on magnetic domain nucleation and magnetic response. The simulations are to demonstrate the method capability in interpreting NDE measurements and understanding signal physics.

$\mathrm{FeCr}$ alloy is taken as the model system in the case study. The nonmagnetic particles/precipitates could be $\mathrm{Cr}$ rich precipitates which are formed during irradiation-induced phase separation in $\mathrm{FeCr}$ alloys. The magnetization vector $\mathbf{M}(\mathbf{r}, t)$ is used to describe the spatial and time distribution of magnetic domains. The magnetic domain evolution is simulated by solving the Landau-Lifshitz-Gilbert (LLG) equation, (Hubert and Schaefer 1998) 


$$
\left(1+\alpha^{2}\right) \frac{\partial \mathbf{M}}{\partial t}=-\gamma_{0} \mathbf{M} \times \mathbf{H}_{e f f}-\frac{\gamma_{0} \alpha}{M_{s}} \mathbf{M} \times\left(\mathbf{M} \times \mathbf{H}_{e f f}\right),
$$

where $\mathbf{M}(\mathbf{r}, t)$ is the magnetization vector, $M_{s}$ is the saturation magnetization of the magnetic phase, $\gamma_{0}$ is the gyromagnetic ratio, $\alpha$ is the dimensionless damping constant, and $\mathbf{H}_{e f f}$ is the effective magnetic field, which can be represented as a variational derivative of the total free energy of the system with respect to magnetization, $\mathbf{H}_{e f f}=-\frac{1}{\mu_{0}} \frac{\delta F}{\delta \mathbf{M}}$, where $\mu_{0}$ is the permeability of vacuum and $\mathrm{F}$ is the total energy including magnetocrystalline anisotropy energy, exchange energy, magnetostatic energy, external field energy, and elastic energy [see $\mathrm{Hu}$ et al. " $360^{\circ}$ Bloch domain wall stability and its interaction with nonmagnetic particles in Fe alloys: computer simulation of magnetic hardening" submitted to IEEE Magnetics Letters (2012)].

We simulated magnetization switching in a single crystal of iron with a simulation cell of $64 l_{0} \times 128 l_{0} \times 64 l_{0} . l_{0}$ is a real spatial length that should be smaller than the exchange length $l_{e x}=\sqrt{2 A_{c} /\left(\mu_{0} M_{s}^{2}\right)}=2.86 \mathrm{~nm}$ (Rave et al. 1998; Bertotti 2008). Periodic boundary conditions were applied in the three directions. The material constants of body-centered cubic $\alpha$-phase single crystal iron are listed in

Table VIII. The damping constant is usually a small value of $\alpha \leq 0.1$. In our simulation $\alpha$ $=0.05$. In addition, the magnetostrictive constants are relatively small so the elastic interaction energy is ignored.

Error! Reference source not found.-13 summarize the predictive magnetic hysteresis loops and magnetic domain evolution in a single crystal of iron with or without nonmagnetic particles, respectively. The nonmagnetic particle is described by an order parameter field $\eta$. $\eta=1$ represents the magnetic phase while $\eta=0$ for the nonmagnetic phase. $\eta$ varies smoothly from 1 to 0 across the interface. Therefore, $\mathbf{M}(\mathbf{r}, t)=M_{s} \mathbf{M}^{*}(\mathbf{r}, t)=M_{s} \eta(\mathbf{r}) \mathbf{m}(\mathbf{r}, t)$, where $\mathbf{m}(\mathbf{r}, \mathrm{t})$ is a unit vector, and $\eta(\mathbf{r})$ does not evolve with time. The applied external magnetic field $\mathbf{H}_{e x}=\left(\mathrm{H}_{e x 1}, 0,0\right)$ varies from $-40 \mathrm{kAm}^{-1} \sim+40 \mathrm{kAm}^{-1}$ with an increment or decrement of $\Delta \mathrm{H}_{e x 1}=0.1 \mathrm{kAm}^{-1}$ for each 26 ps. The simulation time step is $\Delta t=0.1 t_{0}=0.26$ ps where $t_{0}=\left(1+\alpha^{2}\right)\left(\gamma_{0} M_{s}\right)^{-1}=2.6 \mathrm{ps}$.

For a perfect single crystal, i.e., without any nonmagnetic particle, the hysteresis loop started from point (A) where multiple domains coexist as shown in Fig. 11(b)(A). When the applied magnetic field $H_{e x 1}$ reached its maximum, a $360^{\circ}$ domain wall was formed and remained (see Fig. 11(b)(B)). When unloading (i.e., decreasing the field), the $360^{\circ}$ domain wall thickened as shown by Fig. 11(b)(C). With the applied magnetic field $H_{e x 1}$ switched its direction, an antidirection domain of $\left(-M_{s}, 0,0\right)$ nucleated and grew by splitting the $360^{\circ}$ domain wall into two $180^{\circ}$ domain walls. From Fig. 11(b)(B) to Fig. 11(b)(H), it is seen that a process of emerging and splitting of a $360^{\circ}$ domain wall occurred repeatedly during the domain switching. Consequently, the corresponding hysteresis loop is repeatable. Both the $360^{\circ}$ domain wall and $180^{\circ}$ domain wall 
are Bloch domain walls as illustrated by Fig. 11(c). The result demonstrates that the $360^{\circ}$ domain wall can be stable with the applied magnetic field and is a nucleation site of an anti-direction domain during domain switching.

Table VIII. Material properties of iron (Fe) used in the simulations.

$\begin{array}{lllll}\text { Symbol } & \text { Name } & \text { Units } & \text { Value } & \text { Ref. } \\ \alpha & \text { damping constant } & \text { Unitless } & 0.05 & * \\ \mathrm{Ms} & \text { saturation magnetization } & \mathrm{Am}^{-1} & 1.71 \times 10^{6} & \text { (Craik 1995) } \\ \mu_{0} \mathrm{M}_{\mathrm{S}} & & \mathrm{NA}^{-1} \mathrm{~m}^{-1} & 2.16 & \text { (d'Aquino 2004) } \\ \mathrm{K}_{1} & \text { anisotropy constants } & \mathrm{J} / \mathrm{m}^{3} & 4.80 \times 10^{4} & \text { (Cullity and Graham 2009) } \\ \mathrm{K}_{2} & \text { anisotropy constants } & \mathrm{J} / \mathrm{m}^{3} & 5.0 \times 10^{3} & \text { (Cullity and Graham 2009) } \\ \mathrm{A}_{\mathrm{c}} & \text { exchange stiffness } & \mathrm{J} / \mathrm{m} & 1.5 \times 10^{-11} & \text { (Bertotti 1998) } \\ \lambda_{100} & \text { magnetostrictive coefficient } & \text { Unitless } & 2.10 \times 10^{-5} & \text { (Cullity and Graham 2009) } \\ \lambda_{111} & \text { magnetostrictive coefficient } & \text { Unitless } & 1.57 \times 10^{-5} & \text { (Cullity and Graham 2009) } \\ \left(\gamma_{0} \mathrm{Ms}\right)^{-1} & & \mathrm{ps} & 2.6 & \text { (d'Aquino 2004) } \\ \mathrm{c}_{11} & \text { elastic constant } & \mathrm{GPa} & 230 & \text { (Adams et al. 2006) } \\ \mathrm{c}_{12} & \text { elastic constant } & \mathrm{GPa} & 134 & \text { (Adams et al. 2006) } \\ \mathrm{c}_{44} & \text { elastic constant } & \mathrm{GPa} & 116 & \text { (Adams et al. 2006) }\end{array}$

*this value of $\alpha$ was used in simulations of (d'Aquino 2004). Much larger values have been used in other phase field models (Zhang and Chen 2005), but their physical basis is questionable (Chun et al. 2012). Assuming the spectroscopic splitting factor $(g)$ of Fe is 2.094 (Craik 1995), the gyromagnetic ratio $\gamma_{0}$ is $1.84 \times 10^{7} \mathrm{rad} / \mathrm{s} / \mathrm{Oe}$ or $29.316 \mathrm{GHz} / \mathrm{T}$ since $\gamma=-g^{*} e /\left(2 m_{\mathrm{e}}\right)$ in SI units, where $e$ is the charge and $m_{\mathrm{e}}$ is the mass of the electron. The damping parameter $(\alpha)$ is then calculated from the measured ferromagnetic resonance linewidth $(\Delta H)$ and the resonant frequency $f_{0}$ for Fe in (Frait and Heinrich 1964) as $\alpha=\gamma_{0} \Delta H /\left(2 \omega_{0}\right)$, where $\omega_{0}=2 \pi f_{0}=\gamma_{0} H_{0}$ and $H_{0}$ is the internal field, sometimes taken as the anisotropy field. The result of this analysis yields $\alpha=$ 0.005 , which is similar to values for magnetic garnets and other microwave materials (Chun et al. 2012). In the phase field modeling work, it was shown that $\alpha=0.05$ and $\alpha=0.005$ resulted in the same loop, but that $\alpha=0.005$ required a smaller time step. For ease of computation, $\alpha=0.05$ was used in the simulations.

The effect of nonmagnetic particles on the stability of $360^{\circ}$ domain wall and magnetic response can be seen from Figs. 12-13 where only particles with spherical shape were considered for simplicity. The particle size is counted by its volume faction with respect to the simulation cell. It is seen from Fig. 12(a) that a small nonmagnetic particle (e.g., $V_{f}=0.02336 \%$ ) does not bring any influence on the magnetic hysteresis loop comparing with the case without any particle. The domain morphologies shown in Fig. 12(b) also illustrated the same conclusion. There is almost no difference between the domain morphologies in Fig. 11(b) with $V_{f}=0$ and Fig. 12(b) with $V_{f}=0.02336 \%$. However, when the particle size increases, its impact on the magnetic hysteresis loop and domain morphologies is significant and can be seen clearly from Figs. 12 and 13. The impact is reflected in two aspects. On one hand, the presence of the nonmagnetic particle prevents the formation or reformation of the $360^{\circ}$ domain wall as shown by Fig. 12(b) (D') and (E) with $V_{f}=0.10285 \%$. On the other hand, the particle location becomes the nucleation site of any new anti-direction domain as demonstrated by Fig. 13(b) (N1) and (N2). In such cases, the larger the particle, the easier the nucleation and the smaller the coercive field. The coercive field is the applied field value at $M_{1}=0$. However, the corresponding coercive field cannot be smaller than the case with a $360^{\circ}$ domain wall as displayed by Fig. 13(c). When the particle is too small (e.g., $V_{f}=0.10285 \%$ ), it is very difficult to switch back as depicted by Fig. 12(a). 


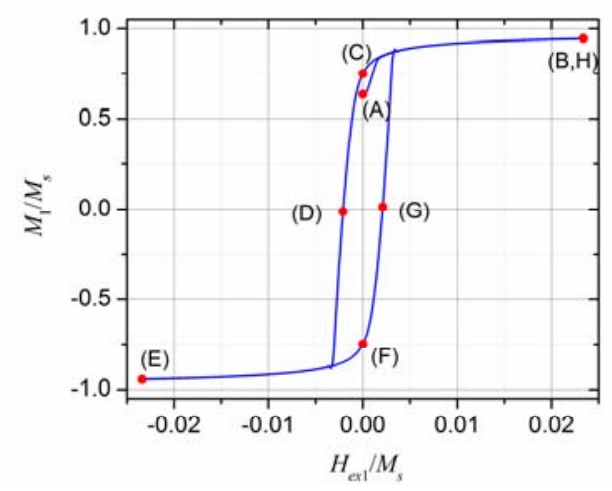

(a)

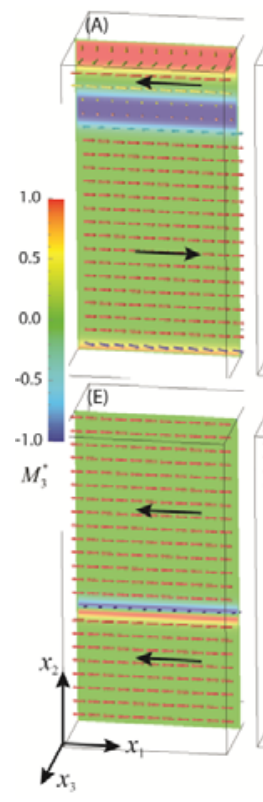

$(\mathrm{E})$

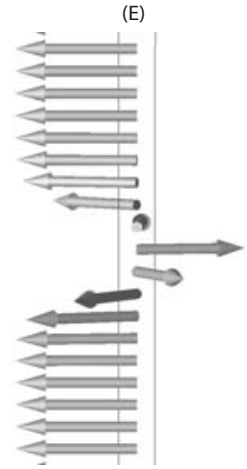

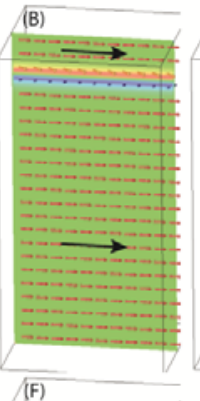
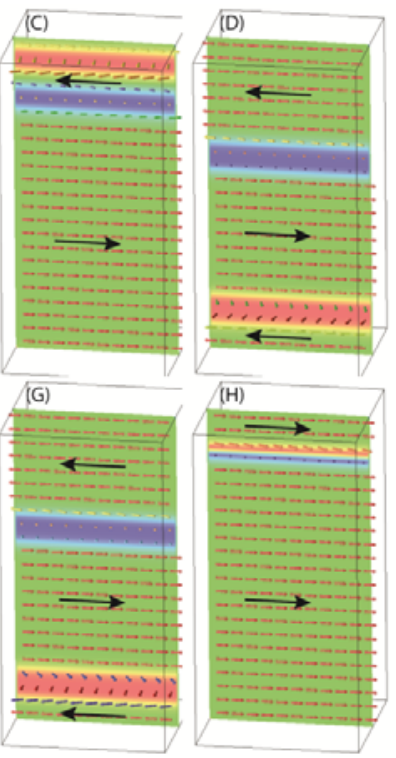

(b)
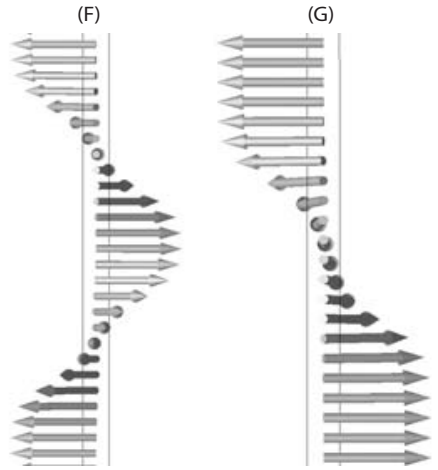

(c)

Figure 11. (a) Magnetic hysteresis loop of a single crystal iron; (b) Magnetic domain morphologies of the central $x_{1} x_{2}$ plane at the labeled points of (a). The outside box is the 3D simulation cell, the black arrows are the magnified magnetization vectors shown in the corresponding domains, and the color illustrates the magnitude of the magnetization component $\left(M_{3}^{*}=M_{3} / M_{s}\right)$ as depicted by the color bar (e.g., blue is into the page and red is out of the page). (c) Arrowed Bloch domain walls at the given points (E,F,G). (E) represents a $360^{\circ}$ wall, (F) shows two split $180^{\circ}$ walls, and (G) shows a single $180^{\circ}$ wall. 


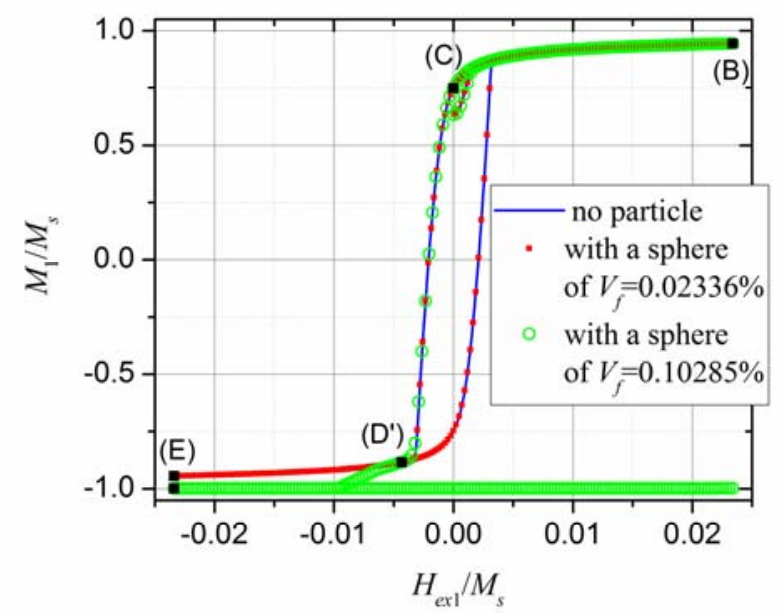

(a)
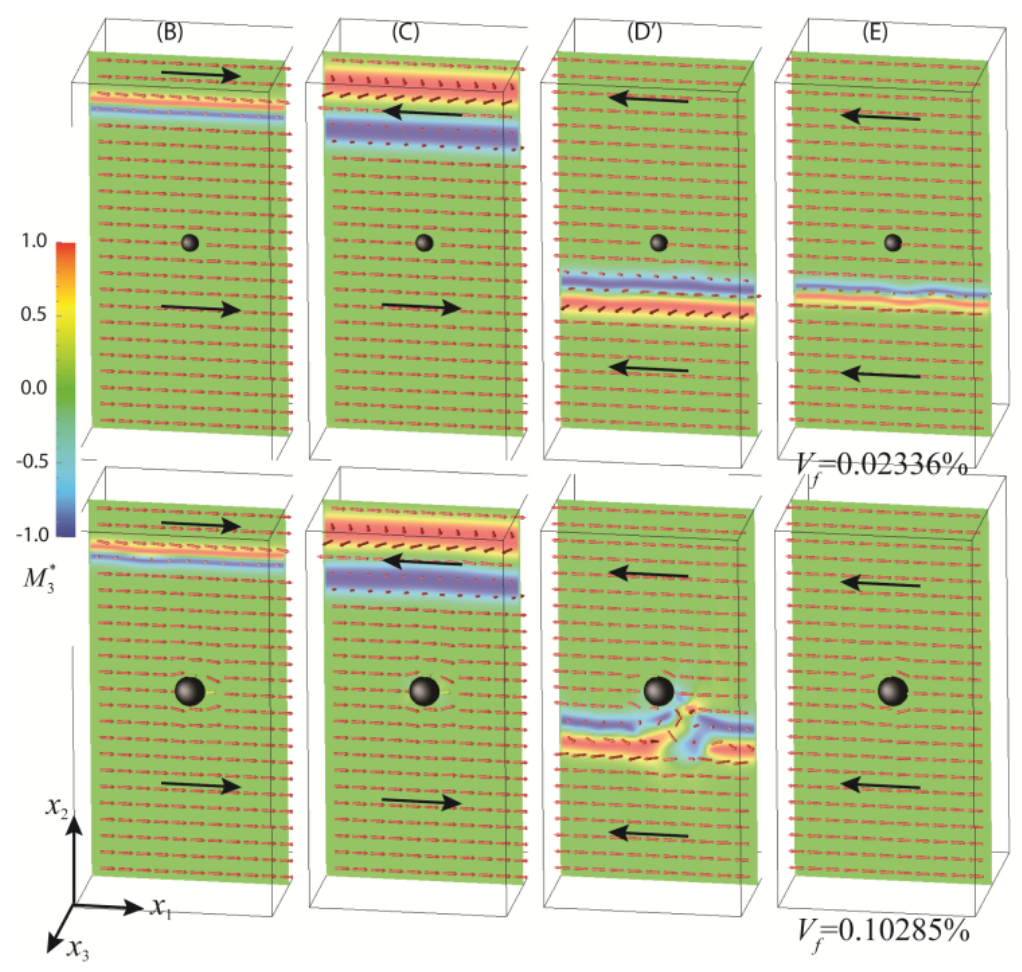

(b)

Figure 12. (a) Magnetic hysteresis loops for the cases of $V_{f}=0.0$ (no particle), $V_{f}=0.02336 \%$ and $V_{f}=0.10285 \%$, respectively. $V_{f}$ is the volume fraction of the nonmagnetic sphere with respect to the simulation cell. (b) Magnetic domain morphology snapshots at the corresponding points of the hysteresis loops for both cases with nonmagnetic particle (black sphere). 


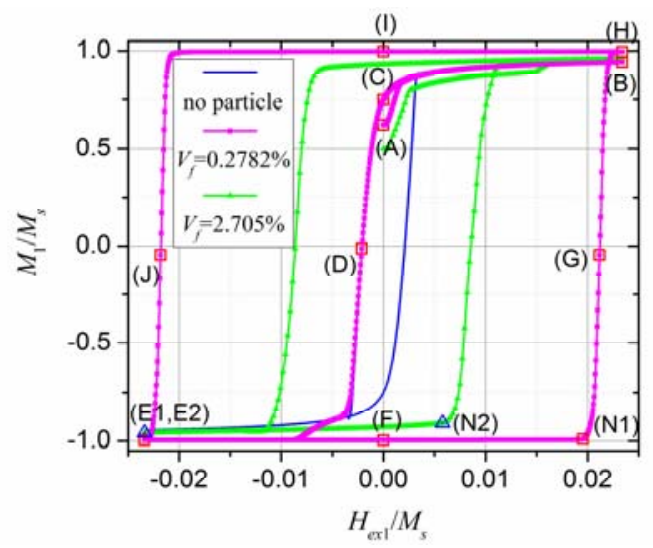

(a)
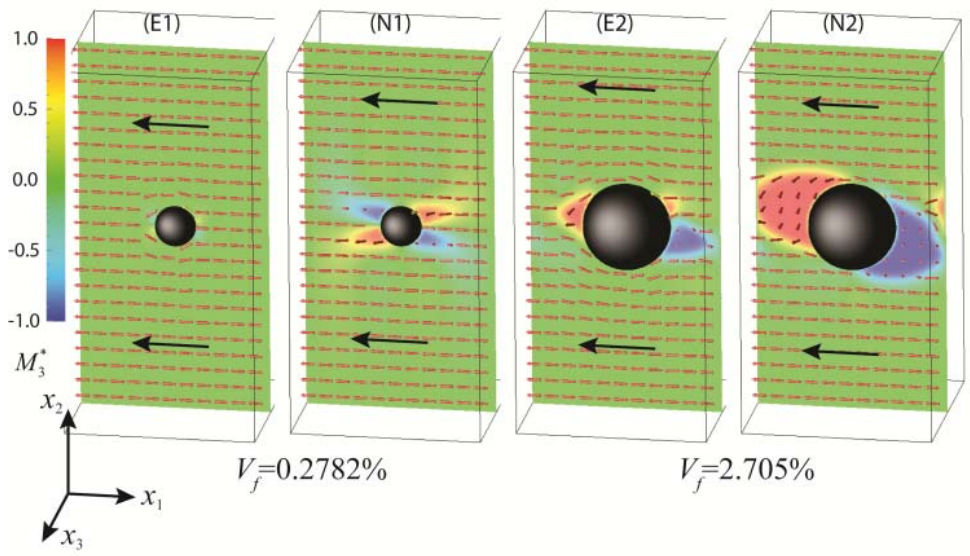

(b)

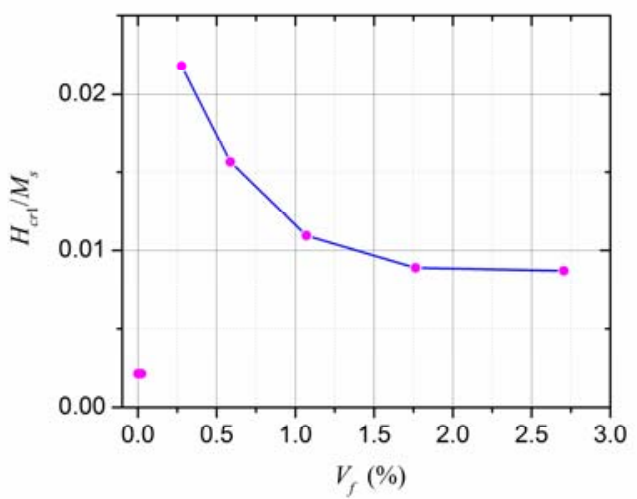

(c)

Figure 13. (a) Magnetic hysteresis loops for the cases of $V_{f}=0.0$ (no particle), $V_{f}=0.2782 \%$ and $V_{f}=2.705 \%$, respectively. $V_{f}$ is the volume fraction of the nonmagnetic sphere with respect to the simulation cell. For the case of $V_{f}=0.2782 \%$, the loop follows the sequence of (ABCDE1FN1GHIJ). (b) Magnetic domain morphology snapshots at the indicated points (E1,N1; E2,N2) of the hysteresis loops. The points (E1,E2) are corresponding to the maximum applied external magnetic field. The points $(\mathrm{N} 1, \mathrm{N2})$ are corresponding to the nucleation sites of new anti-direction domains. (c) Summary of the coercive field versus the volume fraction of a nonmagnetic sphere. 
In summary, we have developed a phase-field model to study the interaction between magnetic domain walls and nonmagnetic particles based on the Landau-Lifshitz-Gilbert equation. From simulations, we found that both nonmagnetic particles and $360^{\circ}$ domain walls are the nucleation sites of an anti-direction domain during domain switching. But an anti-direction domain nucleates much easier at a $360^{\circ}$ domain wall through splitting the $360^{\circ}$ domain wall into two $180^{\circ}$ domain walls, which results in the smallest coercive field. The appearance of any defect, such as a void or nonmagnetic precipitate, could result in larger coercive field, i.e., magnetic hardening, if it can prevent the formation of $360^{\circ}$ domain walls during domain switching.

More importantly, the developed model enables investigation of the interaction mechanisms between nonmagnetic particles and magnetic domain walls and improves the understanding of the physics behind observed signals in NDE, a critical component for the development of advanced NDE and sensors for monitoring material degradation under thermal and irradiation environments.

In irradiated materials there are complex microstructure including initial microstructures such as martensitic phases, grain boundaries, and dislocations in ferritic-martensitic steels, and radiation-induced defects such as precipitates, dislocation loops, and voids. Material property degradation depends on the types of defects, defect densities, and spatial and temporal evolution of defect morphology and distributions. Our ultimate goal of modeling is to quantitatively study the effect of different microstructures on material response to applied fields, understand the interaction mechanisms and signal physics, validate the simulation results with experimental measurements including domain nucleation at defects, magnetic domain structures, first order reversal curves (FORCs), and hysteresis loop, statistically analyze the correlation between distributed defects and response, and provide insights for the development of advanced monitoring methods and sensor materials.

\section{Acoustic Case Study}

Another in-situ approach to detecting materials degradation is through the use of acoustic methods to characterize and monitor material performance. The intent of this document is not to describe all of the available ultrasonic measurement methods for materials characterization. The behavior of acoustic waves in solids (and the consequent measurable parameters that may be used to correlate with microstructural changes) are described in detail elsewhere (for instance, (Ensminger and Bond 2012; Krautkramer and Krautkramer 1990; Goebbels 1994; Doctor et al. 1989; Raj et al. 2000)). Here, we summarize some of the ultrasonic measurement methods that have been applied for materials characterization:

- Ultrasonic velocity and attenuation: These techniques use classical ultrasonic measurement methods to measure the velocity and attenuation, potentially as a function of frequency, and have been shown to be sensitive to a range of degradation mechanisms. 
- Bulk wave measurements use body or bulk waves to measure the velocity and attenuation, usually as a function of wave mode (longitudinal or shear).

- Guided wave measurements have been proposed as a potential technique for long-range examination of components such as piping. The method uses the structure or component as a waveguide to propagate the applied stress waves over long distances. Sensitivity to large-scale cracking has been shown in prior studies.

- Acoustic emission (AE): AE is a passive technique that "listens" for stress waves initiated by the onset of cracking or other dislocation movement. AE has been shown in prior work to be sensitive to crack growth (Hutton et al. 1993). A potential challenge is to discriminate crack growth signals from environmental noise.

- Nonlinear acoustics (Ogi et al. 2001; Cantrell and Yost 2001): This class of techniques attempts to measure the relative change in the nonlinear elastic wave response of the material due to accumulated damage. Techniques included in this method can employ:

- Bulk measurements (Cantrell and Yost 2001)

- Rayleigh wave measurements (Shui et al. 2008)

- Guided wave measurements (Bermes et al. 2008)

- Acoustic microscopy: This class of techniques (mostly laboratory-based) uses high frequency (typically in excess of $20 \mathrm{MHz}$ ) focused ultrasound to image variation in elastic properties in materials. A number of enhancements are possible, including surface imaging, sub-surface imaging, leaky Rayleigh wave, and nonlinear acoustic microscopy measurements.

In general, resolution for linear acoustics measurements is proportional to the wavelength in the material, and for direct detection of degradation precursor states in steels, the wavelength needed is likely to be on the order of 10-25 microns (corresponding to a frequency of 250-500 $\mathrm{MHz}$ ). While this is possible, the higher frequency range will push the limits of current generation of piezoelectric probes. Also at higher frequencies, there are potential issues with attenuation of the sound field deep into the material, so it may be only possible to image near surface regions. Gaps in this respect include: localized measurement interior to specimens, radiation performance of probes not known (but assumed to be a function of the composition/material, fabrication process and impurities).

In recent years, nonlinear ultrasonics (NLU) has seen increased interest as a means of characterizing the internal damage state of the material early in the fatigue process (Cantrell and Yost 2001; Matlack et al. 2012b). Conventional ultrasonic methods, currently in use in ISI, apply high-frequency (in excess of $500 \mathrm{kHz}$, typically around $2.25 \mathrm{MHz}$ ) acoustic energy and measure the resulting response due to scattering and reflection of the energy at interfaces. The presence of cracking is detected by means of a reflection from the crack surface. Other forms of damage may 
be detected by making use of velocity and attenuation measurements through one or more measurement configurations. However, most such measurements are not sensitive to earlier stages of damage. In contrast, NLU methods rely on the generation of harmonics from an initially monochromatic input. The generation of harmonics is due to nonlinearities in the elastic constants associated with the material (Zarembo and Krasil'nikov 1971). The second harmonic is of particular interest, and the resulting nonlinear material parameter is represented by $\beta$ (KyungYoung 2000). A schematic of a typical single-sided measurement setup for nonlinear acoustics measurements is shown in Figure 12. Alternative setups that use a transmitting probe to transmit acoustic energy through the specimen and a receiving probe on the opposite side of the specimen (through-transmission mode) are also possible, as are methods that generate surface waves.

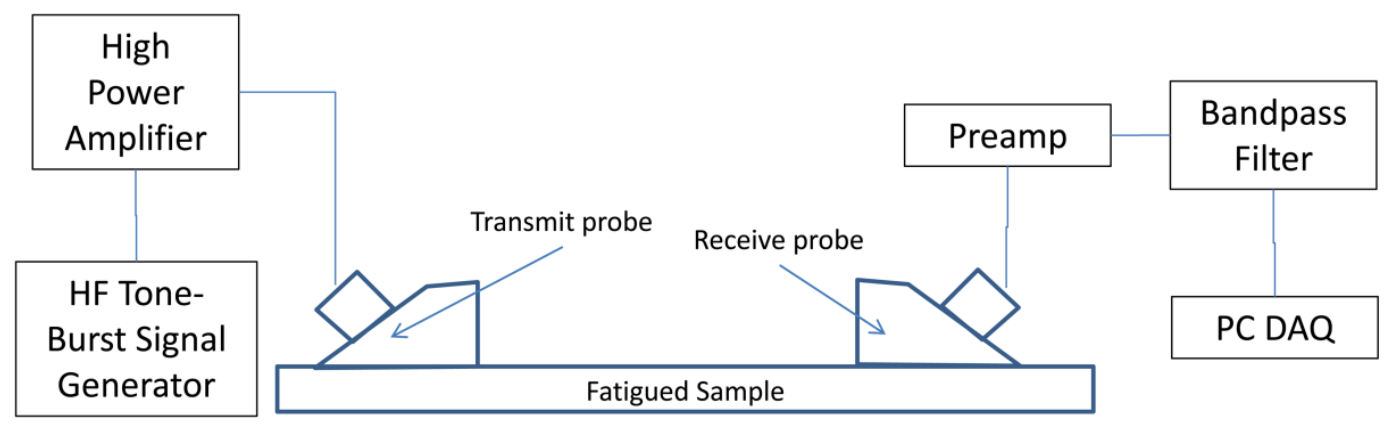

Figure 12. Schematic of NLU Measurement System

NLU has been applied to the characterization of a range of damage mechanisms, including fatigue (Kyung-Young 2000; Cantrell and Yost 2001), irradiation embrittlement (Matlack et al. 2012b), SCC (Matlack et al. 2012a; Shintaku et al. 2010), and corrosion pitting (De et al. 2010).

\subsection{Acoustic Sensor Materials and Irradiation Studies}

The most common sensor materials for ultrasonics are piezoelectric materials. Of the many different piezoelectric materials, PZT (lead zirconate titanate) is among the most widely used, primarily due to its relatively high sensitivity. Magnetostrictive materials are also used for ultrasonic measurements, as are EMAT probes and lasers (both of which enable non-contact measurements).

Ultrasonic measurements for detecting microstructural changes representative of irradiation-related embrittlement in steels have been performed by a number of researchers (Doctor et al. 1989; Blaszkiewicz 1996; Change et al. 2001; Dobmann et al. 2001; Ishii et al. 2002; McHenry 1998). Most studies to date have examined ultrasonic velocity and attenuation of different wave modes and correlated the resulting measurements with some metric of 
embrittlement (usually fluence or microhardness). Results to date appear to indicate some trending; however, the results vary from study to study and in many cases, are based on a limited sample set. In general, the results are likely to be a function of the specific alloy, the starting microstructure, and fluence and flux levels. Recent studies have also examined ultrasonic absorption for sensitivity to irradiation damage; again, the results are encouraging though based on a limited sample set. Recent studies have also examined the capability of nonlinear ultrasonic measurements to assess irradiation damage (Matlack et al. 2012b). While promising, the results are preliminary and require further validation.

A complementary issue is that of sensor material irradiation hardening. Studies to date have shown that several piezoelectric materials may be relatively radiation-hardened, though the fluence levels achieved in these tests is generally rather low $\left(\sim 10^{18} \mathrm{n} / \mathrm{cm}^{2}\right)$. It is likely that longterm exposure, particularly in advanced reactor designs, may result in significantly higher dose, and therefore a recent project to examine the impact of increased irradiation levels on transducer performance was started at Penn State, using the MIT Materials Test Reactor (MITR). The issue of high temperature operation is related, as the sensor is expected to encounter temperatures in excess of $\sim 300^{\circ} \mathrm{C}$ in advanced reactor concepts as well as close to the core. As a result, materials with Curie temperatures less than the expected operating temperature will not survive. On the other hand, materials with Curie temperatures in excess of the operating temperature may still encounter aging and degradation in sensor response over the long term, and this effect needs to be quantified.

\subsection{Acoustic Sensor Modeling and Signal Interpretation}

Acoustic sensor modeling at the macroscale is a relatively well-developed field, with a number of commercial software packages available, including ANSYS and CIVA. However, these packages require modification to handle propagation issues arising from complex materials such as large anisotropic grains. The inverse problem of signal interpretation and analysis at the macroscale has also seen a significant level of attention in the research community and a summary of some of the approaches to addressing the macroscopic signal inversion problem are documented in reference (Daw et al. 2012). Modeling and analysis to address elastic behavior at the microscale are limited.

\subsection{Imaging}

Ferritic steel of grain size $\sim 17 \mu \mathrm{m}$ has been imaged as a function of depth with scanning acoustic microscopy (SAM) at $967 \mathrm{MHz}$ (Hirsekorn et al. 2011). Atomic force microscope (AFM) and atomic force acoustic microscopy (AFAM) images of these steels can be combined with EBSD to give a complete picture of the local crystallographic and acoustic properties. In another example, cementite and ferrite phases in $\mathrm{Fe}-0.8 \% \mathrm{C}$ unalloyed steel can be distinguished using AFAM contact resonance spectra (Batista et al. 2012). Studies of this nature imply that defects could be imaged and local acoustic property maps could be measured, allowing the nano- 
/micro-structural investigation of the effects of voids, second phases, and grain boundaries on physical properties.

\section{Related work at other institutions}

Thought leaders in the aerospace NDE community have already called for the use of integrated materials property assessment in structural materials as a means to achieve state-ofhealth determination ("materials state awareness") (National Research Council 2008; Banerjee et al. 2011). The term "electromagnetic materials state awareness monitoring" has been coined to describe the use of NDE methods that result in an electrical signal produced by an electrical, magnetic, or thermal stimulus (Nagy 2010). Integrated monitoring and prognosis using techniques with sufficient sensitivity and selectivity allow various aspects of material and component state to be assessed through changes in electrical conductivity, magnetic permeability, thermal conductivity, and thermoelectric power, for instance. Through the measurement of these properties, microstructure evolution, phase transformation, hardening, embrittlement, and elastic strain can be assessed. For example, electrical conductivity in metal alloys will change as a function of elastic strain.

Scientists at the Japanese Atomic Energy Agency have recently been developing NDE techniques to detect irradiation-assisted stress corrosion cracking (IASCC) susceptibility in austenitic stainless steels, using eddy current and AC magnetization methods (Nemoto et al. 2011).

Recent work by the Fraunhofer Institute for Non-destructive Testing (IZFP), has combined electron backscatter diffraction (EBSD) imaging with scanning acoustic microscopy (SAM) and scanning probe techniques such as AFM, AFAM, and MFM to show the potential of these techniques for studying the detailed mechanisms of grain and second phase formation in steels (Batista et al. 2012; Hirsekorn et al. 2011).

Researchers at Arizona State University have been evaluating an integrated approach to modeling and measurements with the goal of predicting remaining life of fatigued aerospace materials. They use first principles computational models to study the evolution of damage in the material, and measurements at the bulk scale along with computational approaches to inversion (Soni and Chattopadhyay 2010; Soni et al. 2009).

\section{Acknowledgements}

Support for this work through the Reactor Aging Management Focus Area of the Pacific Northwest National Laboratory Sustainable Nuclear Power Initiative is gratefully acknowledged. 


\section{Appendix: literature review of effects of neutrons on magnetic materials}

\begin{tabular}{|c|c|c|c|c|}
\hline & $\begin{array}{l}\text { flux } \\
\left(\mathrm{n} / \mathrm{cm}^{2} / \mathrm{s}\right)\end{array}$ & $\begin{array}{l}\text { fluence } \\
\left(\mathrm{n} / \mathrm{cm}^{2}\right)\end{array}$ & Ref, notes & Material effects \\
\hline $\begin{array}{l}\text { Mn-Zn ferrite, Ni-Zn } \\
\text { ferrite ceramics }\end{array}$ & $5 \times 10^{13}$ & $\begin{array}{r}10^{18} \text { to } \\
2.3 \times 10^{20}\end{array}$ & $\begin{array}{l}\text { (Chukalkin et al. 1975) Fast neutr } \mathrm{E}>0.8 \\
\mathrm{MeV} \text {; temperature } 70{ }^{\circ} \mathrm{C} \text {, thermal } \\
\text { neutrons removed with } \mathrm{Cd}\end{array}$ & $\begin{array}{l}\text { Above } 10^{18} / \mathrm{cm}^{2} \text { dose, cations redistribute into disordered nanoregions } \\
(1.2-3.5 \mathrm{~nm}), \mathrm{T}_{\mathrm{c}} \text { increases, max magnetization (low T) decreases; at } \\
\text { highest fluence, Ni-Zn conductivity changes from p-type to n-type } \\
\text { (Chukalkin et al. 1974) }\end{array}$ \\
\hline $\mathrm{ZnFe}_{2} \mathrm{O}_{4}$ & & $\begin{array}{r}0.25 \times 10^{19} \text { to } \\
10^{20}\end{array}$ & $\begin{array}{l}\text { (Parkhomenko et al. 1976) Temperature } \\
70{ }^{\circ} \mathrm{C} \text {, thermal neutrons removed with } \\
\mathrm{Cd}\end{array}$ & $\begin{array}{l}\text { Zn ferrite, normally a paramagnet at room temperature, has been shown } \\
\text { to become a ferromagnet at the highest neutron doses, and a } \\
\text { superparamagnet with ferrimagnetic clusters at lower doses due to } \\
\text { replacement cascades of atoms in the spinel sites. Changes to } \\
\text { ferromagnet at highest doses by change of } \mathrm{Fe}^{3+} \text { to } \mathrm{Fe}^{2+}\end{array}$ \\
\hline $\mathrm{BaFe}_{12} \mathrm{O}_{19}$ & & $\begin{array}{r}2 \times 10^{19} \text { to } \\
3.4 \times 10^{20}\end{array}$ & $\begin{array}{l}\text { (Chukalkin et al. 1981) Fast neutrons } \\
\mathrm{E}>1 \mathrm{MeV} \text { in reactor }\end{array}$ & $\begin{array}{l}\text { With increasing fluence, saturation magnetization decreases, does not } \\
\text { totally saturate at high magnetic field, and has kink in curve; magnetic } \\
\text { structure changes to helicoid (and ultimately isolated block) structure } \\
\text { possibly due to removal of } \mathrm{Fe}^{3+} \text { from } 2 \mathrm{~b} \text { sites that normally result in } \\
\text { collinear structure }\end{array}$ \\
\hline $\mathrm{Y}_{3} \mathrm{Fe}_{5} \mathrm{O}_{12}$ & & $\begin{array}{l}5 \times 10^{18} \text { to } \\
1.6 \times 10^{20}\end{array}$ & $\begin{array}{l}\text { (Chukalkin et al. 1983) Fast neutrons } \\
\mathrm{E}>1 \mathrm{MeV} \text { in reactor }\end{array}$ & $\begin{array}{l}\text { Amorphization of YIG at highest fluences; sample becomes a spin } \\
\text { glass with Tf } \sim 70 \mathrm{~K} \text { and shows bifurcation in FC/ZFC magnetization; } \\
\text { summary discussion on spinels and hexaferrite crystal structures not } \\
\text { changes by high fluences but garnets changed due to large ion size } \\
\text { difference between rare earths and transition metals resulting in frozen } \\
\text { disorder. }\end{array}$ \\
\hline $\begin{array}{l}\mathrm{Y}_{3} \mathrm{Fe}_{5} \mathrm{O}_{12} \text { powdered } \\
\text { and polycrystalline }\end{array}$ & $10^{13}$ & & $\begin{array}{l}\text { (Podsekin and Zaitsev 1982) fast } \\
\text { neutrons } \mathrm{E}>0.1 \mathrm{MeV}\end{array}$ & $\begin{array}{l}\text { As dose rate increased, unit cell period increased and Curie temperature } \\
\text { decreased }\end{array}$ \\
\hline $\mathrm{Y}_{3} \mathrm{Fe}_{5} \mathrm{O}_{12}$ & $\begin{array}{l}8 \times 10^{12} \text { to } \\
1.5 \times 10^{13}\end{array}$ & $\begin{array}{r}10^{18} \text { to } \\
10^{20}\end{array}$ & $\begin{array}{l}\text { (Podsekin et al. 1982) fast neutrons } \\
\mathrm{E}>0.1 \mathrm{MeV}\end{array}$ & $\begin{array}{l}\text { Frequencies up to } 10 \mathrm{GHz} \text {, complex magnetic permeability changes } \\
\text { with fast neutron fluxes }>10^{18} / \mathrm{cm}^{2} \text {; permeability in predispersion } \\
\text { region (up to } 100 \mathrm{MHz} \text { ) decreases and increases in RF dispersion } \\
\text { region; resistivity and sat magnetization decreases }\end{array}$ \\
\hline
\end{tabular}




\section{Appendix: literature review of effects of neutrons on magnetic materials (continued)}

\begin{tabular}{|c|c|c|c|c|}
\hline & $\begin{array}{r}\text { flux } \\
(\mathrm{n} / \mathrm{cm} 2 / \mathrm{s})\end{array}$ & $\begin{array}{l}\text { fluence } \\
(\mathrm{n} / \mathrm{cm} 2)\end{array}$ & Ref, notes & Material effects \\
\hline $\begin{array}{l}\mathrm{Y}_{3} \mathrm{Fe}_{5} \mathrm{O}_{12} \text { and } \\
\text { YIG:La epitaxial } \\
\text { films }\end{array}$ & & $\begin{array}{r}10^{17} \text { to } \\
10^{19}\end{array}$ & $\begin{array}{l}\text { (Ubizskii et al. 1993) fast neutrons }>0.2 \\
\mathrm{MeV} \text {, average energy } 2 \mathrm{MeV} \text {; results } \\
\text { compared to electron irradiation }(1.3 \\
\mathrm{MeV} \text { (Ubizskii et al. 1993) and } 3.5 \\
\mathrm{MeV} \text { (Ubizskii et al. 1996)) }\end{array}$ & $\begin{array}{l}\text { At fluences }>5 \times 10^{17} / \mathrm{cm}^{2} \text {, YIG lattice constant increases (restored to } \\
\text { pre-irradiated value after annealing at } 1250 \mathrm{~K} \text { in air), saturation } \\
\text { magnetization decreases }\left(\sim 8 \% \text { at } 10^{19} / \mathrm{cm}^{2}\right) \text {, ferromagnetic linewidth } \\
\left.\text { increases (factor of } 2 \text { at } 10^{19} / \mathrm{cm}^{2}\right) \text {, and shortwave absorption edge } \\
\text { broadens; data are explained by assuming disordered nanoregions of 6- } \\
\text { 8nm created from displacement cascades and resulting in amorphous } \\
\text { areas which spread out the energy of transitions at the optical edge. }\end{array}$ \\
\hline $\begin{array}{l}\text { Sm-Co permanent } \\
\text { magnets }\end{array}$ & & & $\begin{array}{l}\text { (Ito et al. 2001) } 200 \mathrm{MeV} \text { protons } 10^{2}- \\
10^{5} \mathrm{~Gy}\end{array}$ & No change in magnetic flux with irradiation \\
\hline $\begin{array}{l}\text { Nd-Fe-B permanent } \\
\text { magnets }\end{array}$ & & & $\begin{array}{l}\text { (Ito et al. 2001) } 200 \mathrm{MeV} \text { protons } 10^{2}- \\
10^{5} \mathrm{~Gy}\end{array}$ & $\begin{array}{l}\text { Magnetic flux decreased after irradiation; increase of permanence } \\
\text { coefficient and coercive force improved radiation hardening; operating } \\
\text { point on demagnetization curve important }\end{array}$ \\
\hline $\begin{array}{l}\text { Nd-Fe-B and SmCo } \\
\text { permanent magnets }\end{array}$ & $\begin{array}{r}4.2 \times 10^{10} \\
\text { (fast } \\
\text { neutrons, } 1 \\
\mathrm{MeV} \\
\text { equivalent) }\end{array}$ & & $\begin{array}{l}\text { (Spencer and Volk 2003) data on } \\
\text { Hadrons needed for accelerators; } \\
\text { (Anderson et al. 2005) fast neutron test } \\
\text { at UC Davis McClellan Nuclear Reactor } \\
\text { Center, suppressed thermal neutrons and } \\
\text { gammas. }\end{array}$ & $\begin{array}{l}\text { (Anderson et al. 2005) Induced radioactivity discussed; differential } \\
\text { damage in Gauss/Gy negative (demagnetization) }\end{array}$ \\
\hline $\begin{array}{l}\text { Nd-Fe-B and SmCo } \\
\text { permanent magnets }\end{array}$ & & $\begin{array}{r}10^{16} \text { (fast neut, } 1 \\
\text { MeV equiv) }\end{array}$ & $\begin{array}{l}\text { (Liu et al. 2007) fast neutron test at } \\
\text { Ohio State Research Reactor }\end{array}$ & $\begin{array}{l}\text { Radiation-induced thermal spike caused } \mathrm{Nd}_{13} \mathrm{Dy}_{2} \mathrm{Fe}_{77} \mathrm{~B}_{8} \text { to lose } 100 \% \\
\text { of magnetic flux with } 10^{16} \mathrm{n} / \mathrm{cm} 2 \text { of neutron flux. } \mathrm{Sm}(\mathrm{Co}, \mathrm{Fe}, \mathrm{Cu}, \mathrm{Zr}) 2 \\
\text { magnets do not show noticeable change. Best } \mathrm{Sm} \text {-Co magnets have } \\
\text { Tcurie up to } 750-900 \mathrm{C} \text {, so can operate up to } \sim 550 \mathrm{C} \text {. }\end{array}$ \\
\hline $\mathrm{Fe}_{2} \mathrm{O}_{3}$ & & & & $\begin{array}{l}\text { (Bakkaloglu and Thomas 1992) change in Morin T; (Donbaev et al. } \\
\text { 1993) creates low T weak FM phase }\end{array}$ \\
\hline
\end{tabular}




\section{References}

Acton, G, Q-Z Yin, KL Verosub, L Jovane, A Roth, B Jacobsen, and DS Ebel. 2007. "Micromagnetic coercivity distributions and interactions in chondrules with implications for paleointensities of the early solar system." J. Geophys. Res. 112:B03S90. doi:10.1029/2006JB004655.

Adams, JJ, DS Agosta, RG Leisure, and H Ledbetter. 2006. "Elastic constants of monocrystal iron from 3 to 500 K." Journal of Applied Physics 100(11):113530-7.

Alley, RE, Jr. 1959. "In-pile measurements of radiation effects in magnetic materials." Journal of Applied Physics 30(4):284S-85S.

Altpeter, I, G Dobmann, KH Katerbau, M Schick, P Binkele, P Kizler, and S Schmauder. 2001. "Copper precipitates in 15 NiCuMoNb 5 (WB 36) steel: material properties and microstructure, atomistic simulation, and micromagnetic NDE techniques." Nuclear Engineering and Design 206(2-3):337-50. 10.1016/s0029-5493(00)00420-9.

Anderson, S, J Spencer, Z Wolf, A Baldwin, D Pellet, M Boussoufi, and J Volk. 2005. Fast Neutron Damage Studies on NdFeB Materials. Report, Stanford SLAC Natinonal Accerator Laboratory, Menlo Park, CA.

Andresen, PL, FP Ford, K Gott, RL Jones, PM Scott, T Shoji, RW Staehle, and RL Tapping. 2007. Expert Panel Report on Proactive Materials Degradation Assessment. Report, U.S. Nuclear Regulatory Commission, Washington, D.C.

Anon. 1959. "Proceedings of 4th Symposium on magnetism and magnetic materials Nov 17-20 1958." Journal of Applied Physics 30(4, Supp):323.

Anon. 1953. "Washington conference on magnetism." Reviews of Modern Physics 25(1):351.

Ara, K, N Ebine, and N Nakajima. 1996. "New method of nondestructive measurement for assessment of material degradation of aged reactor pressure vessels." Journal of Pressure Vessel Technology, Transactions of the ASME 118(Compendex):447-53.

Artemev, A, Y Jin, and AG Khachaturyan. 2001. "Three-dimensional phase field model of proper martensitic transformation." Acta Materialia 49(7):1165-77.

Babcock, KL, VB Elings, J Shi, DD Awschalom, and M Dugas. 1996. "Field-dependence of microscopic probes in magnetic force microscopy." Applied Physics Letters 69(5):705-07.

Baek, UB, KS Ryu, A Kim, and SH Nahm. 2009. "Aging estimation of reactor pressure vessel in the field using magnetic properties." Journal of Loss Prevention in the Process Industries 22(Compendex):971-74.

Bakkaloglu, ÖF, and MF Thomas. 1992. "The effect of radiation damage on the Morin transition in [alpha]-Fe2O3." Journal of Magnetism and Magnetic Materials 104-107(Part 3):1921-22. 10.1016/03048853(92)91604-r. 
Banerjee, S, L Liu, ST Liu, F-G Yuan, and S Beard. 2011. Integrated material state awareness system with self-learning symbiotic diagnostic algorithms and models. In Proceedings 79840M-12 pp. SPIE, Accessed at http://dx.doi.org/10.1117/12.880511.

Batista, L, U Rabe, and S Hirsekorn. 2012. "Micro- and nanostructure characterization and imaging of TWIP and unalloyed steels." AIP Conference Proceedings 1430(1):1381-88.

Bermes, C, J-Y Kim, J Qu, and LJ Jacobs. 2008. "Nonlinear Lamb Waves for the Detection of Material Nonlinearity." Mechanical Systems and Signal Processing 22(3):638-46. 10.1016/j.ymssp.2007.09.006.

Bertotti, G. 1998. Hysteresis in Magnetism: for physicists, materials scientists, and engineers. Academic Press, San Diego.

Bertotti, G. 2008. Hysteresis in Magnetism: for Physicists, Materials Scientists, and Engineers. Academic Press, the United States of America.

Bida, GV. 2004. "The use of generalized magnetic parameters for magnetic structural analysis and nondestructive testing." Russian Journal of Nondestructive Testing 40(7):476-86. 10.1007/s11181-0050084-y.

Blaszkiewicz, M. 1996. "Development of nondestructive evaluation (NDE) for monitoring the embrittlement in nuclear reactor pressure vessels." Materials Science Forum 210-213(Compendex):9-16.

Bolshakova, I. 1999. "Improvement of radiation resistance of magnetic field microsensors." Sensors and Actuators A: Physical 76(1-3):152-55. 10.1016/s0924-4247(98)00375-6.

Bolshakova, I, V Chekanov, I Duran, R Holyaka, R Konopleva, S Kulikov, C Leroy, E Makido, A Marusenkov, PJ Moreau, I Nazarkin, F Shurygin, J Stockel, G Vayakis, and V Yerashok. 2009. Methods and instrumentation for investigating hall sensors during their irradiation in nuclear research reactors. In Proceedings of Advancements in Nuclear Instrumentation Measurement Methods and their Applications (ANIMMA), 2009 First International Conference on, 1-6 pp. Accessed at

Bond, LJ, SR Doctor, JW Griffin, AB Hull, and SN Malik. 2011. "Damage Assessment Technologies for Prognostics and Proactive Management of Materials Degradation." Nuclear Technology 173(1):46-55.

Bond, LJ, SR Doctor, JW Griffin, AB Hull, and SN Malik. 2009. Damage assessment technologies for prognostics and proactive management of materials degradation (PMMD). Presented at ANS NPIC HMIT 2009 Topical meeting - Nuclear Plant Instrumentation, Controls, and Human Machine Interface Technology, American Nuclear Society.

Brandt, A. 2001. "Multiscale and Multiresolution Methods: Theory and Applications." In Multiscale Scientific Computation: Review 2001, eds. TJ Barth, TF Chan and R Haimes, pp. 3-96. Springer Verlag.

Brown, RD, JR Cost, and JT Stanley. 1984. "Effects of neutron irradiation on magnetic permeability of amorphous and crystalline magnetic alloys." Journal of Applied Physics 55(6):1754-56. 
Cantrell, JH, and WT Yost. 2001. "Nonlinear Ultrasonic Characterization of Fatigue Microstructures." International Journal of Fatigue 23:487-90.

Carroll, TK. 2010. "Radiation Damage in GMR Spin Valves." The Ohio State University, Columbus: Physics. Master of Science

Carvallo, C, AR Muxworthy, DJ Dunlop, and W Williams. 2003. "Micromagnetic modeling of first-order reversal curve (FORC) diagrams for single-domain and pseudo-single-domain magnetite." Earth and Planetary Science Letters 213(3-4):375-90.

Chang, K-O, S-H Chi, K-J Choi, B-C Kim, and S-L Lee. 2002. "Changes in magnetic parameters of neutron irradiated RPV Linde80 high copper weld surveillance specimens." International Journal of Pressure Vessels and Piping 79(11):753-57. 10.1016/s0308-0161(02)00097-2.

Change, K, B Kim, and S Lee. 2001. The research activities of irradiation damage evaluation on reactor pressure vessel materials using NDE techniques in Korea. Presented at 10th APCNDT.

Chen, AP, R Egli, and BM Moskowitz. 2007. "First-order reversal curve (FORC) diagrams of natural and cultured biogenic magnetic particles." J. Geophys. Res. 112(B8):B08S90. 10.1029/2006jb004575.

Chen, LQ. 2002. "Phase-field models for microstructure evolution." Annual Review of Materials Research 32:113-40. DOI 10.1146/annurev.matsci.32.112001.132041.

Chen, $Q$, and A Konrad. 1997. "A Review of Finite Element Open Boundary Techniques for Static and Quasi-Static Electromagnetic Field Problems." IEEE Transactions on Magnetics 33(1):663-76.

Choe, S-B, D-H Kim, Y-C Cho, H-J Jang, K-S Ryu, H-S Lee, and S-C Shin. 2002. "Magneto-optical microscope magnetometer for simultaneous local probing of magnetic properties." Review of Scientific Instruments 73(8):2910-16.

Chou, H-P, Y-S Chang, S-K Chen, and J-W Yeh. 2009. "Microstructure, thermophysical and electrical properties in AlxCoCrFeNi ( $0 \leq x \leq 2)$ high-entropy alloys." Materials Science and Engineering: B 163(3):18489. 10.1016/j.mseb.2009.05.024.

Chukalkin, YG, BN Goshchitskii, SF Dubinin, N Sidorov, VV Petrov, VD Parkhomenko, and VG Vologin. 1975. "Radiation effects in oxide ferrimagnets." Phys. Stat. Sol. (a) 28:345-54.

Chukalkin, YG, VV Petrov, and BN Goshchitskii. 1981. "Radiation effects in hexagonal ferrite $\mathrm{BaFe}_{12} \mathrm{O}_{19}$." Phys. Stat. Sol. (a) 67:421-26.

Chukalkin, YG, VR Shtrits, and BN Goshchitskii. 1983. "Amorphization in neutron-irradiated yttrium iron garnet." Phys. Stat. Sol. (a) 79:361-66.

Chukalkin, YG, VG Vologin, BN Goshchitskii, SF Dubinin, VV Petrov, VD Parkhomenko, and SK Sidorov. 1974. "Magnetic transformation and p-n transition in nickel-zinc ferrite induced by a neutron field." Phys. Stat. Sol. (a) 23:K159-K61. 
Chun, J, AM Jones, and JS McCloy. 2012. "Effects of domain, grain, and magnetic anisotropy distributions on magnetic permeability: Monte-Carlo approach." Journal of Applied Physics 112(2):023904-8.

Clark, AE, M Wun-Fogle, JB Restorff, and TA Lograsso. 2002. "Magnetostrictive properties of galfenol alloys under compressive stress." Materials Transactions 43(5):881-86.

Coble, JB, RM Meyer, P Ramuhalli, LJ Bond, HM Hashemian, BD Shumaker, and DS Cummins. 2012. A Review of Sensor Calibration Monitoring for Calibration Interval Extension in Nuclear Power Plants. Report, Pacific Northwest National Laboratory, Richland, WA.

Craik, D. 1995. Magnetism: Principles and Applications. John Wiley \& Sons, Chichester.

Cullity, BD, and CD Graham. 2009. Introduction to Magnetic Materials. 2nd ed., Wiley \& IEEE Press.

d'Aquino, M. 2004. "Nonlinear Magnetization Dynamics in Thin-films and Nanoparticles." Universita degli studi di Napoli "Federico II", Facolta di Ingegneria, Electrical Engineering. Doctorate

Davies, JE, O Hellwig, EE Fullerton, G Denbeaux, JB Kortright, and K Liu. 2004. "Magnetization reversal of Co/Pt multilayers: Microscopic origin of high-field magnetic irreversibility." Physical Review $B$ 70(22):224434.

Davies, JE, J Wu, C Leighton, and K Liu. 2005. "Magnetization reversal and nanoscopic magnetic-phase separation in La1-x Srx CoO3." Physical Review B 72(13):134419.

Daw, J, JL Rempe, P Ramuhalli, R Montgomery, CL Chien, B Tittmann, and B Reinhardt. 2012. NEET In-Pile Ultrasonic Sensor Enablement-FY 2012 Status Report. Report No. INL/EXT-12-27233, Idaho National Laboratory, Idaho Falls, ID.

Day, R, M Fuller, and VA Schmidt. 1977. "Hysteresis properties of titanomagnetites: Grain-size and compositional dependence." Physics of The Earth and Planetary Interiors 13(4):260-67. 10.1016/00319201(77)90108-x.

De, S, S Palit Sagar, S Dey, A Prakash, and I Chattoraj. 2010. "Quantification of Pitting in Two Tempers of 7075 Aluminium Alloy by Non-destructive Evaluation." Corrosion Science 52(5):1818-23. 10.1016/j.corsci.2010.01.023.

Debarberis, L, B Acosta, A Zeman, S Pirfo, P Moretto, A Chernobaeva, and Y Nikolaev. 2007. "Ductile-tobrittle transition temperature of thermally segregated WWER-1000 base metal." International Journal of Microstructure and Materials Properties 2(Copyright 2008, The Institution of Engineering and Technology):326-38.

Díaz-Michelena, M. 2009. "Small Magnetic Sensors for Space Applications." Sensors 9(4):2271-88.

Dobmann, G. 2006. "NDE for material characterization of ageing due to thermal embrittlement, fatigue and neutron degradation." International Journal of Materials and Product Technology 26(1/2):122-39. 
Dobmann, G. 1994. "NDT tools for the prediction of strength and toughness parameters of pressure vessel steels." Welding in the World, Le Soudage Dans Le Monde 33(Compendex):141-47.

Dobmann, G, I Altpeter, and M Kopp. 2006a. "Nondestructive materials characterization of irradiated nuclear pressure-vessel steel samples by the use of micromagnetic techniques and in terms of mechanical properties." Russian Journal of Nondestructive Testing 42(Compendex):272-77.

Dobmann, G, I Altpeter, K Szielasko, and M Kopp. 2006b. "Nondestructive damage characterization with examples of thermal aging, neutron degradation and fatigue." Journal of Theoretical and Applied Mechanics 44(Copyright 2006, The Institution of Engineering and Technology):649-66.

Dobmann, G, L Debarberis, and J-F Coste. 2001. "Aging material evaluation and studies by nondestructive techniques (AMES-NDT) - a European network project." Nuclear Engineering and Design 206(2-3):363-74. 10.1016/s0029-5493(00)00422-2.

Dobmann, G, M Kronig, W Theiner, H Willems, and U Fiedler. 1992. "Nondetructive characterization of materials (ultrasonic and micromagnetic techniques) for strength and toughness prediction and the detection of early creep damage." Nuclear Engineering and Design 157:137-58.

Doctor, SR. 2008. The History and Future of NDE in the management of Nuclear Power Plant Materials Degradation. Presented at Proceedings of PVP2008, ASME Pressure Vessel and Piping Division Conference 197-207 pp. American Society of Mechanical Engineers, New York.

Doctor, SR, SM Bruemmer, MS Good, LA Charlot, TT Taylor, DM Bond, JD Deffenbaugh, and LD Reid. 1989. Utilization of Ultrasonic Measurements to Quantify Aging-Induced Material Microstructure and Property Changes. Presented at Nondestructive Monitoring of Materials Properties, 143-49 pp. Materials Research Society, Warrendale, Pennsylvania, Mat. Res. Soc. Symp. Proc., Symposium U.

Donbaev, KM, AK Zhetbaev, and MK Mukusheva. 1993. "New Spin-Reorientation Transition in Irradiated Single Crystal Hematite." physica status solidi (b) 176(1):219-26. 10.1002/pssb.2221760121.

Durin, G, C Beatrice, C Appino, V Basso, and G Bertotti. 2000. "Connection between hysteresis, Barkhausen noise, and microstructure in magnetic materials." Journal of Applied Physics 87(9):4768-70.

Ensminger, D, and LJ Bond. 2012. Ultrasonics: Fundamentals, Technologies, and Applications. 3rd ed., CRC Press.

Ford, FP. 2007. "Appendix B, Section B.8, Stress Corrosion Cracking of Carbon and Low Alloy Steels." In Expert Panel Report on Proactive Materials Degradation Assessment, pp. B135-B57. U.S. Nuclear Regulatory Commission, Washington, D.C.

Frait, Z, and B Heinrich. 1964. "Intrinsic Ferromagnetic Resonance Linewidth in Metal Single Crystals." Journal of Applied Physics 35(3):904-05. 10.1063/1.1713529.

Fujii, I, M Ugorek, and S Trolier-McKinstry. 2010. "Grain size effect on the dielectric nonlinearity of BaTiO3 ceramics." Journal of Applied Physics 107(10):104116. 
Ganpule, CS, V Nagarajan, BK Hill, AL Roytburd, ED Williams, R Ramesh, SP Alpay, A Roelofs, R Waser, and LM Eng. 2002. "Imaging three-dimensional polarization in epitaxial polydomain ferroelectric thin films." Journal of Applied Physics 91(3):1477-81.

Geisler, AH. 1953. "Coercive force of precipitation alloys." Reviews of Modern Physics 25(1):316-22.

Ginsztler, J, I Meszaros, B Hidasi, and L Devenyi. 1994. "Magnetic testing methods of high-temperature steels." International Journal of Pressure Vessels and Piping 59(Compendex):271-73.

Goebbels, K. 1994. Materials Characterization for Process Control and Product Conformity. CRC Press, Boca Raton, Florida.

Gordon, DI. 1953. "An experimental study of Barkhausen noise in Nickel-Iron alloys." Reviews of Modern Physics 25(1):56-57.

Guers, M. 2010. "Magnetostrictive sleeve transducer for in situ monitoring of specimens." Proc. SPIE 7650(1):765010.

Gurkunov. 2000. Russian Journal of Nondestructive Testing 36(6):389-417.

Hirsekorn, S, U Rabe, L Batista, and L Behl. 2011. "Microstructure characterization and imaging of finegrained steel by microscopic ultrasonic techniques." AIP Conference Proceedings 1335(1):1097-103.

Holbert, KE, S Sankaranarayanan, SS McCready, DR Spearing, and AS Heger. 2003. Response of piezoelectric acoustic emission sensors to gamma radiation. In Proceedings of Radiation and Its Effects on Components and Systems, 2003. RADECS 2003. Proceedings of the 7th European Conference on, 559$65 \mathrm{pp}$. Accessed at

Hsu, S-S, and T-T Chang. 1996. "Aging monitoring via magnetic property change of pressure vessel materials." International Journal of Pressure Vessels and Piping 66(Compendex):319-23.

Hu, SY, CH Henager, and LQ Chen. 2010. "Simulations of Stress-Induced Twinning and De-twinning: A Phase Field Model." Acta Materialia 58(19):6554-64. DOI 10.1016/j.actamat.2010.08.020.

Hubert, A, and R Schaefer. 1998. Magnetic domain: the analysis of magnetic microstructures. Springer, Berlin.

Hutton, PH, MA Friesel, and JF Dawson. 1993. Continuous AE Crack Monitoring of a Dissimilar Metal Weldment at Limerick Unit 1. Report, U.S. Nuclear Regulatory Commission, Washington, D.C.

IAEA. 2007. Assessment and Management of Ageing of Major Nuclear Power Plant Components Important to Safety: PWR Pressure Vessel Internals, 2007 Update. Report, International Atomic Energy Agency (IAEA), Vienna, Austria.

Ishii, T, N Ooka, T Hoshiya, H Kobayashi, J Saito, M Niimi, and H Tsuji. 2002. "Development of a nondestructive testing technique using ultrasonic wave for evaluation of irradiation embrittlement in 
nuclear materials." Journal of Nuclear Materials 307-311, Part 1(0):240-44. 10.1016/S00223115(02)01035-8.

Ito, Y, K Yasuda, R Ishigami, S Hatori, O Okada, K Ohashi, and S Tanaka. 2001. "Magnetic flux loss in rareearth magnets irradiated with $200 \mathrm{MeV}$ protons." Nuclear Instruments and Methods in Physics Research Section B: Beam Interactions with Materials and Atoms 183(3-4):323-28.

Jhang, K-Y. 2009. "Nonlinear Ultrasonic Techniques for Non-destructive Assessment of Micro Damage in Material: A Review." International Journal of Precision Engineering and Manufacturing 10(1):123-35.

Jiles, DC. 2000. "Dynamics of Domain Magnetization and the Barkhausen Effect." Czechoslovak Journal of Physics 50(8):893-924.

Jiles, DC, and DL Atherton. 1986. "Theory of ferromagnetic hysteresis." Journal of Magnetism and Magnetic Materials 61(1-2):48-60. 10.1016/0304-8853(86)90066-1.

Jin, J. 2002. The Finite Element Method in Electromagnetics, Second Edition. John Wiley and Sons, Inc., New York.

Kameda, J, and R Ranjan. 1987. "Nondestructive evaluation of steels using acoustic and magnetic barkhausen signals-I. Effect of carbide precipitation and hardness." Acta Metallurgica 35(7):1515-26.

Karma, A, and WJ Rappel. 1998. "Quantitative phase-field modeling of dendritic growth in two and three dimensions." Physical Review E 57(4):4323-49.

Kataja, M, and S van Dijken. 2011. "Magneto-optical Kerr effect susceptometer for the analysis of magnetic domain wall dynamics." Review of Scientific Instruments 82(10):103901-6.

Katzgraber, HG, G Friedman, and GT Zimányi. 2004. "Fingerprinting hysteresis." Physica B: Condensed Matter 343(1-4):10-14. 10.1016/j.physb.2003.08.051.

Katzgraber, HG, F Pazmandi, CR Pike, K Liu, RT Scalettar, KL Verosub, and GT Zimanyi. 2002. "ReversalField Memory in the Hysteresis of Spin Glasses." Physical Review Letters 89(25):257202.

Kee-Ok, C, C Se-Hwan, K Taek-Soo, K Byoung-Chul, and L Sam-Lai. 1999. The measurement of material degradation in neutron irradiated Mn-Mo-Ni low alloy steels using magnetic techniques. In Proceedings of Nondestructive Characterization of Materials IX, 28 June-2 July 1999, 202-7 pp. AIP, Accessed at

Kida, K, EC Santos, T Honda, H Koike, and J Rozwadowska. 2012. "Observation of magnetic flux density around fatigue crack tips in bearing steel using an SHPM with a three-dimensional small-gap probe." International Journal of Fatigue 39(0):38-43. 10.1016/j.ijfatigue.2011.05.013.

Kikuchi, H, M Harada, K Ara, Y Kamada, S Kobayashi, and S Takahashi. 2007. "Development of apparatus for magnetic measurements of Charpy impact test pieces." Journal of Materials Processing Technology 181(Compendex):190-93. 
Kikuchi, H, M Harada, K Ara, Y Kamada, S Kobayashi, and S Takahashi. 2006. "Nondestructive evaluation of mechanical property by apparatus for magnetic measurements of charpy test pieces." IEEE Transactions on Magnetics 42(Compendex):3536-38.

Kim, BG, JL Rempe, JF Villard, and S Solstad. 2011. "Review of Instrumentation for Irradiation Testing of Nuclear Fuels and Materials." Nuclear Technology 176(2):155-87.

Kim, DJ, DG Park, and JH Hong. 2002. "Nondestructive evaluation of reactor pressure vessel steels using the giant magnetoimpedance sensor." Journal of Applied Physics 91(Copyright 2003, IEE):7421-3.

Kim, HC, SC Yu, CG Kim, HS Han, WK Cho, and DH Kim. 2000. "Effect of neutron irradiation on soft magnetic properties in amorphous FeCuNbSiB alloy." Journal of Applied Physics 87(9):7115-17.

Kim, J-H, D-G Park, C-I Ok, E-P Yoon, and J-H Hong. 1999. "Effect of microstructures on magnetic Barkhausen noise level in the weld HAZ of an RPV steel." Journal of Magnetism and Magnetic Materials 196-197:351-53. 10.1016/s0304-8853(98)00745-8.

Kleber, X, A Hug, J Merlin, and M Soler. 2004. "Ferrite-Martensite steels characterization using magnetic Barkhausen noise measurements." ISIJ Int. 44(Copyright (C) 2012 American Chemical Society (ACS). All Rights Reserved.):1033-39. 10.2355/isijinternational.44.1033.

Kobayashi, S, H Kikuchi, S Takahashi, Y Kamada, K Ara, T Yamamoto, D Klingensmith, and GR Odette. 2009. "The effect of copper and manganese on magnetic minor hysteresis loops in neutron irradiated Fe model alloys." Journal of Nuclear Materials 384(2):109-14. 10.1016/j.jnucmat.2008.10.031.

Kobayashi, S, H Kikuchi, S Takahashi, Y Kamada, K Ara, T Yamamoto, D Klingensmith, and GR Odette. 2008. "Neutron irradiation effects on magnetic minor hysteresis loops in nuclear reactor pressure vessel steels." Philosophical Magazine 88(12):1791-800. 10.1080/14786430802286989.

Kopcewicz, M, and A Dunlop. 2001. "Magnetic texture in amorphous Fe $40 \mathrm{Ni} 35$ Si 10 B 15 alloy irradiated with swift heavy ions*." Journal of Physics: Condensed Matter 13(27):6067.

Kou, X, X Fan, RK Dumas, Q Lu, Y Zhang, H Zhu, X Zhang, K Liu, and JQ Xiao. 2011. "Memory Effect in Magnetic Nanowire Arrays." Advanced Materials 23(11):1393-97. 10.1002/adma.201003749.

Krause, TW, L Clapham, and DL Atherton. 1994. "Characterization of the magnetic easy axis in pipeline steel using magnetic Barkhausen noise." Journal of Applied Physics 75(12):7983-88.

Krautkramer, J, and H Krautkramer. 1990. Ultrasonic testing of materials. Springer-Verlag, Berlin.

Kunz, KS, and RJ Luebbers. 1993. The Finite Difference Time Domain Method for Electromagnetics. CRC Press.

Kwon, OY, K Ono, GE Lucas, and GR Oddette. 1988. Detection of Irradiation Effects on Reactor Vessel Steels by Magneto-Acoustic Emission. Report, United States. 
Kyung-Young, J. 2000. "Applications of Nonlinear Ultrasonics to the NDE of Material Degradation." IEEE Transactions on Ultrasonics, Ferroelectrics and Frequency Control 47(3):540-48. 10.1109/58.842040.

Lain, T. 2008. Materials Reliability Program: Pressurized Water Reactor Issue Management Tables. Report, Electric Power Research Institute, Palo Alto, California.

Lau, JW, and JM Shaw. 2011. "Magnetic nanostructures for advanced technologies: fabrication, metrology and challenges." Journal of Physics D: Applied Physics 44(30):303001.

Lee, H-S, K-S Ryu, K-R Jeon, SSP Parkin, and S-C Shin. 2011. "Breakdown of Barkhausen critical-scaling behavior with increasing domain-wall pinning in ferromagnetic films." Physical Review B 83(6):060410.

Li, J. 2011. "Soft-ferromagnetic bulk glassy alloys with large magnetostriction and high glass-forming ability." AIP Advances 1(4):042110.

$\mathrm{Li}, \mathrm{YL}$, SY Hu, and LQ Chen. 2005. "Ferroelectric domain morphologies of (001) $\mathrm{PbZr}_{1-x} \mathrm{Ti}_{\mathrm{x}} \mathrm{O}_{3}$ epitaxial thin films." Journal of Applied Physics 97(3):034112-7.

Lide, DR, ed. 2006. CRC Handbook of Chemistry and Physics. 87th Ed., Taylor and Francis, Boca Raton.

Liu, J, P Vora, P Dent, M Walmer, CH Chen, J Talnagi, S Wu, and M Harmer. 2007. Thermal stability and radiation resistance of Sm-Co based permanent magnets. In Proceedings of Space Nuclear Conference, 2036 pp. Accessed at http://www.electronenergy.com/media/EEC SmCo Permanent Magnets.pdf.

Ludwig, R, and W Lord. 1988. "A Finite Element Formulation for the Study of Ultrasonic NDT Systems." IEEE Transactions on Ultrasonics, Ferroelectrics and Frequency Control 35(6):809-20.

Maeda, N, A Yamaguchi, K Saito, T Hirasawa, I Komura, and N Chujou. 1999. Nondestructive evaluation of neutron irradiation embrittlement for reactor vessel steel by magnetomechanical acoustic emission technique. In Proceedings of Proceedings of the 1996 18th International Symposium: Effects of Radiation on Materials, June 25, 1996 - June 27, 1996, 576-88 pp. ASTM, Accessed at

Matlack, KH, JY Kim, L Jacobs, J Qu, and PM Singh. 2012a. "Nonlinear Rayleigh Waves to Detect Initial Damage Leading to Stress Corrosion Cracking in Carbon Steel." AIP Conference Proceedings 1430(1):1452-59.

Matlack, KH, JJ Wall, JY Kim, J Qu, LJ Jacobs, and HW Viehrig. 2012b. "Evaluation of radiation damage using nonlinear ultrasound." Journal of Applied Physics 111(5):054911-3.

Maziasz, PJ. 1989. "Formation and stability of radiation-induced phases in neutron-irradiated austenitic and ferritic steels." Journal of Nuclear Materials 169:95-115. 10.1016/0022-3115(89)90525-4.

McCloy, J, P Ramuhalli, and CH Henager Jr. 2012. Use of First Order Reversal Curve Measurements to Understand Barkhausen Noise Emission in Nuclear Steel. Presented at Review of Progress in Quantitative Nondestructive Evaluation, American Institute of Physics. 
McCord, J, T Gemming, L Schultz, J Fassbender, MO Liedke, M Frommberger, and E Quandt. 2005. "Magnetic anisotropy and domain patterning of amorphous films by He-ion irradiation." Applied Physics Letters 86(16):162502-3.

McHenry, H. 1998. Nondestructive Characterization of Reactor Pressure Vessel Steels: A Feasibility Study. Report, NIST.

Meyer, RM, P Ramuhalli, BM Toloczko, L Bond, and RO Montgomery. 2012. Assessment of NDE Technologies for Detection and Characterization of Stress Corrosion Cracking in LWRs. Presented at Third International Conference on NPP Life Management (PLiM) for Long Term Operations (LTO).

Moffett, MB, AE Clark, M Wun-Fogle, J Linberg, JP Teter, and EA McLaughlin. 1991. "Characterization of Terfenol-D for magnetostrictive transducers." The Journal of the Acoustical Society of America 89(3):1448-55.

Moorthy, V, S Vaidyanathan, T Jayakumar, and B Raj. 1997. "Microstructural characterization of quenched and tempered $0.2 \%$ carbon steel using magnetic Barkhausen noise analysis." Journal of Magnetism and Magnetic Materials 171(1-2):179-89. 10.1016/s0304-8853(97)00049-8.

Nagaishi, T, K Ara, Y Morita, and H Itozaki. 2003. "Gamma ray irradiation tests of high-T, SQUID." Applied Superconductivity, IEEE Transactions on 13(2):254-57. 10.1109/tasc.2003.813698.

Nagase, T, T Sanda, A Nino, W Qin, H Yasuda, H Mori, Y Umakoshi, and JA Szpunar. 2012. "MeV electron irradiation induced crystallization in metallic glasses: Atomic structure, crystallization mechanism and stability of an amorphous phase under the irradiation." Journal of Non-Crystalline Solids 358(3):502-18. 10.1016/j.jnoncrysol.2011.11.010.

Nagy, PB. 2010. "Non-destructive methods for materials' state awareness monitoring." Insight 52(2):6171.

Nalladega, V. 2009. "Design and development of scanning eddy current force microscopy for characterization of electrical, magnetic and ferroelectric properties with nanometer resolution." University of Dayton, Ohio, Mechanical Engineering. PhD

National Research Council. 2008. Proceedings of a Workshop on Materials State Awareness. The National Academies Press.

Nemoto, Y, S Keyakida, T Uchimoto, S Takaya, and T Tsukada. 2011. "Development of a magnetic sensor system for predictive IASCC diagnosis on stainless steels in a nuclear reactor." International Journal of Applied Electromagnetics and Mechanics 35(2):123-39. 10.3233/jae-2011-1326.

Newell, AJ. 2005. "A high-precision model of first-order reversal curve (FORC) functions for singledomain ferromagnets with uniaxial anisotropy." Geochem. Geophys. Geosyst. 6(5):Q05010. 10.1029/2004gc000877. 
Nielsen, OV, P Brauer, F Primdahl, T Risbo, JL Jørgensen, C Boe, M Deyerler, and S Bauereisen. 1997. "A high-precision triaxial fluxgate sensor for space applications: layout and choice of materials." Sensors and Actuators A: Physical 59(1-3):168-76. 10.1016/s0924-4247(97)80169-0.

OECD. 2011. Carbon Pricing, Power Markets and the Competitiveness of Nuclear Power. Report, Nuclear Energy Agency, Organisation for Economic Co-operationg and Development (OECD), France.

Ogi, H, M Hirao, and S Aoki. 2001. "Noncontact Monitoring of Surface-Wave Nonlinearity for Predicting the Remaining Life of Fatigued Steels." Journal of Applied Physics 90(1):438-42.

Otaka, M, S Shimizu, R Morinaka, N Maeda, and A Yamaguchi. 1999. Detection of radiation damage in low alloy steel using a squid sensor. In Proceedings of Proceedings of the 1996 18th International Symposium: Effects of Radiation on Materials, June 25, 1996 - June 27, 1996, 568-75 pp. ASTM, Accessed at

Özgür, Ü, Y Alivov, and H Morkoç. 2009. "Microwave ferrites, part 1: fundamental properties." Journal of Materials Science: Materials in Electronics 20(9):789-834.

Park, D-G, J-H Hong, and I-S Kim. 1999a. Irradiation effects on magnetic properties in reactor pressure vessel steel. In Proceedings of Proceedings of the 1999 IEEE International Magnetics Conference 'Digest of Intermag 99', May 18, 1999 - May 21, 1999, FQ-12 pp. IEEE, Accessed at

Park, D-G, J-H Hong, I-S Kim, and H Kim. 1997a. "Evaluation of thermal recovery of neutron-irradiated SA508-3 steel using magnetic property measurements." Journal of Materials Science 32(23):6141-46. 10.1023/a:1018608321067.

Park, D-G, H-T Jeong, and J-H Hong. 1999b. "A study on the radiation damage and recovery of neutron irradiated vessel steel using magnetic Barkhausen noise." J. Appl. Phys. 85(8):5726-28.

Park, D-G, I-G Park, W-W Kim, Y-M Cheong, and J-H Hong. 2008. "Monitoring of a radiation recovery in neutron-irradiated RPV steel by using the magnetic methods." Nuclear Engineering and Design 238(Compendex):814-19.

Park, DG, TS Byun, YY Song, JH Hong, and IS Kim. 2000. "Radiation damage of reactor pressure vessel steels studied by nondestructive methods." Key Engineering Materials 183(Compendex):I/.

Park, DG, JH Hong, KS Jang, KS Jung, and GM Kim. 1999c. "The changes of the structural, magnetic, and mechanical properties in a reactor pressure vessel steel neutron-irradiated at 70C." Journal of the Korean Physical Society 34(Copyright 1999, IEE):434-8.

Park, DG, CG Kim, HC Kim, JH Hong, and IS Kim. 1997b. Effect of neutron irradiation on magnetic properties in the low alloy Ni-Mo steel SA508-3. 81, AIP.

Park, DG, EJ Moon, DJ Kim, SH Chi, and JH Hong. 2003. "The change of saturation magnetization in neutron-irradiated low-alloy steel." Physica B: Condensed Matter 327(2-4):315-18. 10.1016/s09214526(02)01777-5. 
Park, DG, Cl Ok, HT Jeong, IH Kuk, and JH Hong. 1999d. "Nondestructive evaluation of irradiation effects in RPV steel using Barkhausen noise and magnetoacoustic emission signals." Journal of Magnetism and Magnetic Materials 196-197:382-84. 10.1016/s0304-8853(98)00766-5.

Park, DG, S-S Park, K-O Chang, and J-H Hong. 2004a. "The change of magnetic relaxation in neutron irradiated Ni-Cr-Mo steel." physica status solidi (b) 241(7):1621-24. 10.1002/pssb.200304672.

Park, SS, YH Choi, and CO Kim. 2004b. "The resonant motion of the impedance and the FMR spectra in irradiated low alloy steel." physica status solidi (b) 241(7):1658-61. 10.1002/pssb.200304654.

Parkhomenko, VD, SF Dubinin, BN Goshchitskii, YG Chukalkin, SK Sidorov, VG Vologin, and VV Petrov. 1976. "Peculiarities of Radiation Damage in Ferrites with Spinel Structure." Physica Status Solidi A 38:5766.

Parks, DA, and B Tittmann. 2011. Ultrasonic NDE in a reactor core. Presented at Review of Progress in Quantitative Nondestructive Evaluation, AIP.

Pathania, R. 2008. EPRI Materials Degradation Matrix, Rev. 1. Report, Electric Power Research Institute, Palo Alto, California.

Pérez-Benitez, JA, J Capó-Sánchez, J Anglada-Rivera, and LR Padovese. 2005. "A model for the influence of microstructural defects on magnetic Barkhausen noise in plain steels." Journal of Magnetism and Magnetic Materials 288:433-42. 10.1016/j.jmmm.2004.09.134.

Persson, A, G Thornell, and H Nguyen. 2011. "Radiation tolerance of a spin-dependent tunnelling magnetometer for space applications." Measurement Science and Technology 22(4):045204.

Pike, CR, AP Roberts, MJ Dekkers, and KL Verosub. 2001. "An investigation of multi-domain hysteresis mechanisms using FORC diagrams." Physics of The Earth and Planetary Interiors 126(1-2):11-25.

Pike, CR, AP Roberts, and KL Verosub. 1999. "Characterizing interactions in fine magnetic particle systems using first order reversal curves." Journal of Applied Physics 85(9):6660-67.

Pike, CR, CA Ross, RT Scalettar, and G Zimanyi. 2005. "First-order reversal curve diagram analysis of a perpendicular nickel nanopillar array." Physical Review B 71(13):134407.

Pinnel, MR, and JE Bennett. 1973. "The metallurgy of Remendur: effects of processing conditions." Bell System Technical Journal 52(8):1325-40.

Podsekin, AK, and BD Zaitsev. 1982. "Relationship between the saturation magnetization and the Curie temperature of yttrium iron garnet." Sov. Phys. Solid State 24(2):342-43.

Podsekin, AK, BD Zaitsev, and II Kuz'min. 1982. "Effects of neutron radiation from a reactor on the magnetic spectrum saturation magnetization of yttrium ferrogarnet." Sov. Phys. Tech. Phys. 27(1):54-56.

Pomeroy, JM, TC White, H Grube, JC Read, and JE Davies. 2009. "Magnetoresistance based first-order reversal curve analysis of magnetic tunnel junctions." Applied Physics Letters 95(2):022514-3. 
Raj, B, A Kumar, and T Jayakumar. 2000. "Ultrasonic Spectral Analysis for Microstructural Characterization of Austenitic and Ferritic Steels." Philosophical Magazine A (UK) 80(11):2469-87.

Raj, B, V Moorthy, T Jayakumar, and KBS Rao. 2003. "Assessment of Microstructures and Mechanical Behaviour of Metallic Materials through Non-destructive Characterisation." International Materials Reviews 48(5):273-325.

Ramírez, JG, A Sharoni, Y Dubi, ME Gómez, and IK Schuller. 2009. "First-order reversal curve measurements of the metal-insulator transition in $\mathrm{VO}_{2}$ : Signatures of persistent metallic domains." Physical Review B 79(23):235110.

Ranjan, R, O Buck, and RB Thompson. 1987a. "A study on the effect of dislocation on the magnetic properties of nickel using magnetic NDE methods." Journal of Applied Physics 61(8):3196-98.

Ranjan, R, DC Jiles, O Buck, and RB Thompson. 1987b. "Grain size measurement using magnetic and acoustic Barkhausen noise." Journal of Applied Physics 61(8):3199-201.

Rave, W, K Ramstock, and A Hubert. 1998. "Corners and nucleation in micromagnetics." J. Magn. Magn. Mater. 183(3):329-33. 10.1016/s0304-8853(97)01086-x.

Rempe, JL, DL Knudson, KG Condie, JE Daw, B Heng, BS Fox, and GE Kohse. 2010. "New Sensors for the Advanced Test Reactor National Scientific User Facility." Nuclear Science, IEEE Transactions on 57(5):2653-61.

Rempe, JL, H Maclean, R Schley, D Hurley, JE Daw, S Taylor, J Smith, J Svoboda, D Kotter, DL Knudson, SC Wilkins, M Guers, L Bond, L Ott, J McDuffee, E Parma, and G Rochau. 2011. New in-pile instrumentation to support fuel cycle research and development. Report No. INL/EXT-10-19149, Rev 0, FCRD-FUEL-2011000033, Idaho National Laboratory, Idaho Falls, ID.

Roberts, AP, Q Liu, CJ Rowan, L Chang, C Carvallo, J Torrent, and C-S Horng. 2006. "Characterization of hematite $\left(\alpha-\mathrm{Fe}_{2} \mathrm{O}_{3}\right)$, goethite $(\alpha-\mathrm{FeOOH})$, greigite $\left(\mathrm{Fe}_{3} \mathrm{~S}_{4}\right)$, and pyrrhotite $\left(\mathrm{Fe}_{7} \mathrm{~S}_{8}\right)$ using first-order reversal curve diagrams." J. Geophys. Res. 111(B12):B12S35. 10.1029/2006jb004715.

Roberts, AP, CR Pike, and KL Versub. 2000. "First-order reversal curve diagrams: a new tool for characterizing the magnetic properties of natural samples." Journal of Geophysical Research 105(N12):28,461-28,75.

Rodriguez, P, and B Raj. 1997. "Development of In-service Inspection techniques for nuclear power plants in India." International Journal of Pressure Vessels and Piping 73(Compendex):59-68.

Sanz, R, AB Fernández, JA Dominguez, B Martín, and MD Michelena. 2012. "Gamma Irradiation of Magnetoresistive Sensors for Planetary Exploration." Sensors 12(4):4447-65.

Sato, K, and T Ishibashi. 2008. "Development and Application of Magneto-Optical Microscope Using Polarization-Modulation Technique." IEEJ Transactions on Electrical and Electronic Engineering 3(4):399403. 
Schwarz, A, M Liebmann, U Kaiser, R Wiesendanger, TW Noh, and DW Kim. 2004. "Visualization of the Barkhausen Effect by Magnetic Force Microscopy." Physical Review Letters 92(7):077206.

Serrate, D, JM De Teresa, PA Algarabel, J Galibert, C Ritter, J Blasco, and MR Ibarra. 2007. "Colossal magnetoresistance in $\mathrm{Ca}_{x} \mathrm{Sr}_{2-x} \mathrm{FeReO}_{6}$ double perovskites due to field-induced phase coexistence." Physical Review B 75(16):165109.

Serrate, D, JM De Teresa, PA Algarabel, C Marquina, L Morellon, J Blasco, and MR Ibarra. 2005. "Giant magnetostriction in $\mathrm{Ca}_{2} \mathrm{FeReO}_{6}$ double perovskite." Journal of Magnetism and Magnetic Materials 290291, Part 2(0):843-45. 10.1016/j.jmmm.2004.11.390.

Shintaku, Y, Y Ohara, M Hashimoto, S Horinouchi, and K Yamanaka. 2010. Evaluation of Stress Corrosion Cracks in Metals by Linear and Nonlinear Ultrasound. Presented at 20th International Congress on Acoustics (ICA 2010), 473 pp.

Shong, WJ, M Giacobbe, JF Stubbins, and JG Williams. 1993. Magnetic properties measurements of nuclear pressure vessel steel for monitoring of mechanical properties. In Proceedings of Proceedings of the 6th International Symposium on Environmental Degradation of Materials in Nuclear Power SystemsWater Reactors, August 1, 1993 - August 5, 1993, 153-59 pp. Publ by Minerals, Metals \& Materials Soc (TMS), Accessed at

Shui, G, J-Y Kim, J Qu, Y-S Wang, and LJ Jacobs. 2008. "A New Technique for Measuring the Acoustic Nonlinearity of Materials Using Rayleigh Waves." NDT\&E International 41(5):326-29. 10.1016/j.ndteint.2008.01.007.

Sickafus, KE, RW Grimes, JA Valdez, A Cleave, M Tang, M Ishimaru, SM Corish, CR Stanek, and BP Uberuaga. 2007. "Radiation-induced amorphization resistance and radiation tolerance in structurally related oxides." Nat Mater 6(3):217-23.

Sickafus, KE, L Minervini, RW Grimes, JA Valdez, M Ishimaru, F Li, KJ McClellan, and T Hartmann. 2000. "Radiation Tolerance of Complex Oxides." Science 289(5480):748-51. 10.1126/science.289.5480.748.

Sipahi, LB, MR Govindaraju, and DC Jiles. 1994. "Monitoring neutron embrittlement in nuclear pressure vessel steels using micromagnetic Barkhausen emissions." Journal of Applied Physics 75(10):6981-83.

Škorvánek, I, and R Gerling. 1994. "Neutron irradiation effects on the structural, magnetic and mechanical properties of amorphous and nanocrystalline $\mathrm{Fe}_{73.5} \mathrm{Cu}_{1} \mathrm{Nb}_{3} \mathrm{Si}_{13.5} \mathrm{~B}_{9}$." Magnetics, IEEE Transactions on 30(2):548-51.

Solstad, S, and R Van Nieuwenhove. 2011. "Instrument Capabilities and Developments at the Halden Reactor Project." Nuclear Technology 173(1):78-85.

Soni, S, and A Chattopadhyay. 2010. "Sensitivity studies on sensor selection for crack growth investigation." Smart Materials and Structures 19(10):105015. 
Soni, S, S Das, and A Chattopadhyay. 2009. "Sensor selection and crack growth monitoring using sensitivity studies." Modeling, Signal Processing, and Control for Smart Structures, Proc. SPIE 7286:72860I-60I. 10.1117/12.815886.

Sorescu, M. 1998. "The role of magnetostriction in pulsed laser irradiation of amorphous alloys." Journal of Alloys and Compounds 280:251-54.

Sorop, TG, C Untiedt, F Luis, M Kröll, M Raşa, and $U$ de Jongh. 2003. "Magnetization reversal of ferromagnetic nanowires studied by magnetic force microscopy." Physical Review B 67(1):014402.

Spencer, J, and J Volk. 2003. Permanent Magnets for Radiation Damage Studies. Report, Stanford SLAC Natinonal Accerator Laboratory, Menlo Park, CA.

Sposito, G, C Ward, P Cawley, PB Nagy, and C Scruby. 2010. "A review of non-destructive techniques for the detection of creep damage in power plant steels." NDT \&amp; E International 43(7):555-67. 10.1016/j.ndteint.2010.05.012.

Staehle, RW. 2012. Quantitative Micro-Nano (QMN) Approach to SCC Mechanism and Prediction-Starting a Third Meeting. Presented at 15th International Conference on Environmental Degradation of Materials in Nuclear Power Systems - Water Reactors, TMS, Warrendale, Pennsylvania.

Staley, ME, and $A B$ Flatau. 2005. Characterization of energy harvesting potential of Terfenol-D and Galfenol. 5764, SPIE.

Stancu, A, CR Pike, L Stoleriu, P Postolache, and D Cimpoesu. 2003a. "Micromagnetic and Preisach analysis of the First Order Reversal Curves (FORC) diagram." Journal of Applied Physics 93(10):6620-22.

Stancu, A, D Ricinschi, L Mitoseriu, P Postolache, and M Okuyama. 2003b. "First-order reversal curves diagrams for the characterization of ferroelectric switching." Applied Physics Letters 83(18):3767-69.

Stark, R. 2008. BWR Vessel and Internals Project: Boiling Water Reactor Issue Management Tables. Report, Electric Power Research Institute, Palo Alto, California.

Stubbins, JF, WJ Shong, M Giacobbe, AM Ougouag, and JG Williams. 1993. "Pressure vessel steel embrittlement monitoring by magnetic properties measurements." In Small Specimen Test Techniques Applied to Nuclear Reactor Vessel Thermal Annealing and Plant Life Extension, eds. W Corwin, F Haggag and W Server, pp. 18p. ASTM.

Stupakov, O, J Pal'a, V Yurchenko, I Tomáš, and J Bydžovský. 2008. "Measurement of Barkhausen noise and its correlation with magnetic permeability." Journal of Magnetism and Magnetic Materials 320(34):204-09. 10.1016/j.jmmm.2007.05.022.

Sukegawa, T, and M Uesaka. 2001. "Magnetic nondestructive evaluation of degradation of nuclear pressure vessel steels due to mechanical loading." International Journal of Applied Electromagnetics and Mechanics 15(Compendex):315-21. 
Sukegawa, T, M Uesaka, and K Miya. 2000. "Nondestructive evaluation of pressure vessel steels based on magnetic property change." Journal of the School of Engineering the University of Tokyo 47(Copyright 2001, IEE):107.

Takahashi, S, H Kikuchi, K Ara, N Ebine, Y Kamada, S Kobayashi, and M Suzuki. 2006. "In situ magnetic measurements under neutron radiation in Fe metal and low carbon steel." Journal of Applied Physics 100(2):023902.

Takahashi, S, L Zhang, S Kobayashi, Y Kamada, H Kikuchi, and K Ara. 2005. Analysis of minor hysteresis loops in plastically deformed low carbon steel. 98, AIP.

Takaya, S, T Suzuki, Y Matsumoto, K Demachi, and M Uesaka. 2004. "Estimation of stress corrosion cracking sensitivity of type 304 stainless steel by magnetic force microscope." Journal of Nuclear Materials 327(1):19-26. 10.1016/j.jnucmat.2004.01.016.

Takaya, S, I Yamagata, S Ichikawa, Y Nagae, and K Aoto. 2010. "Nondestructive evaluation of neutron irradiation damage on type 316 stainless steel by measurement of magnetic properties." International Journal of Applied Electromagnetics and Mechanics 33:1335-42.

Ubizskii, SB, AO Matkovsky, RM Kholyavka, and MM Rak. 1993. "Investigation of radiation-stimulated processes in epitaxial yttrium-iron garnet films." Journal of Magnetism and Magnetic Materials 125(12):110-12.

Ubizskii, SB, AO Matkowskii, and M Kuzma. 1996. "Irradiation-induced effects in yttrium-iron garnet films." Journal of Magnetism and Magnetic Materials 157-158:279-80.

Villard, JF, and M Schyns. 2011. "Advanced In-Pile Measurements of Fast Flux, Dimensions, and Fission Gas Release." Nuclear Technology 173:86-97.

Vincent, A, L Pasco, M Morin, X Kleber, and M Delnondedieu. 2005. "Magnetic Barkhausen noise from strain-induced martensite during low cycle fatigue of 304L austenitic stainless steel." Acta Mater. 53(Copyright (C) 2012 American Chemical Society (ACS). All Rights Reserved.):4579-91. 10.1016/j.actamat.2005.06.016.

Wang, YU, YM Jin, AM Cuitino, and AG Khachaturyan. 2001. "Phase field microelasticity theory and modeling of multiple dislocation dynamics." Applied Physics Letters 78(16):2324-26.

Wilkowski, G, R Tregoning, P Scott, and D Rudland. 2002. Status of Efforts to Evaluate LOCA Frequency Estimates Using Combined PRA and PFM Approaches. Presented at 28th MPA-Seminar Materials Testing Institute, Universitaet Stuttgart, Germany.

Wilson, JW, T Gui Yun, V Moorthy, and BA Shaw. 2009. "Magneto-Acoustic Emission and Magnetic Barkhausen Emission for Case Depth Measurement in En36 Gear Steel." Magnetics, IEEE Transactions on 45(1):177-83. 10.1109/tmag.2008.2007537.

Zarembo, LK, and VA Krasil'nikov. 1971. "Nonlinear Phenomena in the Propagation of Elastic Waves in Solids." Soviet Physics Uspekhi 13(6):778-97. 10.1070/PU1971v013n06ABEH004281. 
Zhang, JX, and LQ Chen. 2005. "Phase-field microelasticity theory and micromagnetic simulations of domain structures in giant magnetostrictive materials." Acta Materialia 53(9):2845-55. DOI: 10.1016/j.actamat.2005.03.002.

Zhang, L, B An, S Fukuyama, T lijima, and K Yokogawa. 2010. "Characterization of hydrogen-induced crack initiation in metastable austenitic stainless steels during deformation." Journal of Applied Physics 108(6):063526-4. 10.1063/1.3477321.

Zhang, S, and F Yu. 2011. "Piezoelectric Materials for High Temperature Sensors." Journal of the American Ceramic Society 94(10):3153-70. 10.1111/j.1551-2916.2011.04792.x.

Zhang, Y, YJ Zhou, JP Lin, GL Chen, and PK Liaw. 2008. "Solid-Solution Phase Formation Rules for Multicomponent Alloys." Advanced Engineering Materials 10(6):534-38. 10.1002/adem.200700240.

Zhao, XR, N Okazaki, Y Konishi, K Akahane, Z Kuang, T Ishibashi, K Sato, H Koinuma, and T Hasegawa. 2004. "Magneto-optical imaging for high-throughput characterization of combinatorial magnetic thin films." Applied Surface Science 223(1-3):73-77. 10.1016/j.apsusc.2003.10.005.

Zhu, X, P Grutter, V Metlushko, Y Hao, FJ Castano, CA Ross, B Ilic, and HI Smith. 2003. "Construction of hysteresis loops of single domain elements and coupled permalloy ring arrays by magnetic force microscopy." Journal of Applied Physics 93(10):8540-42. 